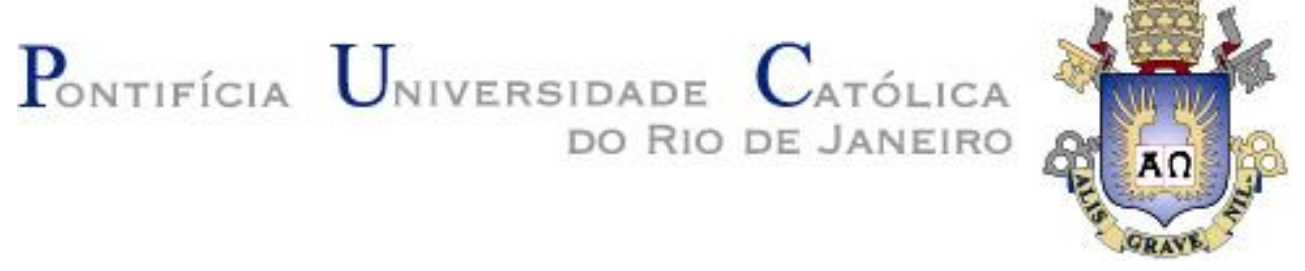

Lizeth Jacquelin Rodriguez Huarsaya

Otimização de Carteiras com Retornos Não Gaussianos

Dissertação de Mestrado

Dissertação apresentada como requisito parcial para obtenção do grau de Mestre pelo Programa de Pósgraduação em Administração de Empresas do Departamento de Administração da PUC-Rio.

Orientador: Prof. Luiz Eduardo Teixeira Brandão Co-orientador: Prof. Javier Gutiérrez Castro

Rio de Janeiro Julho de 2021 
Lizeth Jacquelin Rodriguez Huarsaya

\section{Otimização de Carteiras com Retornos Não Gaussianos}

Dissertação apresentada como requisito parcial para obtenção do grau de Mestre pelo Programa de PósGraduação em Administração de Empresas da PUC-Rio. Aprovada pela Comissão Examinadora abaixo.

Prof. Luiz Eduardo Teixeira Brandão Orientador Departamento de Administração - PUC-Rio

Prof. Javier Gutiérrez Castro Co-orientador UFSC

Prof. Fernando Antonio Lucena Aiube UERJ

Prof. Juan Lazo Lazo Universidad del Pacífico 
Todos os direitos reservados. É proibida a reprodução total ou parcial do trabalho sem autorização da universidade, da autora e do orientador.

\section{Lizeth Jacquelin Rodriguez Huarsaya}

Graduada na Faculdade de Engenheira Industrial da Universidade Católica de Santa Maria de Arequipa (UCSM Peru) em 2016. Possui experiência no setor privado de Produção e na área de logística e abastecimento.

Ficha Catalográfica

Rodriguez Huarsaya, Lizeth Jacquelin

Otimização de carteiras com retornos não gaussianos / Lizeth Jacquelin Rodriguez Huarsaya ; orientador: Luiz Eduardo Teixeira Brandão ; co-orientador: Javier Gutiérrez Castro. - 2021.

74 f. : il. color. ; $30 \mathrm{~cm}$

Dissertação (mestrado)-Pontifícia Universidade Católica do Rio de Janeiro, Departamento de Administração, 2021. Inclui bibliografia

1. Administração - Teses. 2. Teoria Moderna de Carteiras. 3. Alocação de ativos. 4. Medida Ômega. 5. Estatística frequentista. 6. Estatística bayesiana. I. Brandão, Luiz Eduardo Teixeira. II. Castro, Javier Gutiérrez. III. Pontifícia Universidade Católica do Rio de Janeiro. Departamento de Administração. IV. Título.

CDD: 658 
Dedico esta dissertação a meus queridos pais Máximo Rodriguez (in memoriam) e Norma Huarsaya, pelo apoio e confiança. 


\section{Agradecimentos}

A Deus por guiar meu caminho.

Ao meu Orientador, professor Luiz Eduardo Teixeira Brandão, pelos conhecimentos transferidos durante o curso e pelo suporte e confiança depositados no desenvolvimento desta dissertação. Agradeço-o também pela disponibilidade em ter reuniões e pelas propostas sugeridas para concretizar com êxito está dissertação.

Ao meu Co-orientador, professor Javier Gutierrez Castro, pelas inúmeras discussões e aportes técnicos que foram valiosos na condução desta pesquisa acadêmica.

Aos membros da Banca Examinadora pela atenção na revisão desta dissertação e pelas sugestões oferecidas.

Aos professores e funcionários do IAG pelos ensinamentos e pela ajuda.

Aos companheiros da turma do mestrado 2019 pelos momentos gratos e pelo ambiente acolhedor na sala de aula.

À minha família pelo apoio emocional constante que me permitiu seguir em frente nos momentos mais difíceis.

Ao meu pai Máximo Rodriguez (in memoriam) que sempre me incentivou a lutar pelos meus sonhos e objetivos na vida.

O presente trabalho foi realizado com apoio da Coordenação de Aperfeiçoamento de Pessoal de Nível Superior-Brasil (CAPES) - Código de Financiamento 001. 


\section{Resumo}

Rodriguez Huarsaya, Lizeth Jacquelin; Teixeira Brandão, Luiz Eduardo. Otimização de Carteiras com Retornos Não Gaussianos. Rio de Janeiro, 2021. 75 p. Dissertação de Mestrado - Departamento de Administração, Pontifícia Universidade Católica do Rio de Janeiro.

A teoria moderna de carteiras estabelece que a alocação ótima de ativos é uma função da média-variância da distribuição dos retornos. Na prática, estes retornos são modelados por distribuições Gaussianas e seus parâmetros são estimados a partir dos dados históricos do mercado, utilizando técnicas descritivas da estatística Frequentista. A dinâmica atual dos mercados globalizados gera períodos aleatórios de alta e baixa volatilidade e/ou saltos nos retornos dos ativos, provocando mudanças de regime ou quebras estruturais na série temporal dos retornos, tornando-os não Gaussianos. Consequentemente, a teoria moderna de carteiras precisa ser adaptada para atender a estas novas condições do mercado. Para contornar o problema das mudanças de regime, propõe-se a substituição do mecanismo de otimização baseada no índice de Sharpe pela otimização baseada na medida Ômega. Isto porque a medida Ômega tem a vantagem de quantificar o riscoretorno de qualquer distribuição de probabilidade e não somente distribuições Gaussianas como acontece com o índice de Sharpe, ou seja, as distribuições de retornos não Gaussianos provocadas pelas mudanças de regime são tratadas naturalmente pela medida Ômega. Para contornar o problema das quebras estruturais, propõe-se a substituição do procedimento de estimação dos parâmetros da distribuição dos retornos, baseada em técnicas da estatística Frequentista por técnicas da estatística Bayesiana. Isto porque a estatística Bayesiana, tem a vantagem de combinar as informações públicas do mercado (dados históricos dos retornos) com informações privadas do investidor (visões prospectivas do mercado) permitindo corrigir a quebra estrutural e, na sequência, tratar o retorno não Gaussiano, utilizando o mecanismo de otimização baseada na medida Ômega.

\section{Palavras-chave}

Teoria Moderna de Carteiras, Alocação de Ativos, Medida Ômega, Estatística Frequentista, Estatística Bayesiana, Mudanças de Regime, Quebras Estruturais. 


\section{Abstract}

Rodriguez Huarsaya, Lizeth Jacquelin; Teixeira Brandão, Luiz Eduardo. Portfolio Optimization with Non Gaussian Returns. Rio de Janeiro, 2021. 75 p. Dissertação de Mestrado - Departamento de Administração, Pontifícia Universidade Católica do Rio de Janeiro.

Modern portfolio theory states that the optimal asset allocation is a function of the mean-variance of the distribution of returns. In practice, these returns are modeled by Gaussian distributions and their parameters are estimated from historical market data, using descriptive techniques of Frequentist statistics. The current dynamics of globalized markets generate random periods of high and low volatility and/or jumps in asset returns, causing regime shifts or structural breaks in the time series of returns, making them non Gaussian. Consequently, modern portfolio theory needs to be adapted to meet these new market conditions. To circumvent the problem of regime shifts, it is proposed to replace the optimization mechanism based on the Sharpe index by the optimization based on the Omega measure. This is because the Omega measure has the advantage of quantifying the risk-return of any probability distribution and not only Gaussian distributions as with the Sharpe index, that is, non Gaussian returns distributions caused by regime shifts are treated naturally by the Omega measure. To circumvent the problem of structural breaks, it is proposed to replace the estimation procedure for the parameters of the distribution of returns, based on Frequentist statistics techniques, by Bayesian statistical techniques. This is because the Bayesian statistic has the advantage of combining public market information (historical return data) with private investor information (prospective market views) allowing to correct the structural break, and subsequently, treating the non Gaussian return using the optimization based on the Omega measure.

\section{Keywords}

Modern Portfolio Theory, Asset Allocation, Omega Measure, Frequentist Statistics, Bayesian Statistics, Regime Shifts, Structural Breaks. 


\section{Sumário}

10 problema 13

1.1. Introdução 13

1.2. Objetivos da pesquisa 15

1.3. Contribuições e relevância da pesquisa 16

2 Revisão bibliográfica 18

3 Metodologia 23

3.1. Modelo clássico de alocações de ativos 23

3.2. Otimização de carteiras com retornos não Gaussianos provocados por mudanças de regime 40

3.3. Otimização de carteiras com retornos não Gaussianos provocados por quebras estruturais 44

3.3.1. Inferência Bayesiana dos parâmetros da distribuição dos retornos 45

3.3.2. Transformação de Mahalanobis da série temporal dos retornos 52

3.3.3. Diagrama esquemático operacional 52

4 Experimentos numéricos $\quad 55$

4.1. Seleção de carteiras para os experimentos numéricos 55

4.2. Experimentos em carteiras com retornos não Gaussianos provocados por mudanças de regime $\quad 57$

4.3. Experimentos em carteiras com retornos não Gaussianos provocados por quebras estruturais $\quad 60$

4.3.1. Aplicação da etapa da inferência Bayesiana 60

4.3.2. Aplicação da etapa da transformação de Mahalanobis 64

$\begin{array}{ll}5 \text { Conclusões e trabalhos futuros } & 67\end{array}$

6 Referências Bibliográficas $\quad 69$

$\begin{array}{ll}\text { Anexo } 1 & 73\end{array}$ 


\section{Lista de Figuras}

Figura 1. Geometria da equação da variância da equação (3.4). Fonte: Elaboração própria.

Figura 2. Geometria do desvio padrão ou a raiz quadrada da equação (3.4).

Fonte: Elaboração própria.

Figura 3. Geometria da restrição orçamentária da equação (3.1). Fonte: Elaboração própria.

Figura 4. Geometria da fronteira eficiente. Fonte: Elaboração própria.....27

Figura 5. Hipérbole e fronteira eficiente no plano $(\mu \times \sigma)$. Fonte: Elaboração Própria. 33

Figura 6. Carteira de variância mínima. Fonte: Elaboração Própria. 34

Figura 7. Carteira tangente e ativo livre de risco. Fonte: Elaboração Própria.

Figura 8. Estrutura de investimento da teoria moderna de carteiras. Fonte: Elaboração Própria. 38

Figura 9. Função de utilidade e carteira geral do investidor. Fonte: Elaboração Própria. 40

Figura 10. Série temporal dos retornos diários do Bitcoin. Fonte: Elaboração Própria.

Figura 11. Gráfico Q-Q da série de retornos diários do Bitcoin. Fonte: Elaboração Própria. 42

Figura 12. Alocação de ativos com a distribuição a posteriori. Fonte: Elaboração Própria. 51

Figura 13. Aplicação da sequência das adequações do processo de otimização de carteira. Fonte: Elaboração Própria 53

Figura 14. Comparação do risco das carteiras com o CVaR. Fonte: Elaboração Própria 59

Figura 15. Comparação do risco das carteiras com o CVaR. Fonte: Elaboração Própria. 63

Figura 16. Comparação do risco das carteiras com o CVaR. Fonte: Elaboração Própria. 


\section{Lista de tabelas}

Tabela 1. Exemplo de visões prospectivas do mercado. Fonte: Elaboração Própria 48

Tabela 2. Tabela auxiliar para o preenchimento da matriz $\boldsymbol{P}$. Fonte: Elaboração Própria

Tabela 3. Comparação das estatísticas $\boldsymbol{\mu}$ e $\boldsymbol{\mu}$.Fonte: Elaboração Própria50 Tabela 4. Comparação entre carteiras tangentes. Fonte: Elaboração Própria 50

Tabela 5. Comparação entre carteiras gerais do investidor. Fonte: Elaboração Própria.

Tabela 6. Composição das quatro carteiras para análise. Fonte: Elaboração Própria. 55

Tabela 7. Principais estatísticas dos retornos mensais. Fonte: Elaboração Própria. 56

Tabela 8. Matriz de correlações dos retornos mensais. Fonte: Elaboração Própria. 56

Tabela 9. Matriz de variância- covariância dos retornos mensais. Fonte: Elaboração Própria. 56

Tabela 10. Alocação de ativos realizadas pela metodologia de Markowitz. Fonte: Elaboração Própria. 58

Tabela 11. Alocação de ativos realizada pela metodologia Ômega. Fonte: Elaboração Própria. 58

Tabela 12. Estatísticas de risco-retorno da carteira geral do investidor. Fonte: Elaboração Própria. 58

Tabela 13. Visões prospectivas do mercado do investidor. Fonte: Elaboração Própria.

Tabela 14. Alocação de ativos realizada com a estimação Frequentista. Fonte: Elaboração Própria. 62

Tabela 15. Alocação de ativos realizada com a estimação Bayesiana. Fonte: Elaboração Própria.

Tabela 16. Estatísticas de risco-retorno da carteira geral do investidor. Fonte: Elaboração Própria. 
Tabela 17. Alocação de ativos realizada com a metodologia de Markowitz. Fonte: Elaboração Própria. 64

Tabela 18. Alocação de ativos realizada com a metodologia Ômega. Fonte:

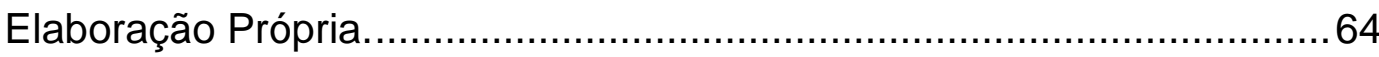

Tabela 19. Estatísticas de risco-retorno da carteira geral do investidor.

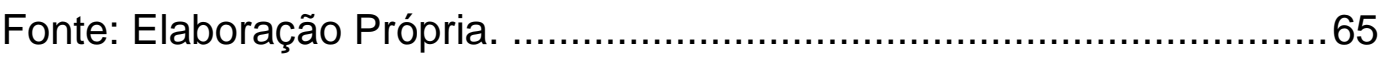




\section{O problema}

\section{1. Introdução}

Empiricamente, é bem conhecido o fato de que os investidores desejam obter a maior rentabilidade dos seus investimentos correndo o mínimo de risco possível. Markowitz (1952), estabeleceu os fundamentos da teoria moderna de carteiras sugerindo que as decisões de investimento devem ser tomadas com base no binômio de risco-retorno. Na literatura acadêmica, os termos "teoria moderna de carteiras", "alocação de ativos", "otimização de carteiras", ou, simplesmente, "análise de carteiras", em essência, tratam do mesmo problema, e, nesta dissertação, todas elas serão tratadas como termos equivalentes. A teoria moderna de carteiras estabelece que a alocação ótima de ativos é uma função da média-variância da distribuição dos retornos. Cabe ressaltar que no artigo original de Markowitz (1952), não foi feita nenhuma suposição sobre algum formato específico da distribuição de probabilidade dos retornos, apenas, restringe que a distribuição seja definida pela média-variância. Por esta razão, em muitos artigos acadêmicos, esta metodologia de análise de carteiras é conhecida como análise de média-variância. Na prática, a distribuição Gaussiana ou distribuição Normal, é por excelência a distribuição padrão da teoria moderna de carteiras.

Segundo Markowitz, ao variar as frações de investimento dos ativos podem ser geradas infinitas carteiras de investimento. Entretanto, somente um subconjunto destas carteiras é eficiente em termos do binômio de risco-retorno e somente estas carteiras devem ser consideradas como alternativas de alocação de ativos. Finalmente, para selecionar uma carteira dentre as carteiras eficientes é necessário maximizar o índice de Sharpe (1966). Esta maximização depende dos parâmetros da média-variância das distribuições dos retornos dos ativos, que, por sua vez, dependem dos dados históricos do mercado, que, por premissa do modelo de Markowitz, devem ser séries temporais de natureza Gaussiana. Entretanto, estas séries temporais, geralmente, são não Gaussianas, gerando como resultado alocações deficientes e pouco intuitivas (JOBSON; KORKIE, 1981; MICHAUD, 1989) 
Existem, pelo menos, duas hipóteses que podem explicar a natureza não Gaussiana das séries temporais dos retornos: (i) A primeira hipótese é de que as séries temporais dos retornos sofrem mudanças de regime (ou estados) que se repetem recorrentemente ao longo do tempo. Assim, os parâmetros da distribuição dos retornos, variam, geralmente, entre um número finito de estados, tipicamente de dois a quatro (SONG, 2014). Entretanto, foi observado que a volatilidade é maior nos regimes de retorno negativo do que nos regimes positivos (CHU; SANTONI; LIU, 1996), em outras palavras, existe uma não linearidade entre a média-variância, provocando uma assimetria na distribuição dos retornos, o que explicaria a natureza não Gaussiana das séries temporais dos retornos. Estas mudanças de regime são produzidas, por exemplo: por crises financeiras, recessões econômicas, hiperinflação, mudanças nas políticas fiscais, etc. (ii) A segunda hipótese é de que as séries temporais dos retornos sofrem quebras estruturais permanentes e não recorrentes ao longo do tempo. Assim, os parâmetros da distribuição dos retornos, variam, de forma imprevisível, entre infinitos estados, provocando uma relação de média-variância do tipo estocástico, o que explicaria a natureza não Gaussiana das séries temporais dos retornos. Estas quebras estruturais são produzidas por eventos de longa duração, como, por exemplo: mudanças climáticas, descoberta de novas tecnologias, disputas geopolíticas, novas tendências sociais, etc.

Para contornar o problema das mudanças de regime, propõe-se a substituição do mecanismo de otimização clássica baseada no índice de Sharpe, pela otimização baseada na medida Ômega. A medida Ômega, inicialmente proposta por Keating e Shadwick (2002), quantifica o risco-retorno de qualquer distribuição de probabilidade, não se restringindo apenas a distribuições Gaussianas, como acontece com o índice de Sharpe, ou seja, a medida Ômega é uma medida universal de quantificação de risco-retorno que permite a otimização de carteiras formadas por ativos de qualquer natureza probabilística. Desta forma, a alocação de ativos com retornos não Gaussianos, provocadas pelas mudanças de regime, são resolvidas naturalmente pela medida Ômega.

Para contornar o problema das quebras estruturais, propõe-se a substituição do procedimento de estimação dos parâmetros da distribuição dos retornos, baseada em técnicas da estatística Frequentista, por técnicas da estatística Bayesiana; dado que a estatística Bayesiana tem a vantagem de combinar as informações públicas do mercado (dados históricos dos retornos) com as informações privadas do investidor (visões prospectivas do mercado), permitindo corrigir as quebras estruturais dos retornos, inserindo as expectativas futuras do 
mercado sob a ótica do investidor. Esta combinação de informações é realizada aplicando o teorema de Bayes, onde, a distribuição a priori dos parâmetros da distribuição dos retornos é construída baseada nos dados históricos do mercado, e, na sequência, é construída uma distribuição de verossimilhança, baseada nas expectativas prospectivas do mercado, sob a ótica do investidor. Finalmente, deve-se aplicar o teorema de Bayes, obtendo como resultado uma distribuição a posteriori dos parâmetros da distribuição dos retornos. A nova estimativa dos parâmetros que emerge da distribuição, a posteriori, é a que será utilizada no processo de otimização de carteiras. Note-se que o teorema de Bayes não está sendo aplicado na distribuição dos retornos, e sim nos parâmetros da distribuição dos retornos. Desta forma, a alocação de ativos com retornos não Gaussianos, provocada pelas quebras estruturais, são resolvidas em duas etapas: primeiramente pelo mecanismo da inferência Bayesiana e, em seguida, pelo mecanismo da otimização baseada na medida Ômega. Tanto Doucet et al.(2000) como Robert e Casella (2004), apresentam maiores detalhes sobre a estatística Bayesiana.

Nos experimentos numéricos realizados em carteiras com retornos não Gaussianos provocados por mudanças de regime, observa-se que a metodologia clássica subestima o risco da carteira em relação a metodologia Ômega, ou seja, a metodologia clássica de Markowitz estima um risco menor, sendo que o investidor corre um risco maior. Nos experimentos realizados em carteiras com retornos não Gaussianos provocados por quebras estruturais, observa-se que a estatística Frequentista não permite inserir informações do especialista (no processo de estimação) como acontece com a estática Bayesiana, ou seja, a estatística Frequentista não permite corrigir as quebras estruturais dos retornos, gerando alocações sub ótimas e subestimando o risco da carteira.

\section{2.}

\section{Objetivos da pesquisa}

Esta pesquisa tem como objetivo principal estudar e adaptar a metodologia clássica de alocação de ativos, levando em consideração investimentos com retornos não Gaussianos. Investimentos com estas características, considerados inicialmente como casos anômalos, estão se tornando cada vez mais frequentes no mundo atual dos negócios nos mercados globalizados. Neste contexto, enumera-se os objetivos pontuais desta pesquisa: 
$\checkmark$ Adaptar a metodologia clássica de alocação de ativos para investimentos com retornos não Gaussianos provocados por mudanças de regime. Estas mudanças de regime são produzidas, por exemplo: por crises financeiras, recessões econômicas, hiperinflação, mudanças nas políticas fiscais, etc.

$\checkmark$ Adaptar a metodologia clássica de alocação de ativos para investimentos com retornos não Gaussianos provocados por quebras estruturais. Estas quebras estruturais são produzidas por eventos de longa duração, por exemplo: mudanças climáticas, descoberta de novas tecnologias, disputas geopolíticas, novas tendências sociais, etc.

$\checkmark$ Realizar experimentos numéricos, tanto com dados sintéticos, quanto, com dados reais do mercado, a fim de comprovar e validar as hipóteses empregadas nesta pesquisa.

\section{3. \\ Contribuições e relevância da pesquisa}

A principal contribuição desta pesquisa é a proposta de uma metodologia integral de alocação de ativos considerando carteiras com retornos não Gaussianos provocados, tanto por mudanças de regime, quanto por quebras estruturais nas séries temporais dos retornos.

Para o caso de carteiras com retornos não Gaussianos, provocados por mudanças de regime, encontrou-se na literatura uma adaptação, embora aplicada a um só regime, utilizando a medida Ômega (TITO et al., 2020). Já para o caso de carteiras com retornos não Gaussianos, provocados por quebras estruturais, não foi encontrada na literatura nenhuma adaptação da maneira que foi proposta nesta dissertação, entretanto, esta adaptação foi inspirada na metodologia de alocação de ativos proposta por Black e Litterman (1992).

A relevância desta pesquisa é que estas duas adaptações permitem otimizar carteiras formadas por ativos de qualquer tipo e de qualquer natureza probabilística, como, por exemplo: carteiras formadas por ações e/ou criptomoedas. O público-alvo de interesse desta pesquisa é formado por pesquisadores acadêmicos e praticantes do mercado financeiro, tais como: bancos, financeiras, investidores profissionais, consultores de negócios, etc.

O restante da dissertação está organizado da seguinte maneira: No capítulo 2 é realizada uma revisão da literatura acadêmica relacionado ao tema desta pesquisa; no capítulo 3 é exposta a metodologia central desta pesquisa; no 
capítulo 4 são realizados os experimentos numéricos; e finaliza-se com o capitulo 5 com as conclusões finais e as propostas de trabalhos futuros. 


\section{2 \\ Revisão bibliográfica}

A teoria moderna de carteiras teve seu início com a publicação do artigo de Markowitz (1952), intitulado "Portfolio Selection". Resumidamente, esta teoria constrói um modelo de alocação de ativos baseado nas seguintes hipóteses: (i) Hipótese do mercado eficiente, pela qual toda informação disponível é rapidamente disseminada e refletida nos preços dos ativos, (ii) Hipótese do mercado em concorrência perfeita, pela qual os preços dos ativos relacionam-se pela lei de oferta e demanda, (iii) Hipótese do mercado em equilíbrio, pela qual a oferta é igual à demanda para todos os ativos, (iv) Hipótese do mercado sem fricções, pela qual, não existem custos de transação nem impostos.

Markowitz, demonstrou, como principal resultado do modelo de alocação de ativos, que as decisões de investimento devem ser tomadas com base no binômio de risco-retorno. Cabe sublinhar que na publicação original, Markowitz não faz nenhuma suposição em relação à distribuição dos retornos, mas, apenas, limita seu estudo às distribuições que são definidas completamente pelos dois primeiros momentos, como é o caso da distribuição Gaussiana, que pode ser considerada como a distribuição padrão do modelo. Entretanto, a dinâmica atual dos mercados globalizados gera períodos aleatórios de alta e baixa volatilidade e/ou saltos nos retornos dos ativos, provocando mudanças de regime ou quebras estruturais na série temporal dos retornos, tornando-os não Gaussianos. Consequentemente, as aplicações reais do modelo de alocação de ativos podem gerar soluções deficientes e/ou pouco intuitivas devido à limitação da distribuição dos retornos nos dois primeiros momentos.

Existem alguns trabalhos na literatura que exploram a análise de carteiras levando em consideração outros momentos da distribuição dos retornos, além dos dois primeiros.

Mhiri e prigent (2010), analisaram o problema de otimização de carteiras aplicado a índices financeiros. Os autores acrescentaram, ao modelo clássico de otimização de média-variância, os momentos de assimetria e curtose. Os resultados obtidos indicam que ao incluir os momentos de assimetria e curtose, geraram-se mudanças significativas nos pesos dos ativos das carteiras, 
concluindo que mais momentos são necessários para o caso dos índices financeiros.

Por sua vez Usta e Kantar ( 2011), abordaram o problema de alocação de ativos propondo um modelo híbrido baseado na média-variância-curtose e no conceito de entropia. Utilizando um conjunto de dados empíricos para teste, os resultados obtidos mostraram que o modelo híbrido tem um bom desempenho em relação ao modelo clássico, demonstrando que a curtose e a entropia são informações relevantes que melhoram os resultados do modelo padrão.

Níguez et al.(2013), examinam o papel dos momentos de ordem superior na estrutura teórica da seleção de carteira e a utilidade esperada pelo investidor. Os autores derivaram as condições exatas sob as quais todos os investidores teriam comportamento imprudente em vez de um comportamento diversificador. Para isto, construíram diversos modelos de seleção de carteiras considerando dois, três, quatro e cinco momentos das distribuições dos retornos. Estimativas empíricas com o índice S\&P500 fornecem evidências para a importância dos momentos superiores da distribuição dos retornos na avaliação do risco das carteiras minimizando as atitudes de imprudência do investidor.

Saranya e Prasanna ( 2014), fizeram testes empíricos de alocação de ativos na bolsa de ações da Índia e constataram que os retornos das ações possuem distribuições não Gaussianas obtendo alocações sub ótimas. Para resolver este problema, propuseram a utilização do terceiro (assimetria) e quarto (curtose) momentos da distribuição dos retornos mostrando que o impacto da adição de mais momentos gera carteiras com maior retorno para o mesmo nível de risco.

Naqvi et al. (2017), demonstraram que, para avaliar corretamente o risco de carteiras com retornos assimétricos e/ou retornos com caudas pesadas, é necessário incluir os momentos de assimetria e curtose na análise padrão de média-variância.

Castro et al.(2020), analisaram diversas carteiras formadas por dois pares de ativos: um deles o Bitcoin e o segundo podendo ser o S\&P500, NASDAQ, Ethereum ou Ripple. Os autores analisaram as carteiras utilizando um modelo de alocação de ativos baseado na medida Ômega, porque as criptomoedas possuem retornos não-Gaussianos o que não permite utilizar o modelo padrão de médiavariância. Os resultados do modelo determinam que deve-se investir uma maior proporção nos ativos S\&P500 ou NASDAQ, mesmo que o Bitcoin apresente um retorno expressivo. No entanto, quando são avaliadas carteiras de pares de criptoativos, não se observa uma clara preferência por algum ativo em especial. 
Tito et al. (2020), demostraram que a medida Ômega é uma generalização do índice de Sharpe. Este resultado permite concluir que a metodologia de seleção de carteiras baseada na medida Ômega é uma metodologia universal de alocação de ativos de qualquer natureza probabilística.

Ahmed e Al Mafrachi (2021), utilizaram dados de preços intradiários do Bitcoin, Ethereum e Ripple para pesquisar a sensibilidade dos retornos das criptomoedas em relação aos momentos de ordem superior como a variância, a assimetria, a curtose, a hiper-assimetria (quinto momento) e a hiper-curtose (sexto momento). Os resultados mostram que os cinco primeiros momentos são relevantes para explicar os retornos das criptomoedas, sendo que o terceiro e o quinto momento foram os que mostraram maior capacidade preditiva, tanto dentro da amostra como fora da amostra, evidenciando, de forma prática, o bom desempenho na precificação de ativos, nas tomadas de decisão e na gestão de risco.

Uma abordagem alternativa para otimizar carteiras com retornos não Gaussianos é assumir que a natureza não Gaussiana dos retornos é uma consequência de mudanças de regime ou quebras estruturais na série temporal dos retornos, decorrentes das movimentações dos mercados globalizados.

Oliveira (2014), estudou a alocação de carteiras com mudanças de regime através de duas perspectivas: a primeira considerando que a distribuição conjunta dos retornos sofre mudanças de regime, e a segunda considerando o modelo de três fatores de Fama, French e Carhart (1997).

Lewin e Campani (2020), estudaram a gestão de carteiras sob múltiplos regimes econômicos para alocação de ativos sob uma função de utilidade estocástica diferencial. Esta função permitiu separar os principais parâmetros de risco do investidor, identificando quatro regimes econômicos para o Brasil.

Em relação ao problema de otimização de carteiras com retornos não Gaussianos provocadas por quebras estruturais, não foram encontradas referências bibliográficas exatas em relação a este problema, entretanto, existem diversos artigos, que serão descritos a seguir, que utilizam o teorema de Bayes na seleção de carteiras.

Black e Litterman (1992), abordaram o problema de alocação de ativos sob uma ótica Bayesiana. Os autores constataram que a maior deficiência do modelo clássico de média-variância não estava relacionada com o próprio modelo de alocação de ativos, e sim pelos dados históricos do mercado, que geravam estimativas ruidosas, em especial, o retorno esperado. Para superar esta deficiência, os autores trataram o retorno esperado como uma variável aleatória e 
na sequência construíram uma distribuição a priori, baseada no modelo de CAPM (Capital Asset Pricing Model), e uma distribuição de verossimilhança, baseada na visão de mercado sob a ótica do investidor, para, finalmente, aplicar o teorema de Bayes, tendo como resultado a distribuição a posteriori. O novo valor esperado do retorno, que emerge da distribuição a posteriori, é que substituirá a estimativa anterior do retorno esperado calculado com dados históricos do mercado. Os resultados obtidos mostraram que o modelo Bayesiano apresenta resultados (alocações) conservadores e intuitivos em relação ao modelo clássico de médiavariância.

Greyserman, Jones e Strawderman (2006), pesquisaram a seleção de carteiras utilizando a previsão Bayesiana da distribuição dos retornos. Para isto, foram deduzidas e implementadas novas distribuições a priori, tanto para média, quanto para a matriz de variância-covariância dos retornos. Foram realizadas comparações entre esta abordagem e a metodologia clássica utilizando 25 anos de dados históricos sobre índices de ações. Os autores mostraram que a metodologia Bayesiana gera 1,5 pontos percentuais a mais por ano no desempenho adicional da carteira, o que é um resultado empírico bastante significativo.

Harvey et al. (2010), utilizaram a teoria Bayesiana para resolver dois problemas comuns da teoria de alocação de ativos: a primeira para manipular elevados momentos da distribuição dos retornos e a segunda para tratar da incerteza da estimação dos parâmetros da distribuição dos retornos. Os autores mostram que a abordagem Bayesiana permite obter melhores estimativas em comparação com a metodologia tradicional de Markowitz.

Bodnar; Mazur e Okhrin (2017), avaliaram carteiras de mínima variância dentro de um contexto Bayesiano. Para isto compararam distribuições a priori não informativas versus as informativas, obtendo uma distribuição posterior do peso da carteira de mínima variância, usando a média e a matriz de covariância.

Zhao et al. (2019), mencionam que o modelo tradicional de Markowitz subestima o risco da carteira, obtendo alocações sub ótimas, portanto, os autores propõem dois modelos de seleção de carteiras para modificar os parâmetros e melhorar o rendimento da carteira desde uma abordagem Bayesiana. Estes modelos são Bayesian - GARCH e Bayesian Markov Regime Switching - GARCH sendo avaliados no mercado de valores de China, obtendo como resultado que ambos os modelos podem minimizar o problema de sobre-estimação (overfitting) e obtendo carteiras de autofinanciamento. 
Bauder et al. (2021), resolvem o problema da escolha ótima do carteira quando os parâmetros da distribuição dos retornos dos ativos são desconhecidos e estimados usando dados históricos. Utilizando distribuições futuras dos retornos dos ativos dada a amostra observável os autores obtém alocações ótimas e a fronteira eficiente Bayesiana supera a fronteira eficiente da amostra. 


\section{3 \\ Metodologia}

\section{1. Modelo clássico de alocações de ativos}

O modelo clássico de alocação de ativos, assume como premissa a existência de um mercado financeiro formado por " $n+1$ " ativos de investimento, um ativo de renda fixa, denotado por $r_{f}$ e " $n$ " ativos de renda variável, denotados por $\left\{r_{1}, r_{2}, \cdots, r_{n}\right\}$, sendo $r_{i}, i=\{1,2, \cdots, n\}$ uma variável aleatória que representa 0 retorno do i-ésimo ativo da carteira. $O$ ativo de renda fixa tem como característica fundamental, oferecer uma rentabilidade constante e livre de risco. Por outro lado, os ativos de renda variável têm como característica fundamental, oferecer rentabilidades potencialmente superiores ao ativo de renda fixa, mas que correm o risco de sofrer variações devido às incertezas do mercado, estas variações de rentabilidade são tipicamente modeladas por uma distribuição Gaussiana, ou seja, $r_{i} \sim N\left(\mu_{i}, \sigma_{i}^{2}\right)$. Neste contexto, os investidores deste mercado defrontam-se com a seguinte sequência de decisões: (i) A decisão do horizonte de investimento, (ii) $A$ decisão da seleção dos ativos de investimento, e (iii) $A$ decisão das frações de investimentos em cada ativo. Em relação a decisão do horizonte de investimento, esta decisão consiste em definir um período de investimento, denotado pelo intervalo $[t, T]$, sendo " $t$ " o tempo em que é realizado o investimento de capital e " $T$ " o tempo em que é realizado o desinvestimento de capital, mais um possível ganho ou perda. O modelo de alocação de ativos assume que os momentos $\mu_{i} \mathrm{e}$ $\sigma_{i}$ da distribuição dos retornos são parâmetros constantes e invariantes no tempo, inclusive no intervalo futuro de tempo $[t, T]$. Em relação à decisão da seleção dos ativos de investimento, esta consiste na seleção de uma carteira com base nos $n+1$ ativos disponíveis no mercado. Esta dissertação não estuda este problema de decisão e de forma genérica a carteira geral do investidor será formada por todos os ativos do mercado. Em relação à decisão das frações de investimento em cada ativo, esta decisão consiste em definir a fração ótima para cada ativo de forma que a carteira tenha o melhor desempenho em termos do binômio de riscoretorno, para isto, é utilizado um algoritmo de otimização que tem como função objetivo uma medida de risco-retorno. 
Para o modelo clássico de alocação de ativos, a função de risco-retorno padrão é o índice de Sharpe. A seguir será exposto o modelo de alocação de ativos em termos matemáticos:

Seja $r_{f}$ o retorno de um ativo livre de risco, em outras palavras, um ativo com rentabilidade fixa e constante ao longo do tempo.

Seja $\left\{r_{1}, r_{2}, \cdots, r_{n}\right\}$ os retornos de " $n$ " ativos com risco, onde $r_{i}, i=\{1,2, \cdots, n\}$, representa o i-ésimo retorno modelado por uma variável aleatória com distribuição gaussiana $N\left(\mu_{i}, \sigma_{i}^{2}\right)$.

Seja $\left\{w_{1}, w_{2}, \cdots, w_{n}\right\}$ as frações de investimentos dos " $n$ " ativos com risco, onde $w_{i}$ representa a fração de investimento no ativo $r_{i}$. Por restrição orçamentária do investidor, temos que:

$$
w_{1}+w_{2}+\cdots+w_{n}=1
$$

Logo, o retorno da carteira $r_{p}$, formado pelos " $n$ " ativos de investimento, pode ser calculado como:

$$
r_{p}=w_{1} r_{1}+w_{2} r_{2}+\cdots+w_{n} r_{n}
$$

Pelo fato de que todos os ativos da carteira possuem uma distribuição Gaussiana $r_{i} \sim N\left(\mu_{i}, \sigma_{i}^{2}\right)$, então, o retorno da carteira também terá uma distribuição Gaussiana, $r_{p} \sim N\left(\mu_{p}, \sigma_{p}^{2}\right)$. Isto porque a somatória de distribuições Gaussianas resulta em outra distribuição Gaussiana (SOURY; ALOUINI, 2015). Os momentos $\mu_{p}$ e $\sigma_{p}$ da distribuição dos retornos da carteira são facilmente calculados pelas equações (3.3) e (3.4):

$$
\begin{gathered}
\mu_{p}=E\left[r_{p}\right]=\sum_{i=1}^{n} w_{i} \mu_{i} \\
\sigma_{p}^{2}=\operatorname{Var}\left[r_{p}\right]=\sum_{i=1}^{n} \sum_{j=1}^{n} w_{i} w_{i} \operatorname{Cov}\left(r_{i}, r_{j}\right)
\end{gathered}
$$

A fim de facilitar o desenvolvimento analítico, é conveniente utilizar a notação matricial. Desta forma, os vetores e matrizes serão escritos com fonte em negrito e os valores escalares com fonte normal. A equação (3.1) pode ser reescrito como um produto vetorial de dos vetores, ou seja:

$$
\left[\begin{array}{llll}
w_{1} & w_{2} & \cdots & w_{4}
\end{array}\right]\left[\begin{array}{c}
1 \\
1 \\
\vdots \\
1
\end{array}\right]=1
$$


Utilizando a notação vetorial, a equação (3.5), pode ser rescrita como:

$$
\mathbf{w}^{\mathbf{T}} \mathbf{1}=\mathbf{1}
$$

Onde $\boldsymbol{w}^{T}=\left[\begin{array}{llll}w_{1} & w_{2} & \cdots & w_{n}\end{array}\right]$ representa o vetor transposto do vetor $\boldsymbol{w}, \mathrm{e}$ 1 representa o vetor coluna formado somente por números 1. Pela propriedade comutativa do produto interno, temos que $\boldsymbol{w}^{T} \mathbf{1}=\mathbf{1}^{T} w$, logo:

$$
\boldsymbol{w}^{T} \mathbf{1}=\mathbf{1}^{T} \boldsymbol{w}=1
$$

Analogamente, a equação (3.3), pode ser reescrita como um produto escalar de dois vetores, ou seja:

$$
\mu_{p}=\left[\begin{array}{llll}
w_{1} & w_{2} & \cdots & w_{n}
\end{array}\right]\left[\begin{array}{c}
\mu_{1} \\
\mu_{2} \\
\vdots \\
\mu_{n}
\end{array}\right]
$$

Utilizando a notação vetorial, a equação (3.8), pode ser reescrita como:

$$
\mu_{p}=\boldsymbol{w}^{T} \boldsymbol{\mu}
$$

Onde $\boldsymbol{\mu}=\left[\begin{array}{llll}\mu_{1} & \mu_{2} & \cdots & \mu_{n}\end{array}\right]^{T}$. Pela propriedade comutativa do produto interno, temos que $\boldsymbol{w}^{T} \boldsymbol{\mu}=\boldsymbol{\mu}^{T} \boldsymbol{w}, \log 0$ :

$$
\mu_{p}=\boldsymbol{w}^{T} \boldsymbol{\mu}=\boldsymbol{\mu}^{T} \boldsymbol{w}
$$

Finalmente, a equação (3.4) pode ser reescrita matricialmente como:

$$
\sigma_{p}^{2}=\boldsymbol{w}^{T} \boldsymbol{\Sigma} \boldsymbol{w}
$$

Onde:

$$
\boldsymbol{\Sigma}=\left[\begin{array}{cccc}
\sigma_{11} & \sigma_{12} & \cdots & \sigma_{1 n} \\
\sigma_{21} & \sigma_{22} & \cdots & \sigma_{21} \\
\vdots & \vdots & \ddots & \vdots \\
\sigma_{n 1} & \sigma_{n 1} & \cdots & \sigma_{n n}
\end{array}\right]
$$

As equações anteriores representam a formulação matemática geral do problema de alocação de ativos, e, para fins ilustrativos, as Figuras 1, 2, 3 e 4 mostram graficamente a geometria destas equações para o caso de dois ativos $(n=2)$. 


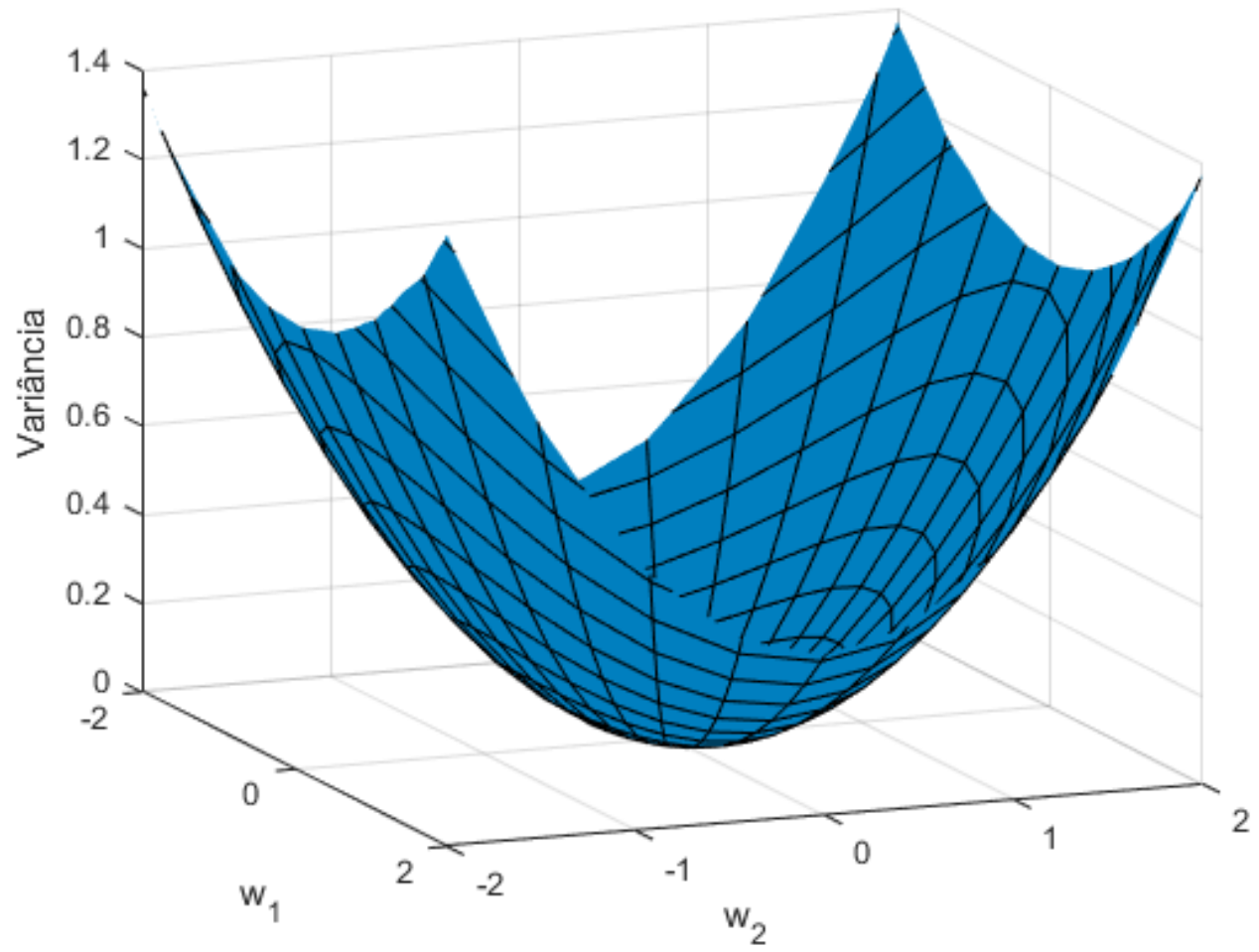

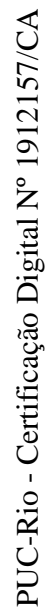

Figura 1. Geometria da equação da variância da equação (3.4). Fonte: Elaboração própria.

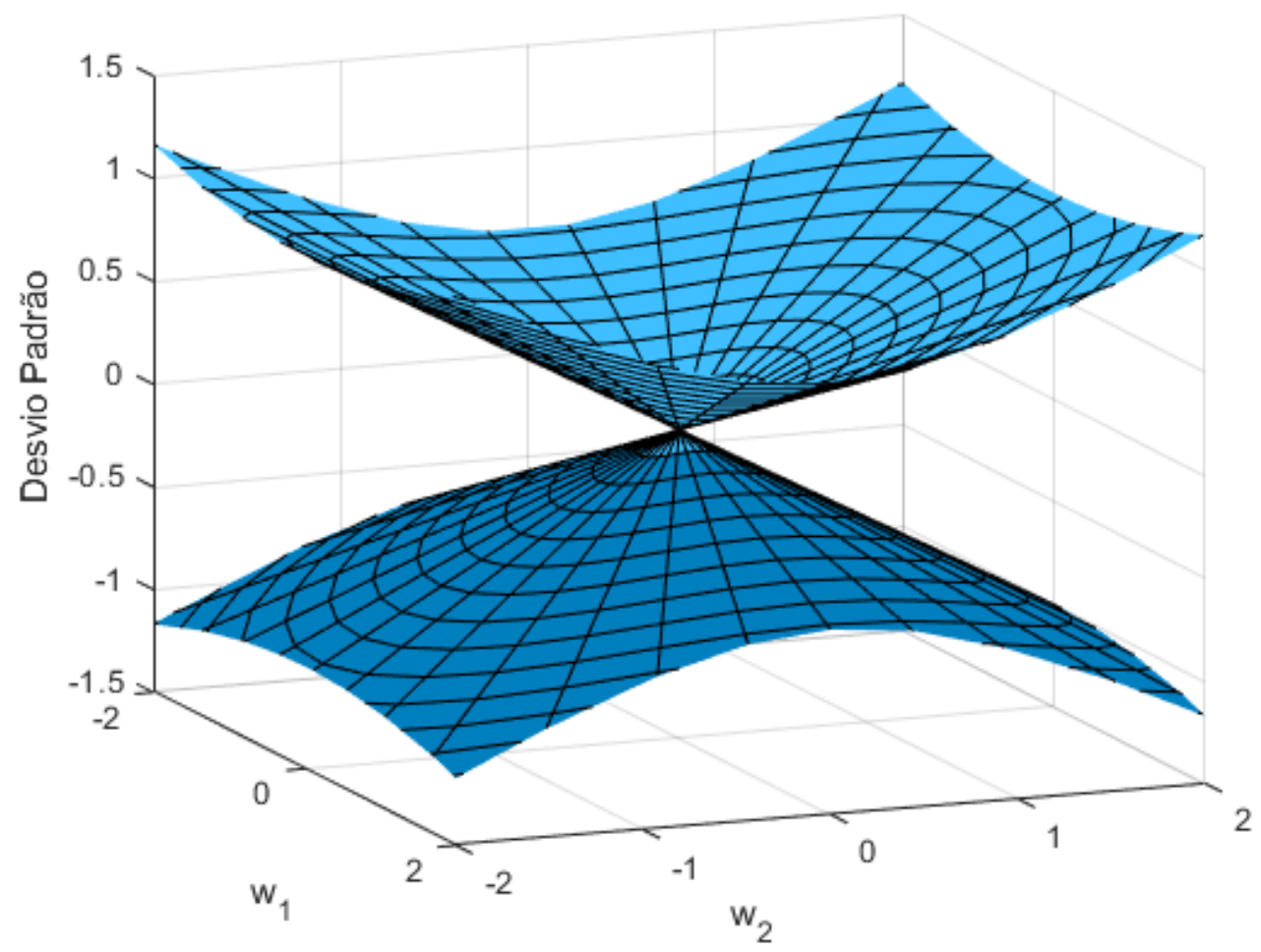

Figura 2. Geometria do desvio padrão ou a raiz quadrada da equação (3.4). Fonte: Elaboração própria. 


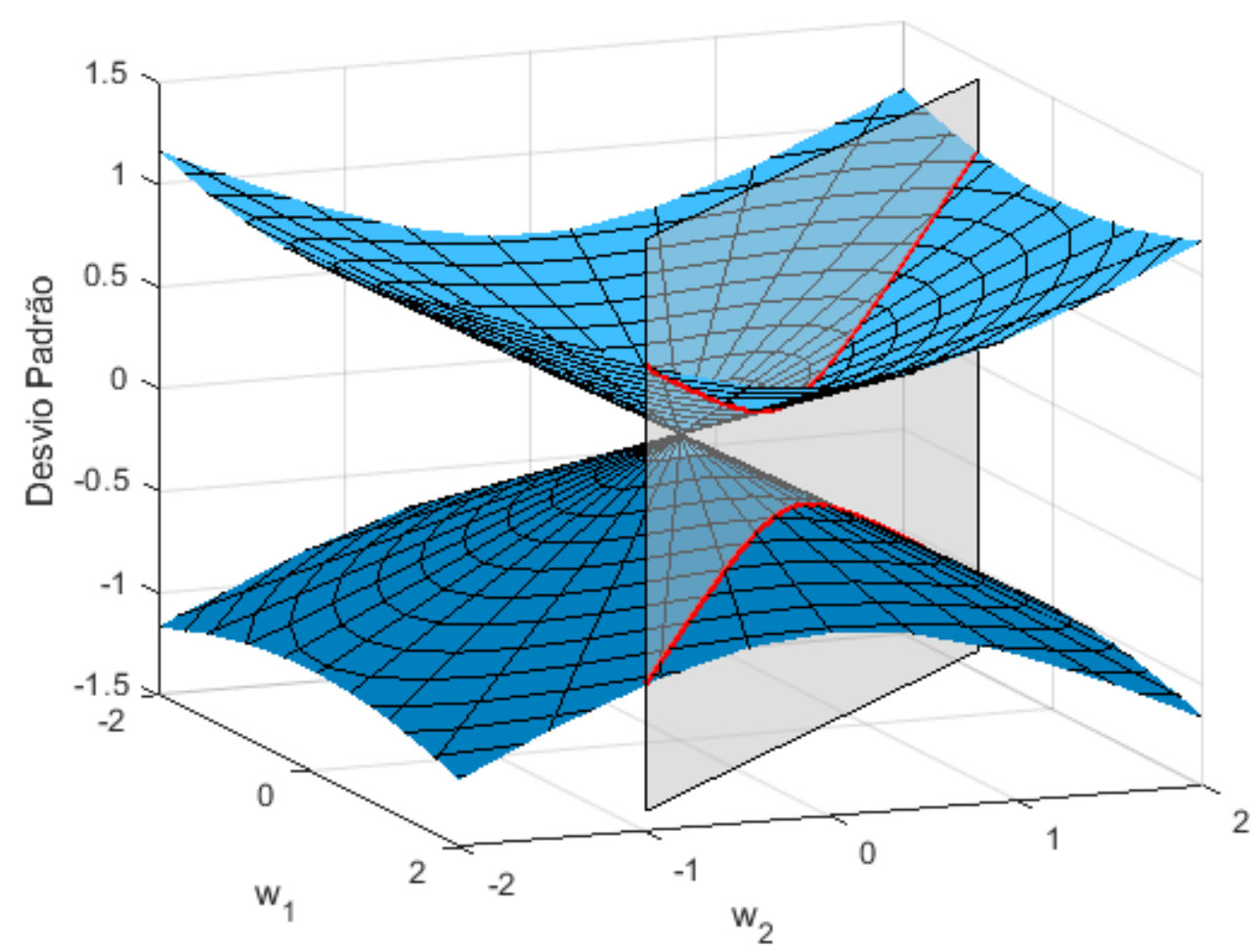

Figura 3. Geometria da restrição orçamentária da equação (3.1). Fonte: Elaboração própria.

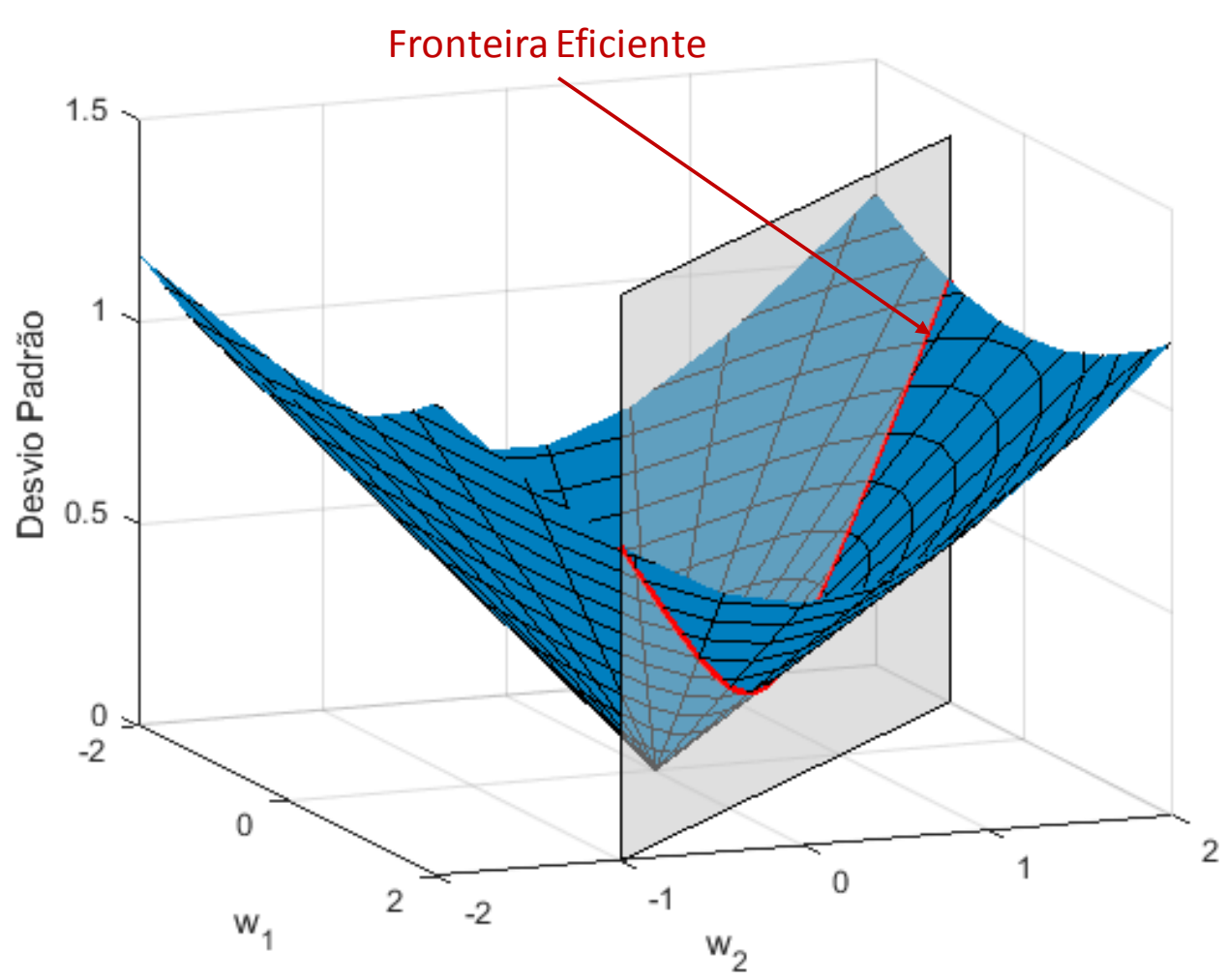

Figura 4. Geometria da fronteira eficiente. Fonte: Elaboração própria. 
A Figura 1, mostra graficamente a equação (3.4), da variância da carteira. Nota-se que a geometria desta equação representa uma superfície com formato paraboloide. A Figura 2, mostra graficamente a raiz quadrada da equação (3.4), note-se que a geometria da raiz quadrada representa duas superfícies com formato hiperboloide, isto porque, a raiz quadrada da variância gera duas raízes com sinal positivo e negativo, entretanto, somente a superfície com sinal positivo tem significado para finanças devido a que representa o risco da carteira. A Figura 3 , mostra a geometria da equação (3.1). Nota-se que esta equação representa um hiperplano que corta as superfícies do hiperboloide. Finalmente, a Figura 4, representa a fronteira eficiente que resulta da interseção do hiperplano com a superfície positiva do hiperboloide.

Retornando-se ao problema geral de alocação de ativos, ou seja, ao cálculo das frações ótimas dos ativos da carteira, a solução deste problema pode ser formulada através da minimização da equação (3.11), sujeito às restrições das equações (3.6) e (3.9), ou seja:

$$
\min _{\boldsymbol{w}}\left\{\sigma_{p}^{2}\right\}=\min _{\boldsymbol{w}}\left\{\boldsymbol{w}^{T} \boldsymbol{\Sigma} \boldsymbol{w}\right\}
$$

Sujeito a:

$$
\left\{\begin{array}{lll}
\boldsymbol{w}^{T} \mathbf{1} & = & 1 \\
\boldsymbol{w}^{T} \boldsymbol{\mu} & = & \mu_{p}
\end{array}\right.
$$

Cabe sublinhar que o problema de alocação de ativos, também pode ser formulado como a maximização da equação (3.9) sujeito às restrições das equações (3.6) e (3.11). Em ambos os casos a solução será a mesma.

Merton (1972), obteve uma solução analítica fechada deste problema utilizando a metodologia dos multiplicadores de Lagrange. Posteriormente, Bertsekas (1996) e Cruz, Medina e Salazar (2013), obtiveram a mesma solução seguindo outros desenvolvimentos analíticos.

A seguir expõe-se a solução do problema de alocação de ativos pela formulação de minimização e pela metodologia dos multiplicadores de Lagrange. Para isto, combina-se a função de minimização da equação (3.13) e as restrições da equação (3.14) em uma única função objetivo $L$, exposta na equação (3.15).

$$
L=\boldsymbol{w}^{T} \boldsymbol{\Sigma} \boldsymbol{w}+\lambda_{1}\left(\mu_{p}-\boldsymbol{w}^{T} \boldsymbol{\mu}\right)+\lambda_{2}\left(1-\boldsymbol{w}^{T} \mathbf{1}\right)
$$

Onde $\lambda_{1}$ e $\lambda_{2}$ representam valores escalares conhecidos como os multiplicadores de Lagrange. 
Suárez (1999) e Cruz et al. (2013), brindam maiores detalhes desta metodologia. Calculando as condições de primeira ordem da função objetivo $L$ obtém-se as equações (3.16), (3.17) e (3.18).

$$
\begin{aligned}
& \frac{\partial L}{\partial \boldsymbol{w}}=2 \boldsymbol{\Sigma} \boldsymbol{w}-\lambda_{1} \boldsymbol{\mu}+\lambda_{2} \mathbf{1}=0 \\
& \frac{\partial L}{\partial \lambda_{1}}=\boldsymbol{w}^{T} \boldsymbol{\mu}-\mu_{p}=0 \\
& \frac{\partial L}{\partial \lambda_{2}}=\boldsymbol{w}^{T} \mathbf{1}-1=0
\end{aligned}
$$

Note-se que na derivação matemática da equação (3.16), foi utilizada a regra do gradiente de um vetor $\boldsymbol{x}$ e uma matriz constante $\boldsymbol{A}$, exposta na equação (3.19).

$$
\frac{\partial}{\partial \boldsymbol{x}}\left(\boldsymbol{x}^{T} \boldsymbol{A} \boldsymbol{x}\right)=(\boldsymbol{A}+\boldsymbol{A})^{T} \boldsymbol{x}=2 \boldsymbol{A}^{T} \boldsymbol{x}
$$

Manipulando-se a equação (3.16), pode ser colocada a variável $\boldsymbol{w}$ em evidência, obtendo-se:

$$
\boldsymbol{w}=\frac{\lambda_{1}}{2} \boldsymbol{\Sigma}^{-1} \boldsymbol{\mu}+\frac{\lambda_{2}}{2} \boldsymbol{\Sigma}^{-1} \mathbf{1}
$$

Calculando-se $\boldsymbol{w}^{T}$ a partir da equação (3.20), obtém-se:

$$
\boldsymbol{w}^{T}=\frac{\lambda_{1}}{2}\left(\boldsymbol{\Sigma}^{-1} \boldsymbol{\mu}\right)^{T}+\frac{\lambda_{2}}{2}\left(\boldsymbol{\Sigma}^{-1} \mathbf{1}\right)^{T}
$$

Substituindo-se a equação (3.21) na equação (3.17) e (3.18), obtém-se que:

$$
\begin{gathered}
\left(\frac{\lambda_{1}}{2}\left(\boldsymbol{\Sigma}^{-1} \boldsymbol{\mu}\right)^{T}+\frac{\lambda_{2}}{2}\left(\boldsymbol{\Sigma}^{-1} \mathbf{1}\right)^{T}\right) \boldsymbol{\mu}=\mu_{p} \\
\left(\frac{\lambda_{1}}{2}\left(\boldsymbol{\Sigma}^{-1} \boldsymbol{\mu}\right)^{T}+\frac{\lambda_{2}}{2}\left(\boldsymbol{\Sigma}^{-1} \mathbf{1}\right)^{T}\right) \mathbf{1}=1
\end{gathered}
$$

Rescrevendo-se matricialmente as equações (3.22) e (3.23) obtém-se:

$$
\frac{1}{2}\left[\begin{array}{ll}
\boldsymbol{\mu}^{T} \boldsymbol{\Sigma}^{-1} \boldsymbol{\mu} & \mathbf{1}^{T} \boldsymbol{\Sigma}^{-1} \boldsymbol{\mu} \\
\boldsymbol{\mu}^{T} \boldsymbol{\Sigma}^{-1} \mathbf{1} & \mathbf{1}^{T} \boldsymbol{\Sigma}^{-1} \mathbf{1}
\end{array}\right]\left[\begin{array}{c}
\lambda_{1} \\
\lambda_{2}
\end{array}\right]=\left[\begin{array}{c}
\mu_{p} \\
1
\end{array}\right]
$$

No desenvolvimento da Equação anterior, a partir da equação (3.22) e (3.23), foram utilizadas as seguintes propriedades matriciais.

$$
(\boldsymbol{A B})^{T}=\boldsymbol{B}^{T} \boldsymbol{A}^{T}
$$




$$
\begin{aligned}
& \left(\boldsymbol{A}^{T}\right)^{-1}=\left(\boldsymbol{A}^{-1}\right)^{T} \\
& (\boldsymbol{A}+\boldsymbol{B})^{T}=\boldsymbol{A}^{T}+\boldsymbol{B}^{T}
\end{aligned}
$$

Como a matriz de covariância $\Sigma$ é uma matriz simétrica positiva e definida, então o termo $\mathbf{1}^{T} \boldsymbol{\Sigma}^{-1} \boldsymbol{\mu}$ da equação (3.24), é equivalente ao termo $\boldsymbol{\mu}^{T} \boldsymbol{\Sigma}^{-1} \mathbf{1}$, logo, a equação (3.24), pode ser expressa como:

$$
\frac{1}{2}\left[\begin{array}{ll}
\boldsymbol{\mu}^{T} \boldsymbol{\Sigma}^{-1} \boldsymbol{\mu} & \boldsymbol{\mu}^{T} \boldsymbol{\Sigma}^{-1} \mathbf{1} \\
\boldsymbol{\mu}^{T} \boldsymbol{\Sigma}^{-1} \mathbf{1} & \mathbf{1}^{T} \boldsymbol{\Sigma}^{-1} \mathbf{1}
\end{array}\right]\left[\begin{array}{c}
\lambda_{1} \\
\lambda_{2}
\end{array}\right]=\left[\begin{array}{c}
\mu_{p} \\
1
\end{array}\right]
$$

Fazendo-se uma troca de variáveis, a equação (3.28), pode ser expressa como a equação (3.29).

$$
\frac{1}{2}\left[\begin{array}{ll}
b & a \\
a & c
\end{array}\right]\left[\begin{array}{l}
\lambda_{1} \\
\lambda_{2}
\end{array}\right]=\left[\begin{array}{c}
\mu_{p} \\
1
\end{array}\right]
$$

Onde $a, b$, e $c$ são constantes numéricas. Resolvendo-se a equação (3.29), obtém-se:

$$
\left[\begin{array}{l}
\lambda_{1} \\
\lambda_{2}
\end{array}\right]=\frac{2}{d}\left[\begin{array}{cc}
c & -a \\
-a & b
\end{array}\right]\left[\begin{array}{c}
\mu_{p} \\
1
\end{array}\right]
$$

Onde $d$ é o determinante, assim:

$$
d=\operatorname{det}\left(\begin{array}{ll}
b & a \\
a & c
\end{array}\right)=b c-a^{2}
$$

Manipulando-se a equação (3.30) obtém-se as soluções de $\lambda_{1}$ e $\lambda_{2}$.

$$
\begin{aligned}
& \lambda_{1}=\frac{2}{d}\left(c \mu_{p}-a\right) \\
& \lambda_{2}=\frac{2}{d}\left(b-a \mu_{p}\right)
\end{aligned}
$$

Substituindo-se as soluções de $\lambda_{1}$ e $\lambda_{2}$ da equação (3.32) e (3.33) na equação (3.20), obtém-se:

$$
\boldsymbol{w}=\frac{1}{d}\left(c \mu_{p}-a\right) \boldsymbol{\Sigma}^{-1} \boldsymbol{\mu}+\frac{1}{d}\left(b-a \mu_{p}\right) \boldsymbol{\Sigma}^{-1} \mathbf{1}
$$

Reagrupando-se o termo $\mu_{p}$.

$$
\boldsymbol{w}=\frac{1}{d}\left(b \boldsymbol{\Sigma}^{-1} \mathbf{1}-a \boldsymbol{\Sigma}^{-1} \boldsymbol{\mu}\right)+\frac{1}{d}\left(c \boldsymbol{\Sigma}^{-1} \boldsymbol{\mu}-a \boldsymbol{\Sigma}^{-1} \mathbf{1}\right) \mu_{p}
$$

A equação (3.35), pode ser reescrita como:

$$
\boldsymbol{w}=\boldsymbol{g}+\boldsymbol{h} \mu_{p}
$$




$$
\begin{aligned}
& \boldsymbol{g}=\frac{1}{d}\left(b \boldsymbol{\Sigma}^{-1} \mathbf{1}-a \boldsymbol{\Sigma}^{-1} \boldsymbol{\mu}\right) \\
& \boldsymbol{h}=\frac{1}{d}\left(c \boldsymbol{\Sigma}^{-1} \boldsymbol{\mu}-a \boldsymbol{\Sigma}^{-1} \mathbf{1}\right)
\end{aligned}
$$

Substituindo-se a equação (3.36) na equação (3.11) da variância $\sigma_{p}^{2}=$ $\boldsymbol{w}^{T} \boldsymbol{\Sigma} \boldsymbol{w}$, obtém-se:

$$
\begin{aligned}
& \sigma_{p}^{2}=\left(\boldsymbol{g}+\boldsymbol{h} \mu_{p}\right)^{T} \boldsymbol{\Sigma}\left(\boldsymbol{g}+\boldsymbol{h} \mu_{p}\right) \\
& \sigma_{p}^{2}=\left(\boldsymbol{g}^{T}+\boldsymbol{h}^{T} \mu_{p}\right) \boldsymbol{\Sigma}\left(\boldsymbol{g}+\boldsymbol{h} \mu_{p}\right) \\
& \sigma_{p}^{2}=\boldsymbol{h}^{T} \boldsymbol{\Sigma} \boldsymbol{h} \mu_{p}^{2}+2 \boldsymbol{g}^{T} \boldsymbol{\Sigma} \boldsymbol{h} \mu_{p}+\boldsymbol{g}^{T} \boldsymbol{\Sigma} \boldsymbol{g}
\end{aligned}
$$

No Anexo 1, mostra-se que:

$$
\begin{aligned}
& \boldsymbol{h}^{T} \boldsymbol{\Sigma} \boldsymbol{h}=\frac{c}{d} \\
& \boldsymbol{g}^{T} \boldsymbol{\Sigma} \boldsymbol{h}=-\frac{a}{d} \\
& \boldsymbol{g}^{T} \boldsymbol{\Sigma} \boldsymbol{g}=\frac{b}{d}
\end{aligned}
$$

Substituindo-se todos os resultados anteriores na equação (3.41) obtém-se que:

$$
\sigma_{p}^{2}=\frac{c}{d} \mu_{p}^{2}+-\frac{2 a}{d} \mu_{p}+\frac{b}{d}
$$

No plano $\left(\mu_{p} \times \sigma_{p}^{2}\right)$, a equação (3.45), representa o lugar geométrico de uma parábola, entretanto, no plano $(\mu \times \sigma)$ a equação (3.45), representa o lugar geométrico de uma hipérbole. Para demonstrar isto, a equação (3.45), pode-se reescrever como:

$$
\frac{\sigma_{p}^{2}}{\frac{1}{c}}-\frac{\left(\mu_{p}-\frac{a}{c}\right)^{2}}{\frac{d}{c^{2}}}=1
$$

Para facilitar a visualização dos parâmetros da hipérbole, mostra-se, a seguir, a equação da hipérbole canônica, utilizando a notação padrão da geometria analítica.

$$
\frac{(x-h)^{2}}{p^{2}}-\frac{(x-k)^{2}}{q^{2}}=1
$$


Onde os parâmetros $p$ e $q$ representam os semieixos da hipérbole, tendo como centro o ponto $(h, k)$.

Fazendo-se um contraste de parâmetros entre a equação (3.46) e (3.47), obtém-se que:

$$
\begin{aligned}
& p=\frac{1}{\sqrt{c}} \\
& q=\frac{\sqrt{d}}{c} \\
& h=0 \\
& k=-\frac{a}{c}
\end{aligned}
$$

$\mathrm{Na}$ teoria de finanças, somente o ramo direito da hipérbole tem sentido, e, em particular, o sub-ramo superior que começa no vértice $\left(h^{*}, k^{*}\right)$ (veja mais à frente a Figura 5).

Em finanças, este sub-ramo é conhecido como fronteira eficiente, devido ao fato de que nesta curva encontram-se localizadas as carteiras eficientes ou carteiras ótimas em termos do binômio de risco-retorno. Somente as carteiras localizadas na fronteira eficiente devem ser consideradas como solução do problema de alocação de ativos. As demais carteiras localizadas no interior da fronteira eficiente, devem ser descartadas.

Em finanças, o vértice $\left(h^{*}, k^{*}\right)$ do ramo direito da hipérbole tem um significado especial, pois, representa, além do início da fronteira eficiente, a carteira de variância mínima. Utilizando-se os conhecimentos de geometria analítica é fácil verificar que este ponto é definido pela equação (3.52).

$$
\left(h^{*}, k^{*}\right)=\left(\frac{1}{\sqrt{c}}, \frac{a}{c}\right)
$$

Isto significa que a carteira de variância mínima tem uma distribuição Gaussiana $N\left(\mu_{p}^{*}, \sigma_{p}^{* 2}\right)$, definida pelos seguintes momentos:

$$
\begin{aligned}
& \mu_{p}^{*}=\frac{a}{c} \\
& \sigma_{p}^{*}=\frac{1}{\sqrt{c}}
\end{aligned}
$$

Para fins ilustrativos, na Figura 5, mostra-se o gráfico da hipérbole e da fronteira eficiente, considerando uma carteira formada por 5 ativos de renda 
variável. Estes ativos estão representados pelos 5 pontos localizados no interior da fronteira eficiente. Além disso, mostra-se também a carteira de variância mínima representada, pelo vértice $\left(h^{*}, k^{*}\right)$ do ramo direito da hipérbole.

A Figura 5 foi gerada utilizando os dados dos seguintes 5 ativos de renda variável.

$$
\begin{aligned}
\boldsymbol{\mu} & =\left[\begin{array}{r}
8 \% \\
13 \% \\
18 \% \\
25 \% \\
30 \%
\end{array}\right] \\
\boldsymbol{\Sigma} & =\left[\begin{array}{rrrrr}
12 \% & 6 \% & -1 \% & 3 \% & 5 \% \\
6 \% & 20 \% & -1 \% & 2 \% & 4 \% \\
-1 \% & -1 \% & 30 \% & 5 \% & -1 \% \\
3 \% & 2 \% & 5 \% & 40 \% & 6 \% \\
5 \% & 4 \% & -1 \% & 6 \% & 50 \%
\end{array}\right]
\end{aligned}
$$

Baseando-se na equação (3.52) é fácil calcular o vértice do ramo direito da hipérbole $\left(h^{*}, k^{*}\right)=(0,2572 ; 0,1422)$, e, como mencionado, este vértice representa a carteira de variância mínima definida pela distribuição Gaussiana $N\left(\mu_{p}^{*}, \sigma_{p}^{* 2}\right)=N\left(14,22 \% ; 25,72 \%^{2}\right)$.

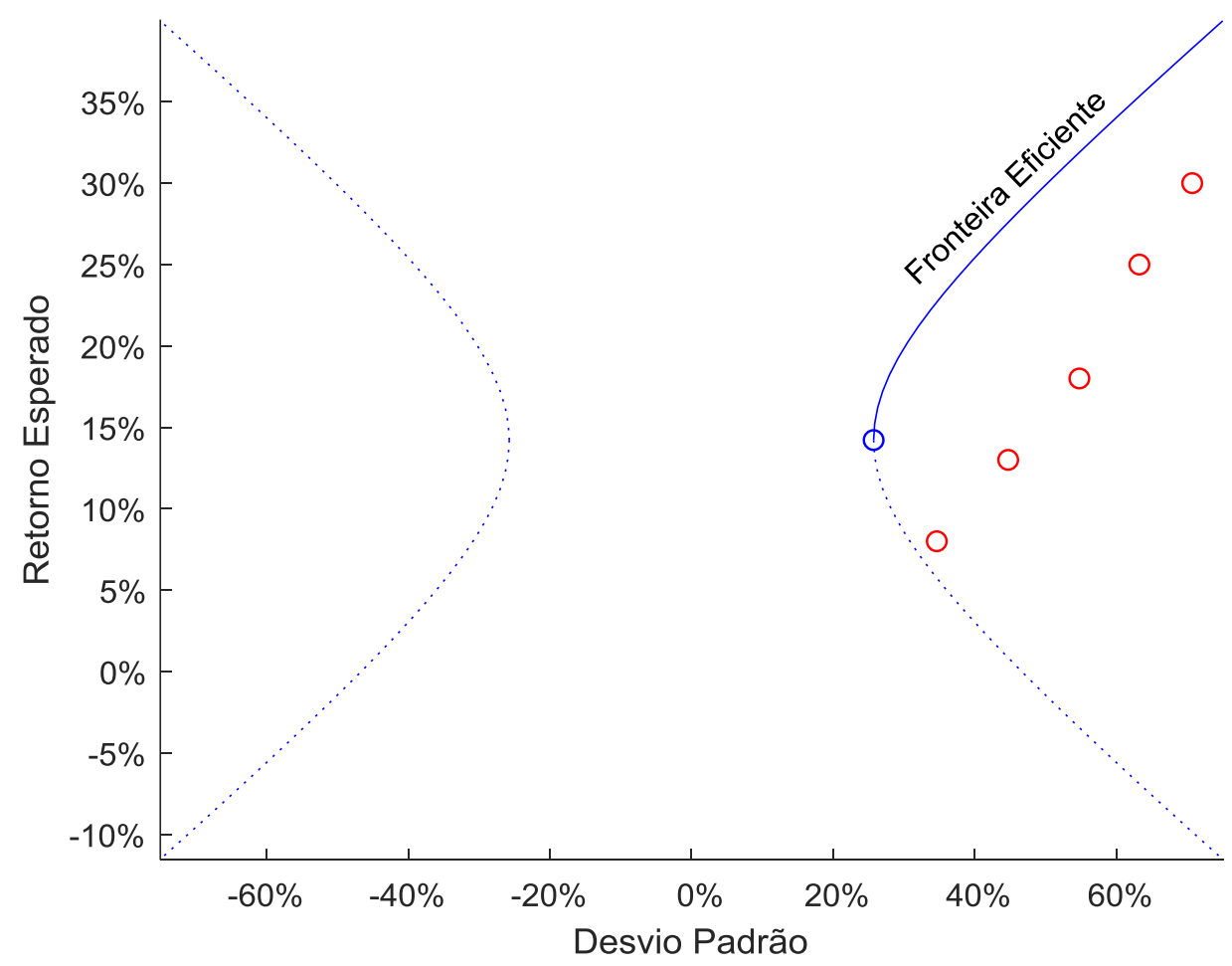

Figura 5. Hipérbole e fronteira eficiente no plano $(\mu \times \sigma)$. Fonte: Elaboração Própria. 
Na Figura 6 mostra-se também a carteira de variância mínima.

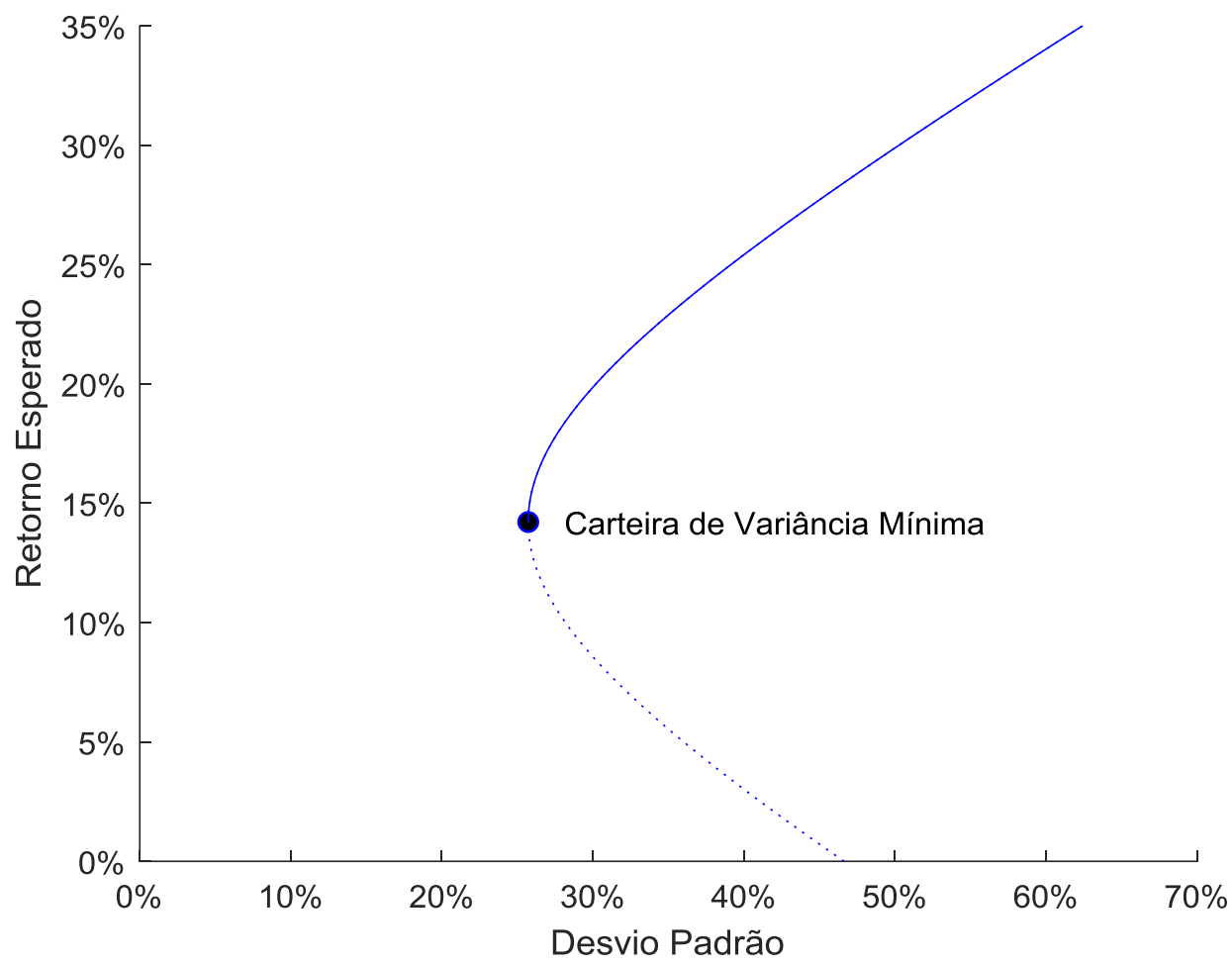

Figura 6. Carteira de variância mínima. Fonte: Elaboração Própria.

Embora os momentos da distribuição Gaussiana dos retornos da carteira de variância mínima possam ser calculados utilizando-se o ferramental de geometria analítica, como foi realizado no exemplo numérico anterior, de maneira geral e independente, estes momentos são calculados minimizando a equação (3.45). Ou seja:

$$
\min _{\mu_{p}}\left\{\sigma_{p}^{2}\right\}=\min _{\mu_{p}}\left\{\frac{c}{d} \mu_{p}^{2}+-\frac{2 a}{d} \mu_{p}+\frac{b}{d}\right\}
$$

Esta minimização tem a vantagem de ser irrestrita (sem restrições) e a solução encontra-se derivando a função objetivo e igualando a zero.

$$
\frac{2 c}{d} \mu_{p}-\frac{2 a}{d}=0
$$

Resolvendo-se $\mu_{p}^{*}$ da equação (3.58) e, na sequencia calculando-se $\sigma_{p}^{*}$ através da equação (3.45), obtém-se as equações (3.59) e (3.60).

$$
\begin{aligned}
& \mu_{p}^{*}=\frac{a}{c} \\
& \sigma_{p}^{*}=\frac{1}{\sqrt{c}}
\end{aligned}
$$


Contrastando-se a solução obtida pela metodologia de minimização com a solução obtida pela metodologia de geometria analítica das equações (3.53) e (3.54), obtém-se os mesmos resultados como já era esperado, entretanto, recomenda-se utilizar a metodologia de minimização, pois, trata-se de uma metodologia geral que funciona inclusive quando se acrescentam novas condições de contorno (restrições) ao problema de alocação de ativos.

Segundo Markowitz (1952), todas as carteiras localizadas na fronteira eficiente são igualmente eficientes em termos do binômio de risco-retorno. A questão que surge é, como selecionar uma carteira em particular? .Sharpe (1966), resolveu este problema definindo uma medida de desempenho que permitiu comparar o desempenho de risco-retorno das diversas carteiras da fronteira eficiente. Sharpe propôs uma medida baseada no conceito do prêmio de risco $\left(\mu_{p}-r_{f}\right)$ e normalizada pelo risco das carteiras $\sigma_{p}$. O conceito de prêmio de risco define-se como o excesso de retorno da carteira, em relação ao retorno do ativo livre de risco $\left(r_{f}\right)$. Na literatura de finanças esta medida de desempenho é conhecida como índice de Sharpe $S_{p}$, a qual está definida pela equação (3.61).

$$
S_{p}=\frac{\mu_{p}-r_{f}}{\sigma_{p}}
$$

Logo, para selecionar uma carteira em particular pelo critério de Sharpe é necessário maximizar o índice de Sharpe, assim:

$$
\max _{\mu_{p}}\left\{S_{p}\right\}=\max _{\mu_{p}}\left\{\frac{\mu_{p}-r_{f}}{\sigma_{p}}\right\}
$$

Este problema de maximização tem a vantagem de ser irrestrito (sem restrições) e a solução encontra-se derivando a função objetivo e igualando a zero, conforme a equação (3.63).

$$
\frac{\partial y}{\partial x}\left(\frac{\mu_{p}-r_{f}}{\sigma_{p}}\right)=0
$$

Resolvendo-se $\mu_{p}^{*}$ da equação (3.63) e na sequencia calculando-se $\sigma_{p}^{*}$ através da equação (3.45), obtém-se as equações (3.64) e (3.65).

$$
\begin{aligned}
\mu_{p}^{*} & =\frac{a r_{f}-b}{c r_{f}-a} \\
\sigma_{p}^{*} & =\sqrt{\frac{c}{d}\left(\mu_{p}^{*}\right)^{2}-\frac{2 a}{d} \mu_{p}^{*}+\frac{b}{d}}
\end{aligned}
$$


Esta solução particular é conhecida na literatura de finanças como a "Carteira Tangente", devido ao fato de que esta carteira representa um ponto de tangência, entre a fronteira eficiente e uma reta que passa pelo ponto $\left(0, r_{f}\right)$ onde $r_{f}$ é o retorno do ativo livre de risco. Utilizando-se os mesmos dados numéricos do exemplo anterior, da carteira de 5 ativos, da equação (3.55) e (3.56), e considerando-se, $r_{f}=5 \%$, obtém-se a carteira tangente definida pela distribuição Gaussiana $N\left(\mu_{p}^{*}, \sigma_{p}^{* 2}\right)=N\left(23,8 \% ; 36,74 \%^{2}\right)$. Na Figura 7 , mostra-se a carteira tangente e a reta tangente que passa pelo ponto $(0 ; 5 \%)$.

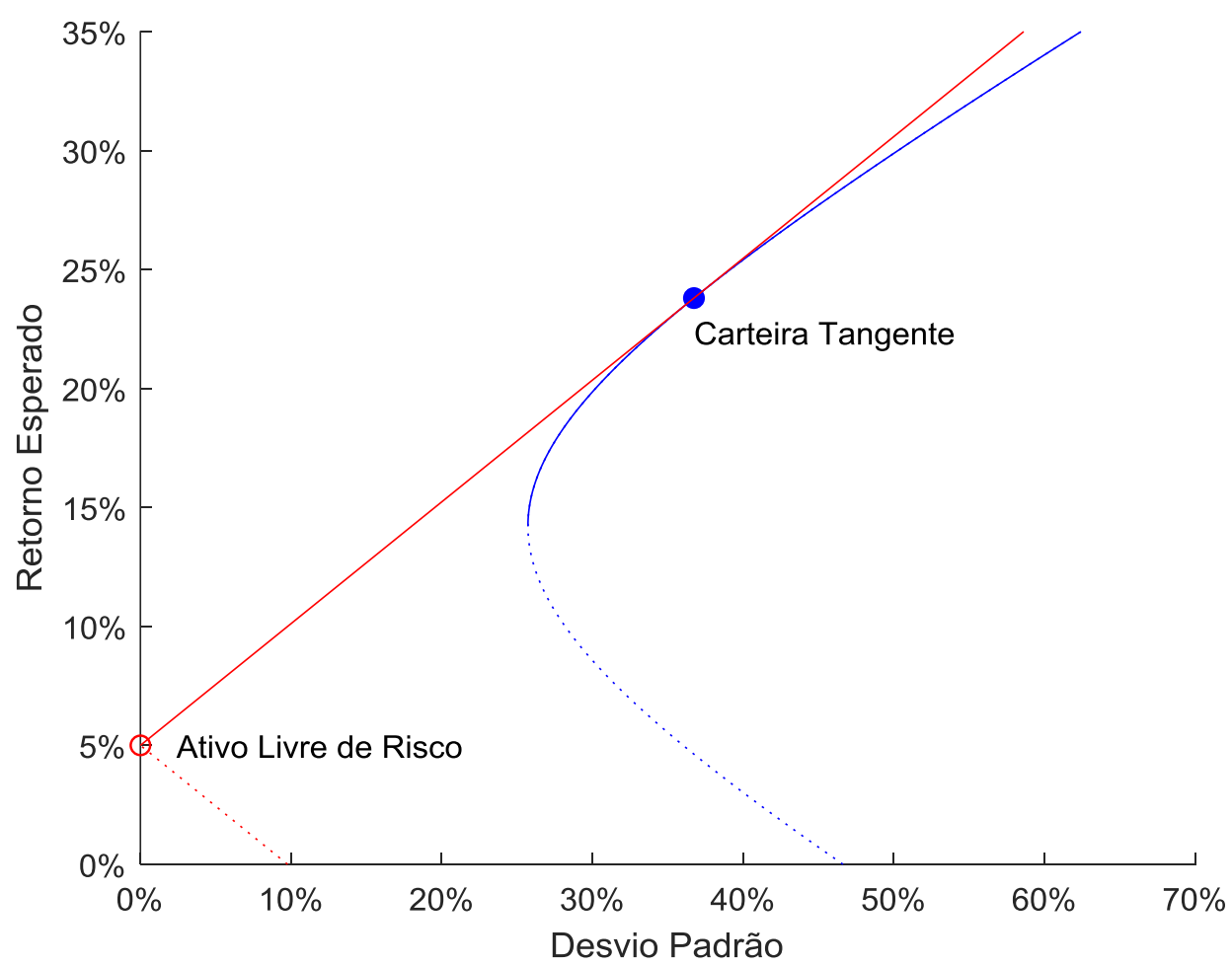

Figura 7. Carteira tangente e ativo livre de risco. Fonte: Elaboração Própria.

Logo, substituindo-se o momento $\mu_{p}^{*}=23,8 \%$ da carteira tangente na equação (3.36), obtém-se a seguinte alocação de ativos:

$$
\boldsymbol{w}_{p}=\left[\begin{array}{r}
-12,35 \% \\
24,61 \% \\
28,06 \% \\
27,21 \% \\
32,46 \%
\end{array}\right]
$$

Nota-se que, na solução anterior, a carteira tangente tem uma alocação com valor negativo (-12,35\%). Esta alocação é conhecida como venda ao descoberto ou short Selling. Na prática, esta alocação implica na venda de um ativo que não 
se possui, esperando que seu preço caia para, então, comprá-lo e lucrar na transação com a diferença. Esta transação pode ser executada alugando-se, através de uma corretora de valores, o ativo de um terceiro, em geral um investidor conservador, que, em troca, recebe uma taxa pequena, mas, certa, pelo aluguel de seu ativo. Este tipo de operação é comum nos mercados financeiros para lucrar em épocas de baixa, com a desvalorização e quedas de preço dos ativos (D’AVOLIO, 2002; LINNERTOVÁ, 2011).

Após o encerramento da operação, o especulador devolve ao investidor, via corretora de valores, os ativos alugados. O risco dessa operação para o especulador é que o preço do ativo negociado não caia o suficiente ou suba, gerando prejuízo. Gestores conservadores de carteiras de investimentos evitam este tipo de alocações acrescentando à equação (3.14), a restrição ( $\boldsymbol{w} \geq 0)$. Esta restrição é conhecida como restrição de vendas ao descoberto. Em geral, é possível acrescentar diversas outras restrições ao problema de alocação de ativos. Entretanto, para este caso geral, tipicamente não existe uma solução analítica fechada e a solução precisa ser calculada através de algoritmos numéricos de otimização.

Uma característica importante da carteira tangente é que o seu risco depende apenas do risco do mercado e independe do perfil de risco do investidor (avesso, neutro, propenso). Em outras palavras, o retorno da carteira tangente depende unicamente do potencial intrínseco dos ativos na geração de valor. Para considerar o perfil de risco do investidor, a teoria moderna de carteira, propõe formar uma segunda carteira, conhecida pelo nome de "carteira geral do investidor", formada pelo ativo livre de risco e a carteira tangente. A Figura 8, mostra a estrutura completa de alocação de ativos da teoria moderna de carteiras. Analogamente ao procedimento realizado na análise da carteira tangente, o retorno da carteira geral do investido calcula-se segundo a equação (3.67).

$$
r_{g}=y r_{p}+(1-y) r_{f}
$$

Onde y representa a fração de investimento na carteira tangente e $(1-y)$ é a fração remanescente de investimento no ativo livre de risco. Pelo fato de que a carteira tangente possui uma distribuição Gaussiana $r_{p} \sim N\left(\mu_{p}, \sigma_{p}^{2}\right)$ e, o ativo livre de risco ser uma constante numérica, então o retorno da carteira geral do investidor também terá uma distribuição Gaussiana $r_{g} \sim N\left(\mu_{g}, \sigma_{g}^{2}\right)$. 


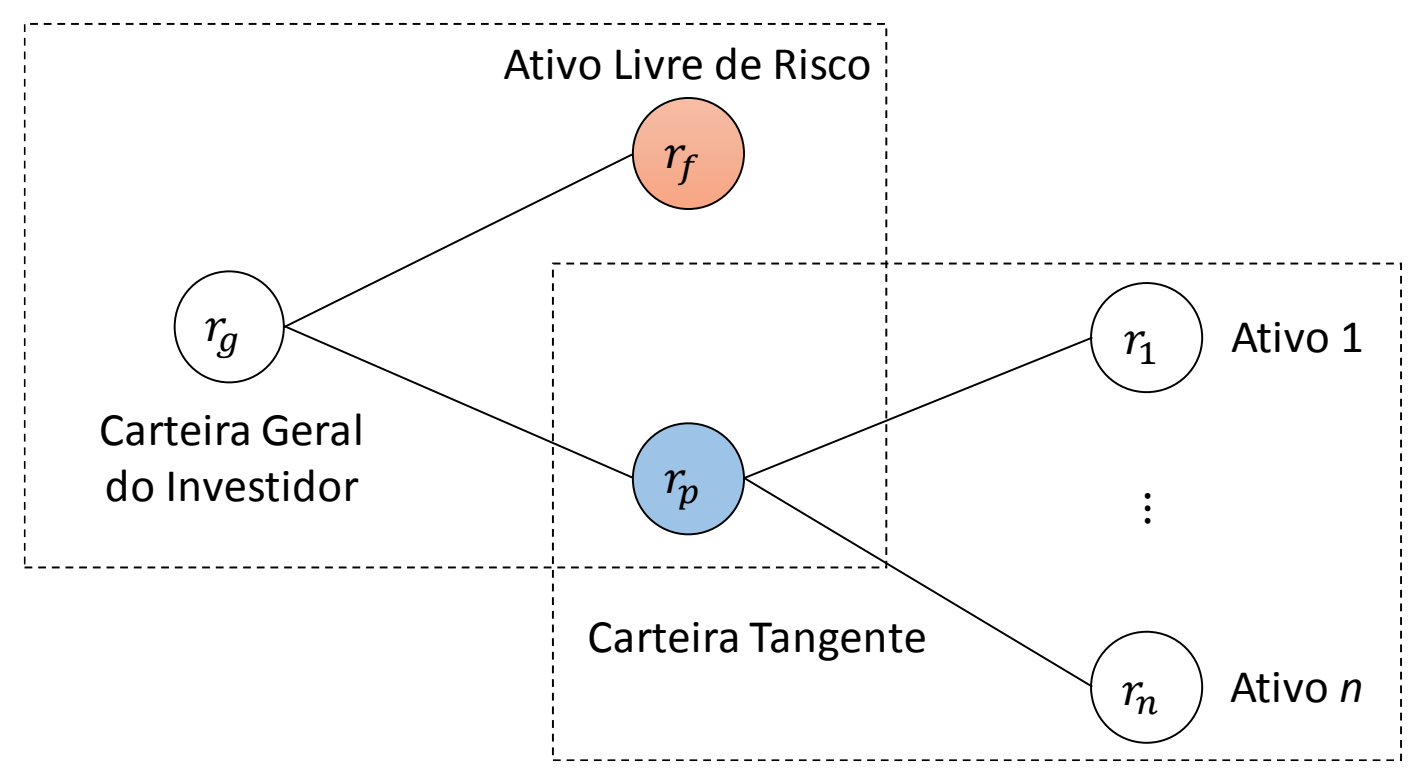

Figura 8. Estrutura de investimento da teoria moderna de carteiras. Fonte: Elaboração Própria.

Este argumento justifica-se pelo fato de que a soma de uma distribuição Gaussiana e uma constante numérica resulta em outra distribuição Gaussiana. Assim, os momentos $\mu_{g}$ e $\sigma_{g}$ da distribuição dos retornos da carteira geral do investidor calculam-se através das equações (3.68) e (3.69):

$$
\begin{aligned}
& \mu_{g}=E\left[r_{g}\right]=y \mu_{p}+(1-y) r_{f} \\
& \sigma_{g}^{2}=\operatorname{Var}\left[r_{g}\right]=y^{2} \sigma_{p}^{2}
\end{aligned}
$$

Nas equações (3.68) e (3.69), a única variável desconhecida é a fração y de investimento; o restante de variáveis possuem valores conhecidos. Esta fração $y$ de investimento depende do perfil de risco do investidor (conservador, moderado, agressivo). A função padrão de utilidade comumente utilizada é a função quadrática de média-variância $U\left(\mu_{g}, \sigma_{g}^{2}\right)$, definida pela equação (3.70).

$$
U\left(\mu_{g}, \sigma_{g}^{2}\right)=\mu_{g}-\frac{1}{2} \gamma \sigma_{g}^{2}
$$

Onde $\gamma$ é o coeficiente de aversão ao risco do investidor. Segundo Bodie, Kane e Marcus (2009), o valor típico do coeficiente de aversão ao risco para um investidor médio é de $\gamma=2,85$.

Logo, a fração $y$ de investimento, calcula-se maximizando a função de utilidade da equação (3.71).

$$
\max _{y}\left\{U\left(\mu_{g}, \sigma_{g}^{2}\right)\right\}=\max _{y}\left\{\mu_{g}-\frac{1}{2} \gamma \sigma_{g}^{2}\right\}
$$


Substituindo-se, $\mu_{g}$ e $\sigma_{g}^{2}$ da equação (3.68) e (3.69), na equação (3.71) e, na sequência, derivando-se a expressão resultante em relação a $y$, e igualandose tudo a zero, obtém-se a seguinte solução expressa pela equação (3.72):

$$
y^{*}=\frac{1}{\gamma}\left(\frac{\mu_{p}-r_{f}}{\sigma_{p}^{2}}\right)
$$

A equação (3.72), pode ser reescrita de forma mais compacta, utilizando-se a relação do índice de Sharpe da equação (3.61). Assim:

$$
y^{*}=\frac{1}{\gamma}\left(\frac{S_{p}}{\sigma_{p}}\right)
$$

Substituindo-se, a fração $y^{*}$ ótima de investimento na equação (3.68) e (3.69), obtém-se os momentos da distribuição dos retornos da carteira geral do investidor, expressos pelas equações (3.74) e (3.75).

$$
\begin{aligned}
& \mu_{g}^{*}=\frac{1}{\gamma}\left[S_{p}^{2}-\frac{r_{f}}{\sigma_{p}} S_{p}\right] \\
& \sigma_{g}^{*}=\frac{1}{\gamma} S_{p}
\end{aligned}
$$

Na Figura 9, mostra-se a função de utilidade e a carteira geral do investidor, definida pela distribuição Gaussiana $N\left(\mu_{g}^{*}, \sigma_{g}^{* 2}\right)=N\left(14,19 \% ; 17,96 \%^{2}\right)$. Este gráfico foi gerando utilizando os mesmos dados da carteira de 5 ativos da equação (3.55) e (3.56), e considerando-se, $r_{f}=5 \%$ e $\gamma=2,85$. Neste exemplo, a fração ótima de investimento na carteira tangente foi de $y^{*}=48,87$ e, a fração remanescente de investimento no ativo livre de risco foi de $\left(1-y^{*}\right)=51,13 \%$.

$$
\boldsymbol{w}_{g}=(48,87) \boldsymbol{w}_{p}+(51,13 \%) r_{f}
$$

Substituindo-se, a alocação previamente calculada da carteira tangente $\boldsymbol{w}_{p}$, da equação (3.66), na equação (3.76), obtém-se a alocação geral do investidor, expressa pela equação (3.77).

$$
\boldsymbol{w}_{g}=\left[\begin{array}{l}
w_{r f} \\
w_{r 1} \\
w_{r 2} \\
w_{r 3} \\
w_{r 4} \\
w_{r 5}
\end{array}\right]=\left[\begin{array}{c}
51,13 \% \\
-6,03 \% \\
12,03 \% \\
13,72 \% \\
13,30 \% \\
15,13 \%
\end{array}\right]
$$




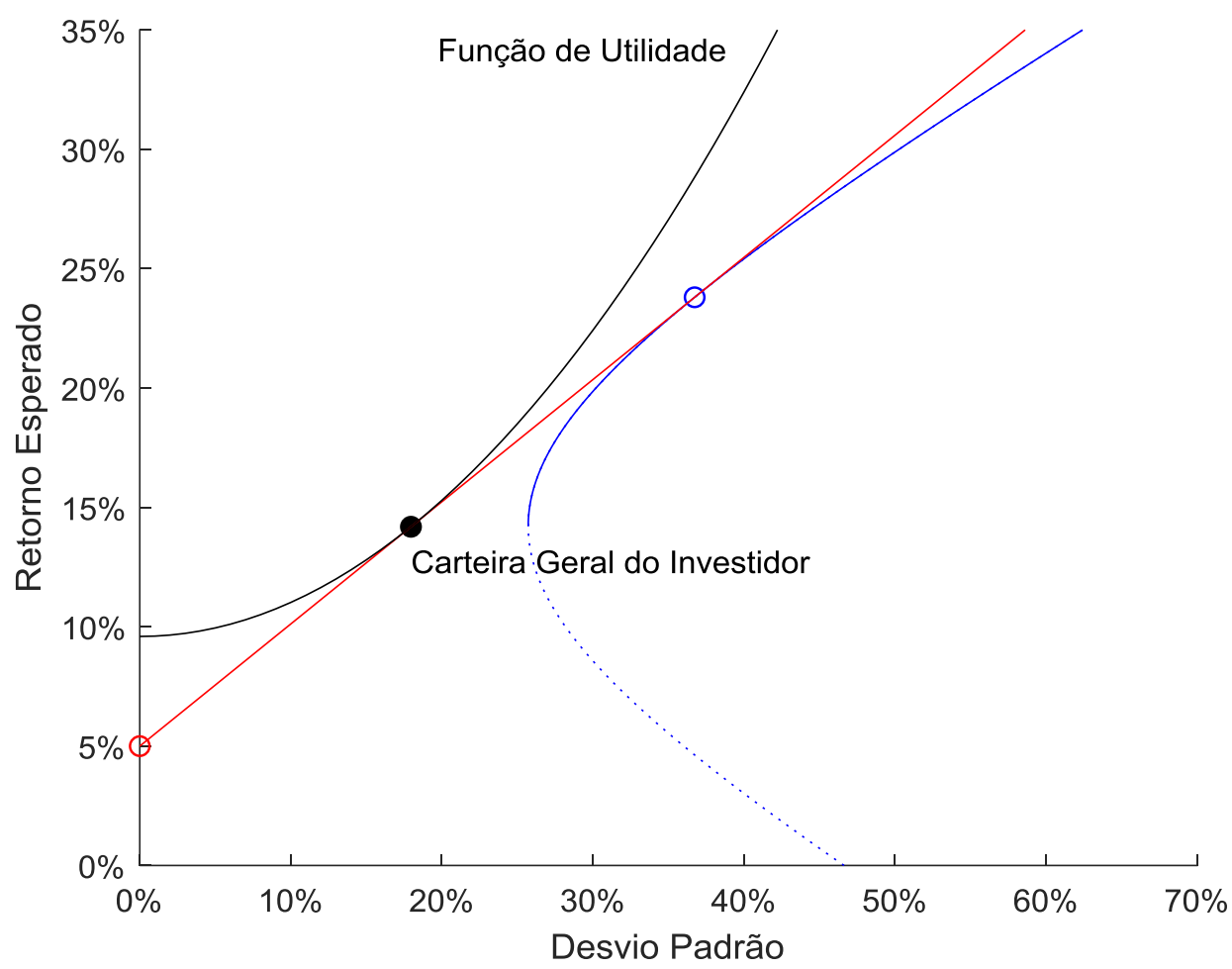

Figura 9. Função de utilidade e carteira geral do investidor. Fonte: Elaboração Própria.

Nesta seção, apresentou-se um resumo da teoria moderna de carteiras. O relevante desta teoria é que estabelece de forma clara que as decisões de investimento devem ser tomadas com base do binômio de risco-retorno e, além disso, estabelece-se um procedimento sólido da sequência de cálculos para determinar a alocação ótima de capital. As aplicações práticas desta teoria nem sempre geram resultados satisfatórios, devido ao fato de que suas premissas não são sempre atendidas (retornos Gaussianos). Este é o caso das carteiras com retornos não Gaussianos, provocados, tanto por mudanças de regime, quanto por quebras estruturais na série temporal dos retornos. Nas próximas seções, serão realizadas adaptações do modelo clássico de alocação de ativos para atender a estas novas condições de contorno.

\section{2.}

\section{Otimização de carteiras com retornos não Gaussianos provocados por mudanças de regime}

Esta seção trata da otimização de carteiras com retornos não Gaussianos, provocados por mudanças de regime (ou estados), que se repetem de forma recorrente ao longo do tempo. O caso mais elementar deste tipo de comportamento é o caso de uma série temporal de retornos, com períodos de alta 
e baixa volatilidade (dois regimes), que apresentam como fato estilizado, que a volatilidade é maior nos regimes de retorno negativo do que nos regimes positivos (CHU; SANTONI; LIU, 1996). Este comportamento, introduz na relação mediavariância uma relação assimétrica, gerando uma distribuição de retornos não Gaussianos. Empiricamente, isto pode ser constatado na série histórica dos retornos das ações (FAMA, 1965; SARANYA; PRASANNA, 2014). Entretanto, em séries históricas das criptomoedas, que representam uma nova categoria de ativos de renda variável, as suas distribuições dos retornos são acentuadamente não Gaussianas, produto de sua alta volatilidade e saltos na série temporal dos seus retornos. Na Figura 10, mostra a série temporal dos retornos diários do Bitcoin no período de 09/09/2010 até 09/10/2021. Nota-se os clusters de volatilidade, assim como, os saltos repentinos dos retornos ao longo do tempo.

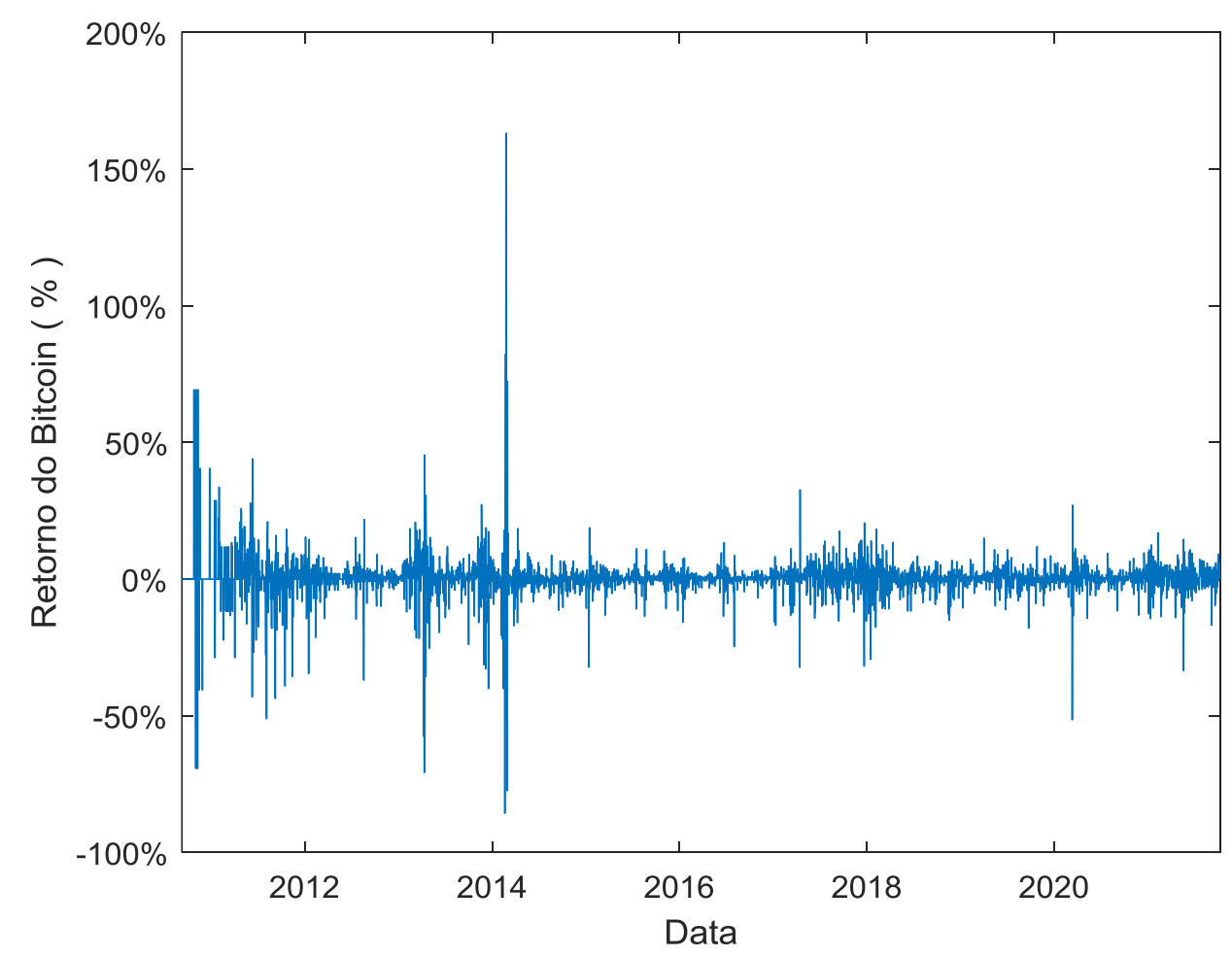

Figura 10. Série temporal dos retornos diários do Bitcoin. Fonte: Elaboração Própria.

Na Figura 11, mostra-se o gráfico do Q-Q (quantil-quantil) da série temporal dos retornos correspondente ao mesmo período de análise. O gráfico $Q-Q$ compara duas distribuições de probabilidade (neste caso a distribuição do Bitcoin versus a distribuição Gaussiana), traçando seus quantis uns contra os outros. Se as duas distribuições são semelhantes, os pontos no gráfico $Q-Q$ vão repousar na linha $y=x$, aproximadamente. Nota-se que o gráfico $Q-Q$ do Bitcoin não repousa na linha $y=x$, evidenciando que a sua distribuição de retornos é não Gaussiana. 


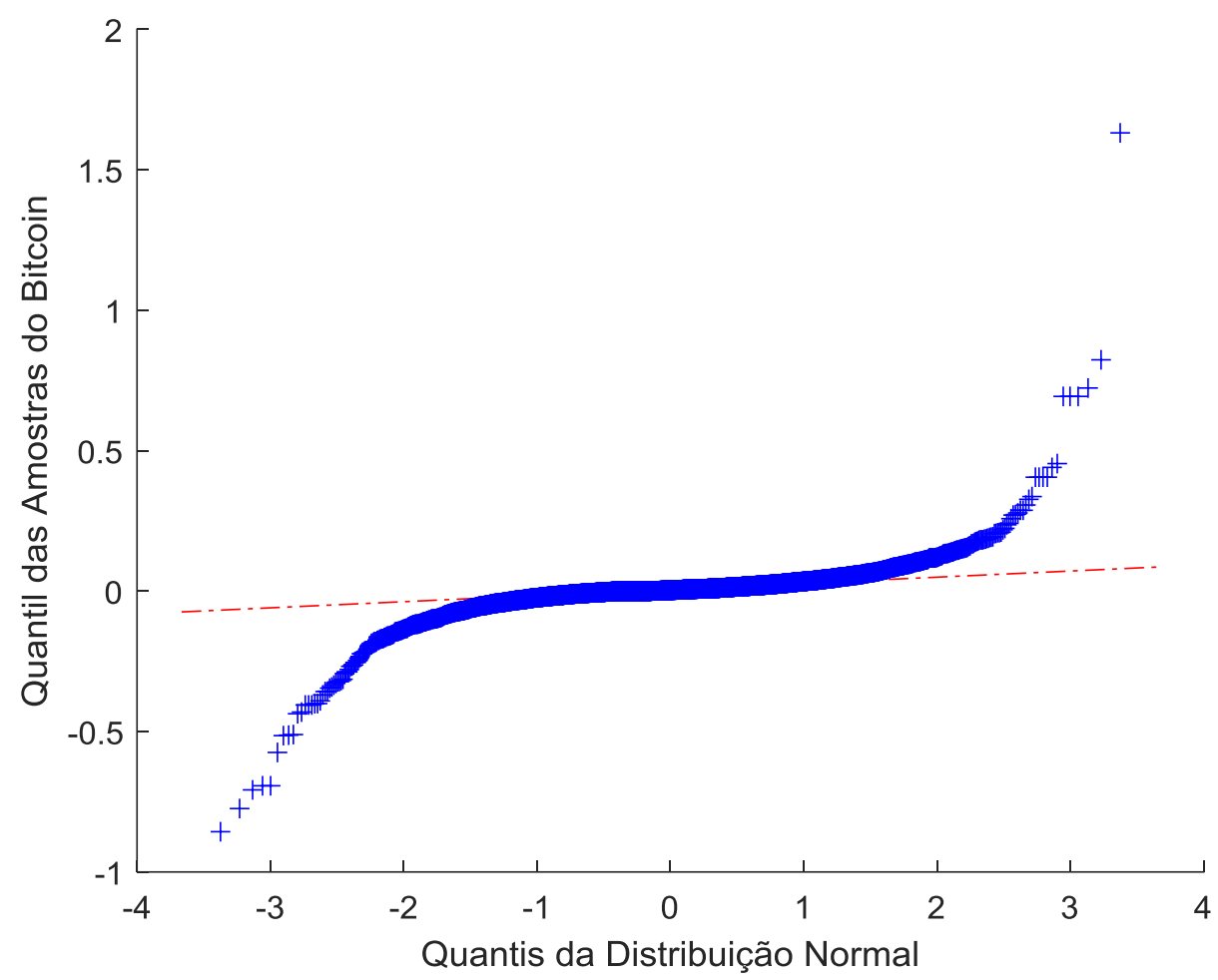

Figura 11. Gráfico Q-Q da série de retornos diários do Bitcoin. Fonte: Elaboração Própria.

Aplicar a metodologia clássica de Markowitz em carteiras com retornos não Gaussianos, resulta em um mascaramento do risco, devido ao fato de que a distribuição Gaussiana não consegue capturar as caudas pesadas típicas dos retornos não Gaussianos. Em outros termos, o investidor está correndo um risco maior e a metodologia Markowitz dá como resultado um risco menor. Para corrigir esta distorção, Tito et al. (2020), propõem alterar duas premissas da metodologia tradicional de Markowitz. A primeira alteração consiste na flexibilização da premissa dos retornos com distribuição Gaussiana para retornos de qualquer natureza probabilística. Em particular, sugerem utilizar a distribuição empírica dos dados. A segunda alteração consiste na substituição da medida de desempenho da carteira, do índice de Sharpe para a medida Ômega.

A medida Ômega é uma medida de desempenho proposta por Keating e Shadwick (2002), que se caracteriza por considerar todos os momentos da distribuição dos retornos e não somente a média e variância como acontece com o índice de Sharpe. Por esta razão, a medida Ômega é uma medida de desempenho universal que pode ser aplicada a qualquer carteira independentemente da premissa adotada na modelagem dos retornos dos ativos. 
A seguir, apresenta-se a equação (3.78) da medida Ômega:

$$
\Omega(L)=\frac{\int_{L}^{b}\left[1-F\left(r_{p}\right)\right] d x}{\int_{a}^{L} F\left(r_{p}\right) d x}
$$

Onde:

$\Omega(L)$ : medida Ômega de desempenho da carteira

$L$ : retorno mínimo esperado da carteira

$F\left(r_{p}\right)$ : função de distribuição dos retornos $r_{p}$ da carteira.

$(a, b)$ : domínio do retorno $r_{p}$ da carteira, no caso mais geral, $(a, b)=$ $(-\infty, \infty)$.

Kazemi; Schneeweis e Gupta (2004), desenvolveram uma fórmula alternativa da medida de desempenho Ômega expressa pela equação (3.79):

$$
\Omega(L)=\frac{E\left[\max \left(r_{p}-L ; 0\right)\right]}{E\left[\max \left(L-r_{p} ; 0\right)\right]}
$$

Sendo:

$E[\cdot]$ : operador de valor esperado.

$\max (\cdot)$ : operador máximo.

As equações (3.78) e (3.79), podem ser aplicadas a qualquer carteira com retornos de qualquer natureza probabilísticas. Porém, para carteiras com retornos Gaussianos, obtém-se, a medida Ômega da equação (3.80) (TITO et al., 2020):

$$
\Omega(L)=\frac{\varphi\left(\frac{\mu_{p}-L}{\sigma_{p}}\right)+\left(\frac{\mu_{p}-L}{\sigma_{p}}\right) \Phi\left(\frac{\mu_{p}-L}{\sigma_{p}}\right)}{\varphi\left(\frac{\mu_{p}-L}{\sigma_{p}}\right)+\left(\frac{\mu_{p}-L}{\sigma_{p}}\right)\left[\Phi\left(\frac{\mu_{p}-L}{\sigma_{p}}\right)-1\right]}
$$

Sendo:

$\varphi(\cdot)$ : a função de densidade $N(0,1)$

$\Phi(\cdot)$ : a função de distribuição $N(0,1)$

A equação (3.80), permite avaliar o desempenho de qualquer carteira localizada na fronteira eficiente, entretanto, para encontrar uma carteira em particular, precisa-se maximizar $\Omega(L)$ em função de $\mu_{p}$, ou seja: 


$$
\max _{\mu_{p}}\{\Omega(L)\}=\frac{\partial}{\partial \mu_{p}}\left(\frac{\varphi\left(\frac{\mu_{p}-L}{\sigma_{p}}\right)+\left(\frac{\mu_{p}-L}{\sigma_{p}}\right) \Phi\left(\frac{\mu_{p}-L}{\sigma_{p}}\right)}{\varphi\left(\frac{\mu_{p}-L}{\sigma_{p}}\right)+\left(\frac{\mu_{p}-L}{\sigma_{p}}\right)\left[\Phi\left(\frac{\mu_{p}-L}{\sigma_{p}}\right)-1\right]}\right)
$$

A equação (3.81), pode ser simplificada para a expressão apresentada pela equação (3.82). Os detalhes dessa derivação se apresenta em Tito et al. (2020).

$$
\max _{\mu_{p}}\{\Omega(L)\}=\frac{\partial}{\partial \mu_{p}}\left(\frac{\mu_{p}-L}{\sigma_{p}}\right)
$$

Por compatibilidade com a metodologia tradicional, o parâmetro do retorno mínimo da carteira $L$, da medida Ômega, deve ser igual ao retorno do ativo livre de risco $r_{f}$, ou seja, $L=r_{f}$, logo, a equação (3.82), pode ser reescrita como:

$$
\max _{\mu_{p}}\{\Omega(L)\}=\frac{\partial}{\partial \mu_{p}}\left(\frac{\mu_{p}-r_{f}}{\sigma_{p}}\right)
$$

A expressão da equação (3.83), é idêntica à expressão da equação (3.62), ou seja:

$$
\max _{\mu_{p}}\{\Omega(L)\}=\max _{\mu_{p}}\left\{S_{p}\right\}
$$

Baseando-se, nesta igualdade, conclui-se que, a carteira ótima $\left(\mu_{p}^{*}, \sigma_{p}^{*}\right)$ selecionada pela medida de desempenho Ômega é exatamente a mesma carteira selecionada pela medida de desempenho do índice de Sharpe, ou seja, em condições de retornos Gaussianos, igualando $L=r_{f}$, o índice de Sharpe é um caso particular da medida Ômega.

Com este resultado teórico, a metodologia tradicional pode ser estendida para um caso mais geral apenas fazendo-se duas alterações. A primeira alteração é a flexibilização da premissa dos retornos Gaussianos para retornos de qualquer natureza probabilística. A segunda alteração é a substituição da medida de desempenho da carteira, do índice de Sharpe para a medida Ômega. Com estas duas alterações tem-se uma metodologia genérica para a otimização de carteiras com retornos não Gaussianos provocados pelas mudanças de regime.

\section{3.}

\section{Otimização de carteiras com retornos não Gaussianos provocados por quebras estruturais}

Esta seção trata da otimização de carteiras com retornos não Gaussianos provocados por quebras estruturais permanentes e não recorrentes ao longo do 
tempo, que ocasionam, que os parâmetros da distribuição dos retornos variem de forma imprevisível, entre, infinitos estados possíveis, em outras palavras, ocasionam um comportamento estocástico na relação média-variância, gerando uma série temporal de retornos não Gaussianos.

Para contornar este problema propõe-se, a substituição do procedimento de estimação dos parâmetros da distribuição dos retornos, baseado em técnicas da estatística Frequentista por técnicas da estatística Bayesiana. Isto porque a estatística Bayesiana, tem a vantagem de combinar as informações públicas do mercado (dados históricos dos retornos) com informações privadas do investidor (visões prospectivas do mercado) permitindo corrigir a quebra estrutural. Nota-se que o teorema de Bayes não será aplicado diretamente nos dados da série temporal dos retornos, e sim nos parâmetros da distribuição dos retornos. Por esta razão, a correção das quebras estruturais será realizada em duas etapas: (i) $\mathrm{Na}$ primeira etapa será aplicado a inferência Bayesiana dos parâmetros da distribuição dos retornos e; (ii) Na segunda etapa será aplicada a transformação de Mahalanobis da série temporal dos retornos, corrigindo os dados originais refletidas pela distribuição a priori para um novo conjunto de dados que refletirão a nova distribuição a posteriori gerada pelo teorema de Bayes. Finalmente a nova série temporal corrigida será utilizada pelo mecanismo de otimização baseado na medida Ômega.

\subsection{1.}

\section{Inferência Bayesiana dos parâmetros da distribuição dos retornos}

A teoria moderna de carteiras realiza a alocação ótima dos ativos em função da média-variância da distribuição dos retornos. Na prática, estes parâmetros $\boldsymbol{\mu} \mathrm{e}$ $\boldsymbol{\Sigma}$ são estimados a partir dos dados históricos do mercado, utilizando técnicas descritivas da estatística Frequentista. Estes dados históricos podem ser especificados por uma matriz $\boldsymbol{X}$ de " $m$ " linhas e " $n$ " colunas, como mostrada na equação (3.85).

$$
\boldsymbol{X}=\left[\begin{array}{cccc}
r_{11} & r_{12} & \cdots & r_{1 n} \\
r_{21} & r_{22} & \cdots & r_{2 n} \\
\vdots & \vdots & \ddots & \vdots \\
r_{m 1} & r_{m 2} & \cdots & r_{m n}
\end{array}\right]=\left[\begin{array}{c}
\boldsymbol{x}_{1} \\
\boldsymbol{x}_{2} \\
\vdots \\
\boldsymbol{x}_{m}
\end{array}\right]
$$

Onde " $n$ " representa o número de variáveis aleatórias $\left\{r_{1}, r_{2}, \cdots, r_{n}\right\}$ dos ativos da carteira, e " $m$ " representa o número de observações de retornos do mercado, desta forma, o dado $r_{i j}$ representa a observação " $i$ " da variável aleatória " $j$ " e o vetor linha $\boldsymbol{x}_{i}$ representa a linha $i$ da matriz $\boldsymbol{X}$. 
Neste contexto, a estatística Frequentista estima os parâmetros $\boldsymbol{\mu}$ e $\boldsymbol{\Sigma}$ da distribuição dos retornos através das equações (3.86) e (3.87).

$$
\begin{aligned}
& \widehat{\boldsymbol{\mu}}=\frac{1}{n} \sum_{i=1}^{m} \boldsymbol{x}_{i}^{T} \\
& \boldsymbol{S}=\frac{1}{n-1} \sum_{i=1}^{m}\left(x_{i}-\widehat{\boldsymbol{\mu}}\right)\left(x_{i}-\widehat{\boldsymbol{\mu}}\right)^{T}
\end{aligned}
$$

Onde, $\hat{\boldsymbol{\mu}}$ e $\boldsymbol{S}$ representam as estatísticas amostrais dos parâmetros populacionais $\boldsymbol{\mu}$ e $\boldsymbol{\Sigma}$. De forma equivalente, estes parâmetros podem ser estimados pelas equações (3.88) e (3.89) (JOHNSON; WICHERN, 2007):

$$
\begin{aligned}
& \widehat{\boldsymbol{\mu}}=\frac{1}{n} \boldsymbol{X}^{T} \mathbf{1} \\
& \boldsymbol{S}=\frac{1}{n-1} \boldsymbol{X}^{T}\left(\boldsymbol{I}-\frac{1}{n} \mathbf{1 1}^{T}\right) \boldsymbol{X}
\end{aligned}
$$

O procedimento de estimação dos parâmetros $\boldsymbol{\mu}$ e $\boldsymbol{\Sigma}$ realizado pela estatística Frequentista não permite tratar quebras estruturais dos retornos, devido a que suas fórmulas dependem exclusivamente dos dados históricos do mercado. Existem cenários econômicos futuros, que possuem uma expectativa de saltos iminentes no retorno de determinados ativos, para estes casos, as estatística $\widehat{\mu} \mathrm{e}$ $\boldsymbol{S}$, estimados pela estatística Frequentista não serão capazes de capturar essas informações, devido ao fato de que o salto ainda não ocorreu e esse dado não está contemplado nos dados históricos de retornos do mercado.

Em contraste, a estatística Bayesiana estima os parâmetros $\boldsymbol{\mu}$ e $\boldsymbol{\Sigma}$ combinando as informações públicas do mercado (dados históricos dos retornos) com informações privadas do investidor (visões prospectivas do mercado) permitindo, inserir informações no processo de estimação dos parâmetros, obtendo estatísticas mais precisas, permitindo ao investidor corrigir as quebras estruturais na série temporal dos retornos. Embora a estatística Bayesiana possa ser aplicada na estimação, tanto do parâmetro $\boldsymbol{\mu}$ quanto do parâmetro $\boldsymbol{\Sigma}$, as quebras estruturais afetam preferencialmente o parâmetro $\boldsymbol{\mu}$, por esta razão, a seguir será realizada a inferência Bayesiana, somente do parâmetro $\boldsymbol{\mu}$, mantendo a estimativa do parâmetro $\boldsymbol{\Sigma}$ com a mesmo valor, $\boldsymbol{S}$, calculado pela estatística Frequentista.

Para isto, a estatística Bayesiana constrói uma distribuição a priori $\boldsymbol{\mu} \sim N(\widehat{\boldsymbol{\mu}} ; \tau \boldsymbol{S})$, baseada nas informações históricas dos retornos, e uma distribuição 
de verossimilhança $\boldsymbol{P} \boldsymbol{\mu} \sim N(\boldsymbol{Q} ; \boldsymbol{\Omega})$, baseada nas informações prospectivas do investidor, e através do teorema de Bayes é gerado uma nova distribuição a posteriori $\boldsymbol{\mu} \mid \boldsymbol{Q} \sim N(\widetilde{\boldsymbol{\mu}} ; \tilde{\boldsymbol{S}})$, que combina probabilisticamente as duas informações anteriores. A distribuição a priori $\boldsymbol{\mu} \sim N(\widehat{\boldsymbol{\mu}} ; \tau \boldsymbol{S})$ é definida por uma distribuição Gaussiana com média $\widehat{\boldsymbol{\mu}}$, calculada pela equação (3.88), e uma matriz de covariância $\tau \boldsymbol{S}$, onde $\boldsymbol{S}$ é calculada pela equação (3.89), e $\tau$ um fator de encolhimento da matriz de covariância $\boldsymbol{S}$. Este fator tipicamente assume valores entre 0,01 e 0,05 (IDZOREK, 2007). A distribuição de verossimilhança $\boldsymbol{P} \boldsymbol{\mu} \sim N(\boldsymbol{Q} ; \boldsymbol{\Omega})$ é definida por uma distribuição Gaussiana com média $\boldsymbol{Q}$ e covariância $\boldsymbol{\Omega}$. A matriz $\boldsymbol{P}$ que multiplica o parâmetro $\boldsymbol{\mu}$ permite especificar as visões prospectivas do mercado sob a ótica do investidor. Estas visões permitem especificar as quebras estruturais dos retornos na estrutura de ativos da carteira.

A seguir, será mostrado um exemplo de como construir estas visões prospectivas do investidor, para isto, serão considerados os mesmos dados das carteiras escritas pelas equações (3.55) e (3.56) e, que estão sendo reescritas novamente pelas equações (3.90) e (3.91).

$$
\begin{aligned}
\boldsymbol{\mu}_{x} & =\left[\begin{array}{r}
8 \% \\
13 \% \\
18 \% \\
25 \% \\
30 \%
\end{array}\right] \\
\boldsymbol{\Sigma}_{x} & =\left[\begin{array}{rrrrr}
12 \% & 6 \% & -1 \% & 3 \% & 5 \% \\
6 \% & 20 \% & -1 \% & 2 \% & 4 \% \\
-1 \% & -1 \% & 30 \% & 5 \% & -1 \% \\
3 \% & 2 \% & 5 \% & 40 \% & 6 \% \\
5 \% & 4 \% & -1 \% & 6 \% & 50 \%
\end{array}\right]
\end{aligned}
$$

Esta carteira está formada por cinco ativos, cujos retornos serão denotados por $\left\{r_{1}, r_{2}, r_{3}, r_{4}, r_{5}\right\}$. Suponha que o investidor possua três visões de mercado, ou seja, três eventuais quebras estruturais. Estas quebras estruturais podem ser divididas em dois grupos: (i) Um primeiro grupo formado por quebras estruturais descorrelacionadas, as quais serão denominadas como "visões absolutas" do investidor e; (ii) Um segundo grupo formado por quebras estruturais correlacionadas, as quais serão denominadas "visões relativas" do investidor.

A Tabela 1 mostra a especificação de três visões de mercado, das quais duas visões são absolutas e uma visão é relativa. 


\begin{tabular}{|c|c|}
\hline Visão Absoluta & $\mu_{1}=N\left(16 \% ; 1 \%^{2}\right)$ \\
\hline Visão Relativa & $\mu_{3}-\mu_{2}=N\left(1 \% ; 1 \%^{2}\right)$ \\
\hline Visão Absoluta & $\mu_{5}=N\left(15 \% ; 1 \%^{2}\right)$ \\
\hline
\end{tabular}

Tabela 1. Exemplo de visões prospectivas do mercado. Fonte: Elaboração Própria.

$\mathrm{Na}$ primeira visão de mercado de tipo absoluta, o investidor tem a expectativa de que a média do ativo 1 , mude de um valor fixo de $\mu_{1}=8 \%$ para um novo valor especificado por uma distribuição Gaussiana com média de 16\% e desvio padrão de $1 \%$, ou seja, $\mu_{1} \sim N\left(16 \% ; 1 \%^{2}\right)$. Nota-se que esta distribuição não se refere à distribuição dos dados do ativo 1 , e sim à distribuição do parâmetro $\mu_{1}$ do ativo $r_{1}$. Além disso, nota-se, que esta visão do investidor é uma visão otimista porque a expectativa do investidor é um salto na rentabilidade do ativo 1.

Na segunda visão de mercado de tipo relativa, o investidor tem a expectativa de que a diferença entre as médias do ativo 3 menos a média do ativo 2, seja uma distribuição Gaussiana com média de $1 \%$ e desvio padrão de 1\%, ou seja, $\mu_{3}-$ $\mu_{2}=N\left(1 \% ; 1 \%^{2}\right)$. Nota-se que esta visão relativa se trata de uma quebra estrutural que impõe uma correlação entre os ativos 2 e 3, de tal forma que a diferença de rentabilidades seja uma constante.

Na terceira visão de mercado de tipo absoluta, o investidor tem a expectativa de que a média do ativo 5 , mude de um valor fixo de $\mu_{1}=30 \%$ para um novo valor especificado por uma distribuição Gaussiana com média de $15 \%$ e desvio padrão de $1 \%$, ou seja, $\mu_{5} \sim N\left(15 \% ; 1 \%^{2}\right)$. Nota-se que esta visão do investidor é uma visão pessimista porque a expectativa do investidor é uma queda na rentabilidade do ativo 5.

Após o investidor definir as suas visões de mercado, o próximo passo é preencher os parâmetros da distribuição de verossimilhança $\boldsymbol{P} \boldsymbol{\mu} \sim N(\boldsymbol{Q} ; \boldsymbol{\Omega})$. Para preencher a matriz $\boldsymbol{P}$, previamente pode-se montar uma tabela auxiliar, como mostra-se na Tabela 2.

\begin{tabular}{|c|c|c|c|c|}
\hline$r_{1}$ & $r_{2}$ & $r_{3}$ & $r_{4}$ & $r_{5}$ \\
\hline 1 & & & & \\
\hline & -1 & 1 & & \\
\hline & & & & 1 \\
\hline
\end{tabular}

Tabela 2. Tabela auxiliar para o preenchimento da matriz $\boldsymbol{P}$. Fonte: Elaboração Própria. 
Cada linha da tabela auxiliar representa uma visão prospectiva do investidor. Por exemplo, a primeira visão do tipo absoluta é representada pelo número 1 embaixo da coluna $r_{1}$, a segunda visão do tipo relativa é representada pelo número - 1 embaixo da coluna $r_{2}$ e pelo número 1 embaixo da coluna $r_{3}$, e a terceira visão do tipo absoluta é representada pelo número 1 embaixo da coluna $r_{5}$.

A tabela anterior, pode ser sintetizada pela matriz $\boldsymbol{P}$ da equação (3.92)

$$
\boldsymbol{P}=\left[\begin{array}{lllll}
1 & & & \\
& -1 & 1 & & \\
& & & & 1
\end{array}\right]
$$

Cabe sublinhar que a somatória de cada linha da matriz deve ser "1" para o caso das visões absolutas e "0" para o caso das visões relativas. Para preencher o vetor $\boldsymbol{Q}$ usamos as informações da Tabela 1, o vetor $\boldsymbol{Q}$ é formado pelas médias das visões, assim:

$$
\boldsymbol{Q}=\left[\begin{array}{r}
16 \% \\
1 \% \\
15 \%
\end{array}\right]
$$

Finalmente, para preencher a matriz de covariância $\boldsymbol{\Omega}$, utilizamos novamente as informações da Tabela 1, a matriz de covariância $\Omega$ é formada pelas variâncias das visões, assim:

$$
\boldsymbol{\Omega}=\left[\begin{array}{lll}
1 \%^{2} & & \\
& 1 \%^{2} & \\
& & 1 \%^{2}
\end{array}\right]
$$

Aplicando-se o teorema de Bayes é gerada uma nova distribuição a posteriori $\boldsymbol{\mu} \mid \boldsymbol{Q} \sim N(\widetilde{\boldsymbol{\mu}} ; \tilde{\boldsymbol{S}})$ em função da distribuição a priori $\boldsymbol{\mu} \sim N(\widehat{\boldsymbol{\mu}} ; \tau \boldsymbol{S})$ e a distribuição de verossimilhança $\boldsymbol{P} \boldsymbol{\mu} \sim N(\boldsymbol{Q} ; \boldsymbol{\Omega})$. Os parâmetros da distribuição a posteriori são calculados através das equações (3.95) e (3.96) (IDZOREK, 2007).

$$
\begin{aligned}
\tilde{\boldsymbol{S}} & =\left[(\tau \boldsymbol{S})^{-1}+\boldsymbol{P}^{T} \boldsymbol{\Omega}^{-1} \boldsymbol{P}\right]^{-1} \\
\widetilde{\boldsymbol{\mu}} & =\tilde{\boldsymbol{S}}\left[(\tau \boldsymbol{S})^{-1} \widehat{\boldsymbol{\mu}}+\boldsymbol{P}^{T} \boldsymbol{\Omega}^{-1} \boldsymbol{Q}\right]
\end{aligned}
$$

Substituindo-se os valores na equações anterior, $\operatorname{com} \tau=0,025$ (IDZOREK, 2007), encontramos a nova estatística da média $\widetilde{\mu}$ estimada pela metodologia da estatística Bayesiana.

$$
\widetilde{\boldsymbol{\mu}}=\left[\begin{array}{r}
9,37 \% \\
14,13 \% \\
16,75 \% \\
24,30 \% \\
22,12 \%
\end{array}\right]
$$


A Tabela 3 compara a estimação do parâmetro $\boldsymbol{\mu}$, realizada pela estatística Frequentista $\widehat{\boldsymbol{\mu}}$ e a realizada pela estatística Bayesiana $\widetilde{\boldsymbol{\mu}}$.

\begin{tabular}{lcc}
\hline & Estatística Frequentista & Estatística Bayesiana \\
\hline$\mu_{1}$ & $8,00 \%$ & $9,37 \%$ \\
$\mu_{2}$ & $13,00 \%$ & $14,13 \%$ \\
$\mu_{3}$ & $18,00 \%$ & $16,75 \%$ \\
$\mu_{4}$ & $25,00 \%$ & $24,30 \%$ \\
$\mu_{5}$ & $30,00 \%$ & $22,12 \%$ \\
\hline
\end{tabular}

Tabela 3. Comparação das estatísticas $\widehat{\mu} \mathbf{e} \widetilde{\mu}$.Fonte: Elaboração Própria.

A Tabela 4 e a Tabela 5 mostram uma comparação entre os resultados obtidos na seção 3.1, com os resultados obtidos pela metodologia Bayesiana.

\begin{tabular}{lcc}
\hline & Modelo de Markowitz & Modelo Bayesiano \\
\hline$W(1)$ & $-12,35 \%$ & $-0,46 \%$ \\
$W(2)$ & $24,61 \%$ & $27,77 \%$ \\
$W(3)$ & $28,06 \%$ & $25,38 \%$ \\
$W(4)$ & $27,21 \%$ & $27,46 \%$ \\
$W(5)$ & $32,46 \%$ & $19,84 \%$ \\
\hline
\end{tabular}

Tabela 4. Comparação entre carteiras tangentes. Fonte: Elaboração Própria.

\begin{tabular}{lcc}
\hline & Modelo de Markowitz & Modelo Bayesiano \\
\hline$W(r f)$ & $51,13 \%$ & $5,56 \%$ \\
$W(1)$ & $-6,03 \%$ & $-0,22 \%$ \\
$W(2)$ & $12,03 \%$ & $13,45 \%$ \\
$W(3)$ & $13,72 \%$ & $12,29 \%$ \\
$W(4)$ & $13,30 \%$ & $13,30 \%$ \\
$W(5)$ & $15,13 \%$ & $9,61 \%$ \\
\hline
\end{tabular}

Tabela 5. Comparação entre carteiras gerais do investidor. Fonte: Elaboração Própria. 
A Tabela 4 mostra os resultados dos pesos da carteira tangente. A Tabela 5 mostra os resultados dos pesos da carteira geral do investidor. Os resultados da Tabela 4 e 5 mostram que as informações prospectivas do investidor provocam alocações distintas, evidenciando a importância da combinação das informações públicas do mercado (dados históricos dos retornos) com informações privadas do investidor (visões prospectivas do mercado).

A Figura 12 mostra a nova alocação de ativos considerando a estimativa Bayesiana, ou seja, considerando a nova distribuição Gaussiana $N(\widetilde{\boldsymbol{\mu}} ; \boldsymbol{S}+\tilde{\boldsymbol{S}})$. Além disso, considerando os mesmo dados de $r_{f}=5 \%$ e $\gamma=2,85$, usados no exemplo da seção 3.1 .

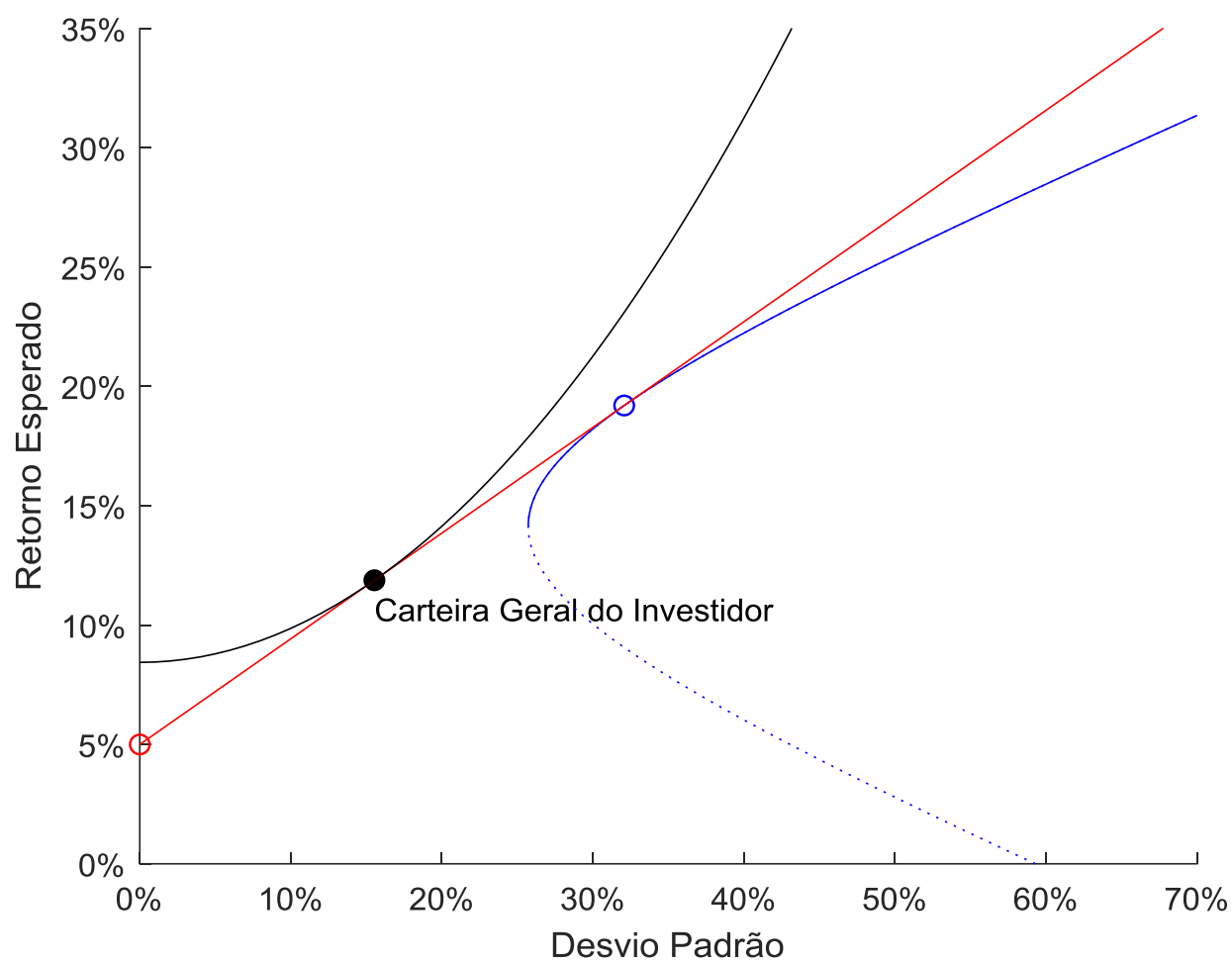

Figura 12. Alocação de ativos com a distribuição a posteriori. Fonte: Elaboração Própria.

Com este exemplo numérico, ilustra-se inferência Bayesiana dos parâmetros da distribuição dos retornos, concluindo a primeira fase da correção das quebras estruturais na série temporal dos retornos. 


\subsection{2.}

\section{Transformação de Mahalanobis da série temporal dos retornos}

$\mathrm{Na}$ etapa anterior, foi aplicada a inferência Bayesiana para corrigir as quebras estruturais a nível dos parâmetros da distribuição dos retornos. Nesta etapa serão corrigidas as quebras estruturais a nível dos dados dos retornos, ou seja, a série temporal original dos retornos, representada pela distribuição a priori $N(\widehat{\boldsymbol{\mu}} ; \boldsymbol{S})$, será corrigido através da transformação de Mahalanobis, para refletir a distribuição a posteriori $N(\widetilde{\boldsymbol{\mu}} ; \boldsymbol{S}+\tilde{\boldsymbol{S}})$ obtida pelo teorema de Bayes.

Esta transformação pode ser realizada através de dois passos: (i) No primeiro passo é realizada a transformação de dados, da distribuição $N(\widehat{\boldsymbol{\mu}} ; \boldsymbol{S})$ para a distribuição $N(\mathbf{0} ; \boldsymbol{I})$, sendo $\boldsymbol{I}$ uma matriz unitária que possui a mesma dimensão que a matriz $\boldsymbol{S}$, esta transformação de dados é conhecida como a transformação de Mahalanobis, a qual é definida pela equação (3.98) (HÄRDLE; SIMAR, 2019):

$$
\boldsymbol{y}=\boldsymbol{S}^{-1 / 2}(\boldsymbol{x}-\widehat{\boldsymbol{\mu}})
$$

Onde $\boldsymbol{y}$, representa uma nova variável aleatória com distribuição $\boldsymbol{y} \sim N(\mathbf{0}, \boldsymbol{I})$, e (ii) No segundo passo é realizada uma transformação de dados da distribuição $N(\mathbf{0} ; \boldsymbol{I})$ para a distribuição $N(\widetilde{\boldsymbol{\mu}} ; \boldsymbol{S}+\tilde{\boldsymbol{S}})$, esta transformação é definida pela equação (3.99).

$$
\boldsymbol{x} \mid \boldsymbol{y}=(\boldsymbol{S}+\tilde{\boldsymbol{S}})^{1 / 2} \boldsymbol{y}+\widetilde{\boldsymbol{\mu}}
$$

O novo conjunto de dados definido pela equação (3.99) é a nova série temporal dos retornos corrigida das quebras estruturais.

\subsection{3.}

\section{Diagrama esquemático operacional}

Na Figura 13, mostra-se o diagrama esquemático de etapas operacionais da otimização de carteiras com retornos não Gaussianos provocados por quebras estruturais.

A Etapa 1, consiste na coleta dos dados históricos do mercado, o resultado desta etapa será a matriz $\boldsymbol{X}$ da equação (3.85).

A Etapa 2, consiste na estimativa dos parâmetros $\widehat{\boldsymbol{\mu}}$ e $\boldsymbol{S}$ calculada pelas equações (3.88) e (3.89). Esta estimativa é realizada pela metodologia da estatística Frequentista, o resultado desta etapa será uma distribuição Gaussiana dos dados, em formato analítico $N(\widehat{\boldsymbol{\mu}} ; \boldsymbol{S})$. 


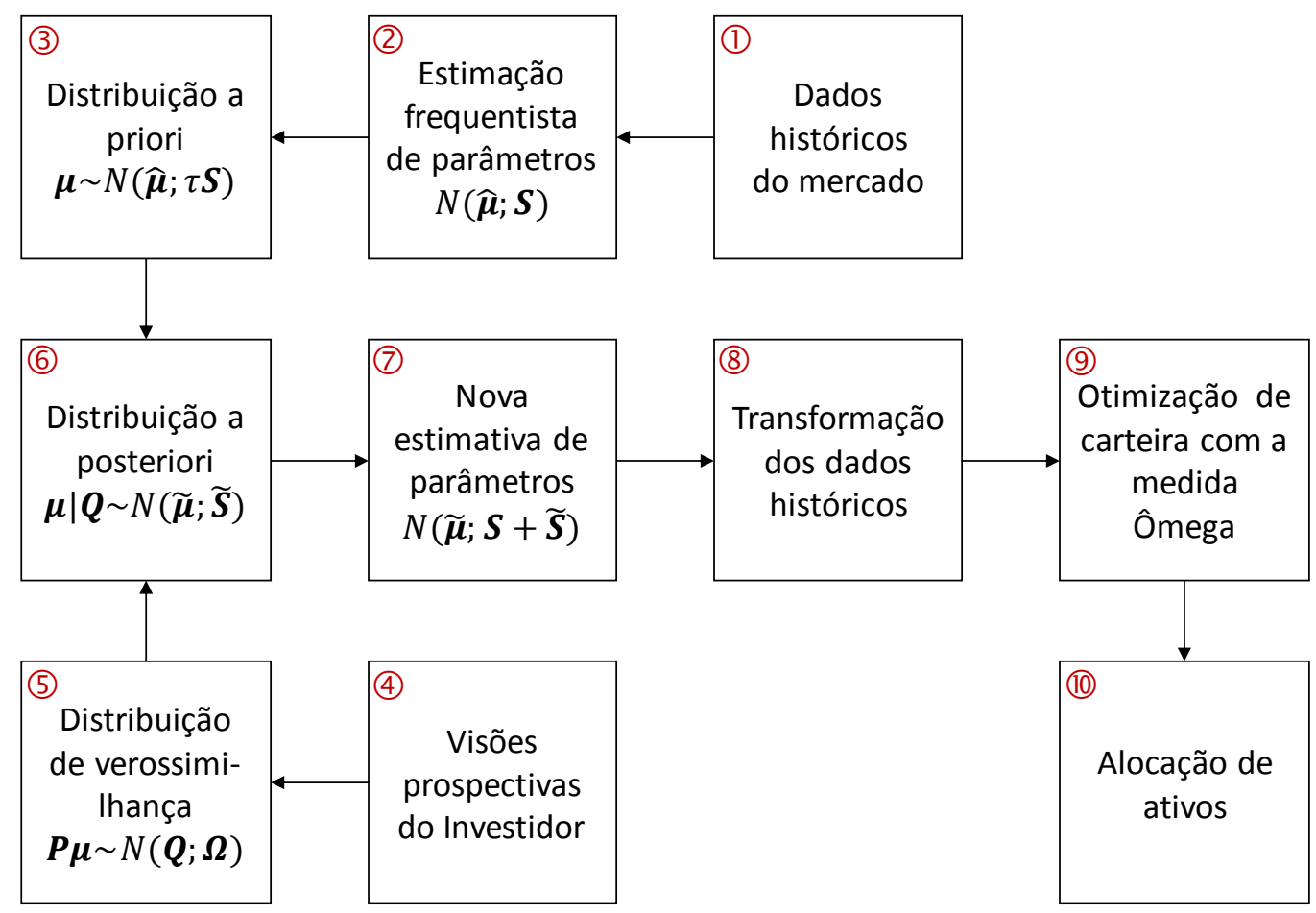

Figura 13. Aplicação da sequência das adequações do processo de otimização de carteira. Fonte: Elaboração Própria.

A Etapa 3, consiste na construção da distribuição a priori do parâmetro $\boldsymbol{\mu} \sim \boldsymbol{N}(\hat{\boldsymbol{\mu}} ; \tau \boldsymbol{S})$ em função das estatísticas $\widehat{\boldsymbol{\mu}}$ e $\boldsymbol{S}$ calculadas previamente na Etapa 2.

A Etapa 4, consiste na especificação das visões prospectivas de mercado sob a ótica do investidor, ou seja, a especificação das quebras estruturais dos retornos, seguindo o exemplo da Tabela 1.

A Etapa 5, consiste na construção da distribuição de verossimilhança $\boldsymbol{P} \boldsymbol{\mu} \sim N(\boldsymbol{Q} ; \boldsymbol{\Omega})$ em função das visões prospectivas do mercado do investidor da Etapa 4, as matrizes $\boldsymbol{P}, \boldsymbol{Q}$ e $\boldsymbol{\Omega}$ devem ser preenchidas de acordo com a metodologia exposta na seção 3.3.

A Etapa 6, consiste na aplicação do teorema de Bayes para gerar a distribuição a posteriori do parâmetro $\boldsymbol{\mu} \mid \boldsymbol{Q} \sim N(\widetilde{\boldsymbol{\mu}} ; \tilde{\boldsymbol{S}})$ em função da distribuição a priori e da distribuição de verossimilhança das Etapas 3 e 5 respectivamente.

A Etapa 7 , consiste na atualização do parâmetro $\boldsymbol{\mu}$, substituindo a estatística $\widehat{\boldsymbol{\mu}}$, calculada pela estatística Frequentista, pela estatística $\widetilde{\boldsymbol{\mu}}$, calculada pela estatística Bayesiana. Nota-se que o resultado desta etapa é uma distribuição Gaussiana $N(\widetilde{\boldsymbol{\mu}} ; \boldsymbol{S}+\tilde{\boldsymbol{S}})$, expressa num formato analítico.

A Etapa 8, consiste em transformar a série temporal dos retornos (dados históricos do mercado) da distribuição $N(\widehat{\boldsymbol{\mu}} ; \boldsymbol{S})$ para a distribuição $N(\widetilde{\boldsymbol{\mu}} ; \boldsymbol{S}+\tilde{\boldsymbol{S}})$, o 
resultado desta etapa será uma nova série temporal dos retornos corrigida das quebras estruturais.

A Etapa 9, consiste na otimização da carteira utilizando a medida Ômega, o resultado desta etapa será a carteira otimizada representado pelas frações ótimas de investimento em cada ativo.

Finalmente, a Etapa 10, consiste na alocação de ativos, ou seja, na alocação de recursos financeiros na carteira otimizada. 


\section{Experimentos numéricos}

\section{1.}

\section{Seleção de carteiras para os experimentos numéricos}

Para realizar os experimentos numéricos foram construídas quatro carteiras formadas por ações e criptomoedas, entre as ações foram selecionadas cinco empresas líderes do índice Dow Jones: Apple (AAPL), Pfizer (PFE), JPMorgam Chase (JPM), Verizon (VZ) e Coca-Cola (KO), entre as criptomoedas foram selecionadas as três de maior valor de mercado: Bitcoin (BTC), Ethereum (ETH) e Ripple (XRP). Os preços das ações foram extraídos do site https://finance.yahoo.com ,YAHOO FINANCE e das criptomoedas do site https://coinmarketcap.com, COINMARKETCAP.

O período de análise compreende o intervalo entre 01/09/2015 e 30/04/2021. Esta janela ficou limitada pela inexistência de dados da criptomoeda do Ripple. Cabe apontar que os ativos selecionados foram os mesmos do artigo Tito et al. (2020).

Na seguinte Tabela 6, mostra-se a composição das quatro carteiras para análise, por exemplo a carteira C5 é formado por 5 ativos que correspondem à 5 ações, a carteira C6 é formado por 6 ativos composta de 5 ações e 1 criptomoeda e assim em diante.

\begin{tabular}{lcccccccc} 
& AAPL & PFE & JPM & VZ & KO & BTC & ETH & XRP \\
\hline Carteira C5 & $\checkmark$ & $\checkmark$ & $\checkmark$ & $\checkmark$ & $\checkmark$ & & & \\
Carteira C6 & $\checkmark$ & $\checkmark$ & $\checkmark$ & $\checkmark$ & $\checkmark$ & $\checkmark$ & & \\
Carteira C7 & $\checkmark$ & $\checkmark$ & $\checkmark$ & $\checkmark$ & $\checkmark$ & $\checkmark$ & $\checkmark$ & \\
Carteira C8 & $\checkmark$ & $\checkmark$ & $\checkmark$ & $\checkmark$ & $\checkmark$ & $\checkmark$ & $\checkmark$ & $\checkmark$ \\
\hline
\end{tabular}

Tabela 6. Composição das quatro carteiras para análise. Fonte: Elaboração Própria.

A Tabela 7, mostra as principais estatísticas dos retornos mensais dos ativos, a Tabela 8, mostra a matriz de correlação dos retornos mensais dos ativos e a Tabela 9 mostra a matriz de covariância dos retornos mensais dos ativos. 


\begin{tabular}{lrrrrrrrr}
\hline & AAPL & PFE & JPM & VZ & KO & BTC & ETH & XRP \\
\hline Média & $1,55 \%$ & $0,30 \%$ & $0,93 \%$ & $0,49 \%$ & $0,61 \%$ & $7,22 \%$ & $10,14 \%$ & $7,33 \%$ \\
Desvio-padrão & $8,79 \%$ & $5,67 \%$ & $7,05 \%$ & $4,86 \%$ & $4,90 \%$ & $21,34 \%$ & $38,49 \%$ & $49,96 \%$ \\
Valor Mínimo & $-21,86 \%$ & $-11,95 \%$ & $-29,99 \%$ & $-12,88 \%$ & $-23,41 \%$ & $-46,22 \%$ & $-78,85 \%$ & $-102,53 \%$ \\
Valor Máximo & $19,85 \%$ & $18,91 \%$ & $16,20 \%$ & $10,19 \%$ & $8,57 \%$ & $54,83 \%$ & $110,64 \%$ & $219,69 \%$ \\
Assimetria & $-0,6261$ & 0,4986 & $-1,1514$ & $-0,3142$ & $-2,0254$ & $-0,1124$ & 0,4453 & 1,7821 \\
Curtose & 3,18 & 3,88 & 7,79 & 2,85 & 10,69 & 2,90 & 3,46 & 8,17 \\
Jarque-Bera Test & 4,54 & 5,03 & 80,06 & 1,18 & 214,14 & 0,17 & 2,84 & 111,71 \\
\hline
\end{tabular}

Tabela 7. Principais estatísticas dos retornos mensais. Fonte: Elaboração Própria.

\begin{tabular}{lrrrrrrrr}
\hline & AAPL & PFE & \multicolumn{1}{c}{ JPM } & \multicolumn{1}{c}{ VZ } & \multicolumn{1}{c}{ KO } & \multicolumn{1}{c}{ BTC } & \multicolumn{1}{c}{ ETH } & \multicolumn{1}{c}{ XRP } \\
\hline APPL & $100,00 \%$ & $25,18 \%$ & $41,31 \%$ & $15,84 \%$ & $33,21 \%$ & $25,13 \%$ & $17,34 \%$ & $4,14 \%$ \\
PFE & $25,18 \%$ & $100,00 \%$ & $44,96 \%$ & $41,70 \%$ & $30,26 \%$ & $15,51 \%$ & $10,04 \%$ & $14,89 \%$ \\
JPM & $41,31 \%$ & $44,96 \%$ & $100,00 \%$ & $24,00 \%$ & $49,13 \%$ & $26,37 \%$ & $1,44 \%$ & $-4,04 \%$ \\
VZ & $15,84 \%$ & $41,70 \%$ & $24,00 \%$ & $100,00 \%$ & $47,46 \%$ & $2,35 \%$ & $3,88 \%$ & $0,93 \%$ \\
KO & $33,21 \%$ & $30,26 \%$ & $49,13 \%$ & $47,46 \%$ & $100,00 \%$ & $26,43 \%$ & $18,02 \%$ & $6,21 \%$ \\
BTC & $25,13 \%$ & $15,51 \%$ & $26,37 \%$ & $2,35 \%$ & $26,43 \%$ & $100,00 \%$ & $48,69 \%$ & $36,89 \%$ \\
ETH & $17,34 \%$ & $10,04 \%$ & $1,44 \%$ & $3,88 \%$ & $18,02 \%$ & $48,69 \%$ & $100,00 \%$ & $58,98 \%$ \\
XRP & $4,14 \%$ & $14,89 \%$ & $-4,04 \%$ & $0,93 \%$ & $6,21 \%$ & $36,89 \%$ & $58,98 \%$ & $100,00 \%$ \\
\hline
\end{tabular}

Tabela 8. Matriz de correlações dos retornos mensais. Fonte: Elaboração Própria.

\begin{tabular}{lcccccccc}
\hline & AAPL & PFE & JPM & VZ & KO & BTC & ETH & XRP \\
\hline APPL & $0,762 \%$ & $0,124 \%$ & $0,252 \%$ & $0,067 \%$ & $0,141 \%$ & $0,464 \%$ & $0,578 \%$ & $0,179 \%$ \\
PFE & $0,124 \%$ & $0,317 \%$ & $0,177 \%$ & $0,113 \%$ & $0,083 \%$ & $0,185 \%$ & $0,216 \%$ & $0,416 \%$ \\
JPM & $0,252 \%$ & $0,177 \%$ & $0,489 \%$ & $0,081 \%$ & $0,167 \%$ & $0,391 \%$ & $0,038 \%$ & $-0,140 \%$ \\
VZ & $0,067 \%$ & $0,113 \%$ & $0,081 \%$ & $0,232 \%$ & $0,111 \%$ & $0,024 \%$ & $0,071 \%$ & $0,022 \%$ \\
KO & $0,141 \%$ & $0,083 \%$ & $0,167 \%$ & $0,111 \%$ & $0,236 \%$ & $0,272 \%$ & $0,335 \%$ & $0,150 \%$ \\
BTC & $0,464 \%$ & $0,185 \%$ & $0,391 \%$ & $0,024 \%$ & $0,272 \%$ & $4,487 \%$ & $3,941 \%$ & $3,875 \%$ \\
ETH & $0,578 \%$ & $0,216 \%$ & $0,038 \%$ & $0,071 \%$ & $0,335 \%$ & $3,941 \%$ & $14,598 \%$ & $11,176 \%$ \\
XRP & $0,179 \%$ & $0,416 \%$ & $-0,140 \%$ & $0,022 \%$ & $0,150 \%$ & $3,875 \%$ & $11,176 \%$ & $24,596 \%$ \\
\hline
\end{tabular}

Tabela 9. Matriz de variância- covariância dos retornos mensais. Fonte: Elaboração Própria.

$\mathrm{Na}$ Tabela 7, ressalta-se que os valores da média, desvio padrão, valores mínimos e máximos, são muito mais expressivos nas criptomoedas do que nas ações tradicionais. Em relação ao teste de normalidade de Jarque e Bera (1980), enquanto mais próximo de zero indicaria maior aproximação a uma distribuição gaussiana, aprecia-se que no período da análise, algumas ações e criptomoedas claramente não apresentam distribuições de retornos Gaussianos, com maior ênfase na criptomoeda do Ripple (XRP). 
$\mathrm{Na}$ Tabela 8, ressalta-se as baixas correlações do grupo das ações, em contraste com as altas correlações no grupo das criptomoedas. Na Tabela 9, ressalta-se as baixas variâncias do grupo das ações, em contraste com as altas variâncias no grupo das criptomoedas.

\section{2. \\ Experimentos em carteiras com retornos não Gaussianos provocados por mudanças de regime}

Nesta seção, foram realizados experimentos numéricos da otimização de carteiras com retornos não Gaussianos provocadas por mudanças de regime. Com este objetivo, foram considerados dois cenários para os dados históricos do mercado: (i) No primeiro cenário, assume-se que os dados históricos do mercado não possuem mudanças de regime, assim, a otimização da carteira foi realizada pela metodologia clássica Markowitz e; (ii) No segundo cenário, assume-se que os dados históricos do mercado possuem mudanças de regime, assim, a otimização da carteira foi realizada pela metodologia exposta na seção 3.2. Em seguida foram contrastados ambos resultados.

Antes de realizar esta comparação, precisa-se configurar o diagrama esquemático operacional da Figura 13 da seguinte maneira: (i) A metodologia de Markowitz seria uma configuração que consiste em conectar a saída da Etapa 2 com a entrada da Etapa 9 e; (ii) A metodologia de Ômega seria uma configuração que consiste em conectar a saída da Etapa 1 com a entrada da Etapa 9, nota-se que a metodologia de Markowitz utiliza a distribuição analítica dos dados e a metodologia de Ômega utiliza a distribuição numérica dos dados, ou seja, a metodologia Ômega utiliza o formato real da distribuição dos dados. Para ambas metodologias foi definido $L=r_{f}=0,21 \%$ ao mês, o qual, é uma proxy da taxa mensal de retorno de um papel do tesouro americano. A seguir, nas Tabelas $10 \mathrm{e}$ 11 , apresentam-se os resultados obtidos da alocação de ativos (pesos) por ambas as metodologias.

Pode-se observar que ambas as metodologias determinam distintas alocações de ativos. Interessante observar que, na alocação de ativos da Pfizer (PFE), Coca-Cola (KO) e Ripple (XRP), a metodologia de Markowitz dá um peso de 0 para estes ativos (exceto em C5 para KO), o que não acontece usando a metodologia Ômega. A explicação para isso, é que a metodologia Ômega considera o formato real da distribuição dos retornos, enquanto que a metodologia 
de Markowitz considera apenas os dois primeiros momentos da distribuição dos retornos (média e matriz de covariâncias).

\begin{tabular}{lrrrrrrrr} 
& AAPL & PFE & JPM & VZ & KO & BTC & ETH & XRP \\
\hline Carteira C5 & $56,17 \%$ & $0,00 \%$ & $21,45 \%$ & $18,12 \%$ & $4,26 \%$ & & & \\
Carteira C6 & $25,58 \%$ & $0,00 \%$ & $0,00 \%$ & $25,92 \%$ & $0,00 \%$ & $48,51 \%$ & & \\
Carteira C7 & $23,74 \%$ & $0,00 \%$ & $0,08 \%$ & $24,85 \%$ & $0,00 \%$ & $40,36 \%$ & $10,96 \%$ & \\
Carteira C8 & $23,74 \%$ & $0,00 \%$ & $0,08 \%$ & $24,85 \%$ & $0,00 \%$ & $40,36 \%$ & $10,96 \%$ & $0,00 \%$ \\
\hline
\end{tabular}

Tabela 10. Alocação de ativos realizadas pela metodologia de Markowitz. Fonte: Elaboração Própria.

\begin{tabular}{lcrrrrrrr} 
& AAPL & PFE & \multicolumn{1}{c}{ JPM } & \multicolumn{1}{c}{ VZ } & \multicolumn{1}{c}{ KO } & BTC & ETH & XRP \\
\hline Carteira C5 & $39,20 \%$ & $1,11 \%$ & $30,74 \%$ & $5,30 \%$ & $23,65 \%$ & & & \\
Carteira C6 & $35,16 \%$ & $0,35 \%$ & $0,87 \%$ & $7,64 \%$ & $0,91 \%$ & $55,07 \%$ & & \\
Carteira C7 & $35,20 \%$ & $1,11 \%$ & $4,08 \%$ & $20,81 \%$ & $2,55 \%$ & $29,18 \%$ & $7,08 \%$ & \\
Carteira C8 & $34,88 \%$ & $1,22 \%$ & $4,45 \%$ & $20,50 \%$ & $2,57 \%$ & $29,04 \%$ & $7,06 \%$ & $0,28 \%$ \\
\hline
\end{tabular}

Tabela 11. Alocação de ativos realizada pela metodologia Ômega. Fonte: Elaboração Própria.

A Tabela 12 mostra as estatísticas da média $\mu_{p}$, desvio padrão $\sigma_{p}$ e 0 indicador do CVaR (5\%) (Conditional Value at Risk) para a carteira geral do investidor.

\begin{tabular}{ccrcccrr} 
Markowitz & $\mu_{p}$ & \multicolumn{1}{c}{$\sigma_{p}$} & CVaR & Ômega & \multicolumn{1}{c}{$\mu_{p}$} & \multicolumn{1}{c}{$\sigma_{p}$} & CVaR_H \\
\hline Carteira C5 & $1,18 \%$ & $6,07 \%$ & $11,34 \%$ & Carteira C5 & $1,07 \%$ & $5,51 \%$ & $15,01 \%$ \\
Carteira C6 & $4,02 \%$ & $11,27 \%$ & $19,22 \%$ & Carteira C6 & $4,57 \%$ & $12,95 \%$ & $27,08 \%$ \\
Carteira C7 & $4,51 \%$ & $12,13 \%$ & $20,50 \%$ & Carteira C7 & $3,53 \%$ & $9,52 \%$ & $21,51 \%$ \\
Carteira C8 & $4,51 \%$ & $12,13 \%$ & $20,50 \%$ & Carteira C8 & $3,53 \%$ & $9,54 \%$ & $21,54 \%$ \\
\hline
\end{tabular}

Tabela 12. Estatísticas de risco-retorno da carteira geral do investidor. Fonte: Elaboração Própria.

Nos resultados da Tabela 12, cabe ressaltar as seguintes duas observações: (i) A primeira observação é que o CVaR, para o caso da metodologia de Markowitz foi calculado pela equação (4.1).

$$
\operatorname{CVaR}_{\alpha}\left(r_{g}\right)=\mu_{g}-\frac{\sigma_{g}}{\alpha} \varphi\left[\Phi^{-1}(\alpha)\right]
$$

Onde $\alpha$ representa o percentil de corte, $\varphi$ representa a função de densidade da distribuição Gaussiana N(0,1), $\Phi^{-1}$ representa a função inversa da distribuição 
Gaussiana N $(0,1)$ e $\left(\mu_{g}, \sigma_{g}\right)$ representa a média e o desvio padrão da carteira geral do investidor, (ii) A segunda observação é que o CVaR_H, para o caso da metodologia de Ômega foi calculado numericamente, ou seja, as amostras da distribuição empírica da carteira, foram ordenadas de menor a maior e na sequencia foi extraída a amostra que representa o percentil $5 \%$ dos dados.

$\mathrm{Na}$ Tabela 12, nota-se que as médias e os desvios padrões das carteiras calculadas pela metodologia de Markowitz tendem a ser a maiores que as médias e desvios padrões das carteiras calculadas pela metodologia Ômega, entretanto, - CVaR das carteias calculadas pela metodologia de Markowitz são menores que o CVaR_H das carteiras calculadas pela metodologia Ômega. Este resultado mostra que a metodologia Ômega, calcula um risco maior para a carteira que a metodologia de Markowitz, ou seja, a metodologia de Markowitz subestima o risco da carteira podendo levar ao investidor a decisões deficientes.

A Figura 14, mostra-se graficamente a comparação do CVaR (5\%) calculada por ambas metodologias.

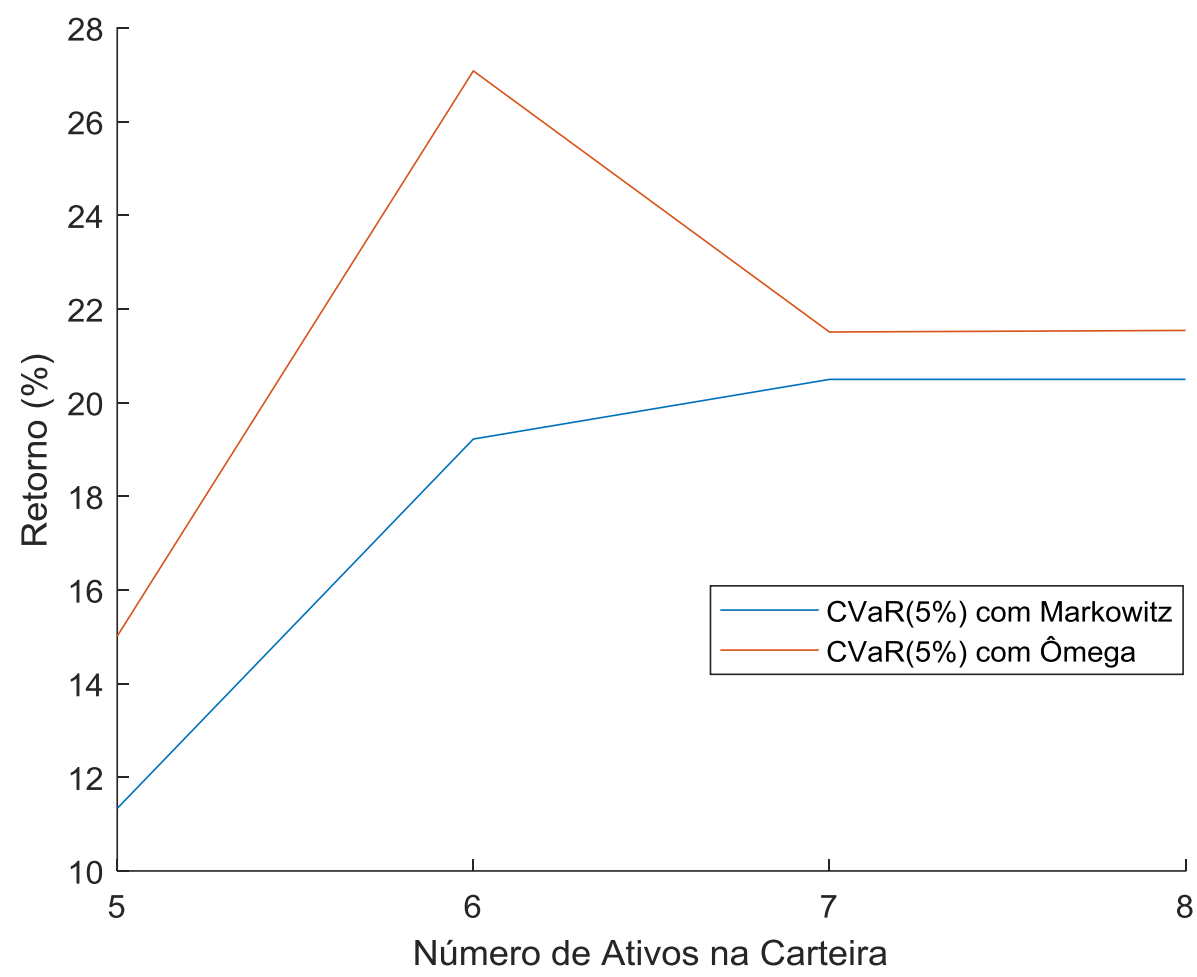

Figura 14. Comparação do risco das carteiras com o CVaR. Fonte: Elaboração Própria.

Nota-se na Figura 14 que o CVaR da carteira C6 sofre um distanciamento expressivo entre o CVaR calculado pela metodologia de Markowitz e o CVaR_H calculado pela metodologia Ômega, a explicação para este comportamento é que 
a carteira C6 inclui o Bitcoin (BTC) e a metodologia Ômega captura corretamente o risco deste ativo, enquanto a metodologia de Markowitz subestima o risco do Bitcoin. Além disso, a carteira C7 e C8, que possuem 2 e 3 criptomoedas respectivamente, o risco destas carteiras não se incrementam como o caso da carteira C6, a explicação para este comportamento é que as criptomoedas são altamente correlacionadas e a sua contribuição no risco da carteira é uma contribuição marginal. Cabe sublinhar que o CVaR em Markowitz tem um comportamento crescente conforme aumenta-se o número de ativos na carteira, porém, o CVaR_H em Ômega não segue o mesmo comportamento pelo fato de que a medida Ômega utiliza o formato real da distribuição dos retornos.

\section{3. \\ Experimentos em carteiras com retornos não Gaussianos provocados por quebras estruturais}

Nesta seção foram realizados experimentos numéricos da otimização de carteiras com retornos não Gaussianos provocados por quebras estruturais. Com este objetivo, foram considerados dois cenários para as séries temporais dos retornos do mercado; (i) No primeiro cenário, assume-se que não ocorrerão quebras estruturais nas séries temporais dos retornos do mercado, assim, a otimização da carteira foi realizada pela metodologia clássica Markowitz e; (ii) No segundo cenário, assume-se que sim ocorrerão quebras estruturais nas séries temporais de retornos do mercado, assim, a otimização da carteira foi realizada pela metodologia exposta na seção 3.3.

Nota-se que esta metodologia (seção 3.3), compreende-se de duas etapas, a seguir serão realizados experimentos numéricos para as ambas etapas.

\subsection{1.}

\section{Aplicação da etapa da inferência Bayesiana}

O experimento numérico desta etapa consiste em corrigir a quebra estrutural a nível dos parâmetros da distribuição dos retornos. Para isto, foram comparadas as carteiras otimizadas, baseadas nos parâmetros da distribuição estimados pela estatística Frequentista versus a estatística Bayesiana.

Para realizar esta comparação precisa-se configurar a Figura 13 da seguinte maneira: (i) A primeira configuração seria conectar a saída da Etapa 2 à entrada da Etapa 9 e; (ii) A segunda configuração seria conectar a saída da Etapa 7 à entrada da Etapa 9. Nota-se que ambas as configurações encontram-se em um 
ambiente Gaussiano, consequentemente, as carteiras serão comparadas utilizando a metodologia tradicional de Markowitz com a diferença de que na primeira configuração, o parâmetro $\boldsymbol{\mu}$ da distribuição dos retornos será a estatística $\widehat{\boldsymbol{\mu}}$ estimada pela estatística Frequentista, enquanto na segunda configuração, o parâmetro $\boldsymbol{\mu}$ será a estatística $\widetilde{\boldsymbol{\mu}}$ estimada pela estatística Bayesiana. A diferença entre a estatística $\widehat{\boldsymbol{\mu}}$ e $\widetilde{\boldsymbol{\mu}}$ é que a primeira leva em consideração apenas os dados históricos dos retornos do mercado, enquanto a segunda leva em consideração, além dos dados históricos dos retornos mercado, as visões prospectivas do mercado sob a ótica do investidor e, estas visões prospectivas do mercado permitem inserir no processo de estimação do parâmetro $\boldsymbol{\mu}$ as informações de quebras estruturais dos retornos dos ativos da carteira.

$\mathrm{Na}$ Tabela 13, mostra-se as especificações de três visões de mercado do investidor, das quais duas visões são absolutas e uma visão é relativa.

\begin{tabular}{|c|c|}
\hline Visão Absoluta & $\mu_{A P P L}=N\left(0,5 \% ; 0,1 \%^{2}\right)$ \\
\hline Visão Absoluta & $\mu_{P F E}=N\left(3 \% ; 0,1 \%^{2}\right)$ \\
\hline Visão Relativa & $\mu_{E T H}-\mu_{X P R}=N\left(0,1 \% ; 0,1 \%^{2}\right)$ \\
\hline
\end{tabular}

Tabela 13. Visões prospectivas do mercado do investidor. Fonte: Elaboração Própria.

$\mathrm{Na}$ primeira visão de mercado de tipo absoluta, o investidor tem a expectativa que a empresa Apple (APPL) tenha uma queda na sua rentabilidade, como consequência de vários fatores, tais como: (i) Crise econômica mundial causada pela Covid-19; (ii) Forte concorrência das empresas chinesas e; (iii) Crise de oferta no mercado de chips (semicondutores) pelo consumo de outras indústrias como carros elétricos, televisores, celulares, etc. O investidor tem a expectativa de que a rentabilidade atual da empresa mude de $\mu_{A P P L}=1,55 \%$ a.m. para um novo valor especificado por uma distribuição Gaussiana com média de $1 \%$ a.m. e desvio padrão de $0,1 \%$, ou seja, $\mu_{1} \sim N\left(1 \% ; 0,1 \%{ }^{2}\right)$. Nota-se que esta distribuição não se refere à distribuição dos dados da Apple, e sim a distribuição do parâmetro $\mu_{A P P L}$ da Apple.

$\mathrm{Na}$ segunda visão de mercado de tipo absoluta, o investidor tem a expectativa de que as empresas do setor de vacinas, como a Pfizer (PFE), tenham uma rentabilidade expressiva por causa da pandemia do Covid-19, ou seja, o retorno da Pfizer, poderia mudar do valor atual de $\mu_{P F E}=0,3 \%$ a.m. para um novo 
valor especificado por uma distribuição Gaussiana com média de 3\% a.m. e desvio padrão de $0,1 \%$, ou seja, $\mu_{P F E} \sim N\left(3 \% ; 0,1 \%^{2}\right)$.

$\mathrm{Na}$ terceira visão de mercado é de tipo relativo, o investidor tem a expectativa de que a criptomoeda Ethereum (ETH) perca relevância a longo prazo e a sua rentabilidade se aproxime da criptomoeda Ripple (XRP), ou seja, que a diferença entre as médias do Ethereum e do Ripple, seja uma distribuição Gaussiana com média de $0,1 \%$ e desvio padrão de $0,1 \%$, assim, $\mu_{E T H}-\mu_{X P R}=$ $N\left(0,1 \% ; 0,1 \%{ }^{2}\right)$.

As Tabelas 14 e 15, apresentam as alocações de ativos (pesos) para ambas configurações.

\begin{tabular}{lccrccccc} 
& APPL & PFE & \multicolumn{1}{c}{ JPM } & VZ & KO & BTC & ETH & XRP \\
\hline Carteira C5 & $56,17 \%$ & $0,00 \%$ & $21,45 \%$ & $18,12 \%$ & $4,26 \%$ & & & \\
Carteira C6 & $25,58 \%$ & $0,00 \%$ & $0,00 \%$ & $25,92 \%$ & $0,00 \%$ & $48,51 \%$ & & \\
Carteira C7 & $23,74 \%$ & $0,00 \%$ & $0,08 \%$ & $24,85 \%$ & $0,00 \%$ & $40,36 \%$ & $10,96 \%$ & \\
Carteira C8 & $23,74 \%$ & $0,00 \%$ & $0,08 \%$ & $24,85 \%$ & $0,00 \%$ & $40,36 \%$ & $10,96 \%$ & $0,00 \%$ \\
\hline
\end{tabular}

Tabela 14. Alocação de ativos realizada com a estimação Frequentista. Fonte: Elaboração Própria.

\begin{tabular}{lrrrrrrrr} 
& APPL & PFE & \multicolumn{1}{c}{ JPM } & VZ & KO & BTC & ETH & XRP \\
\hline Carteira C5 & $12,19 \%$ & $51,44 \%$ & $17,59 \%$ & $18,40 \%$ & $0,39 \%$ & & & \\
Carteira C6 & $0,33 \%$ & $43,57 \%$ & $1,83 \%$ & $26,73 \%$ & $0,00 \%$ & $27,54 \%$ & & \\
Carteira C7 & $0,00 \%$ & $39,83 \%$ & $7,51 \%$ & $24,94 \%$ & $0,00 \%$ & $21,61 \%$ & $6,12 \%$ & \\
Carteira C8 & $0,00 \%$ & $39,06 \%$ & $7,39 \%$ & $25,17 \%$ & $0,00 \%$ & $22,40 \%$ & $3,61 \%$ & $2,38 \%$ \\
\hline
\end{tabular}

Tabela 15. Alocação de ativos realizada com a estimação Bayesiana. Fonte: Elaboração Própria.

$\mathrm{Na}$ Tabela 14 e 15, observa-se que ambas configurações, utilizadas na otimização das carteiras, determinam distintas alocações de ativos como consequência dos efeitos das visões de mercado incorporadas no processo de estimação do parâmetro $\boldsymbol{\mu}$ da distribuição dos dados de mercado.

Nota-se que as alocações de investimentos da Apple e da Pfizer sofreram mudanças drásticas como produto das visões absolutas do mercado, para o caso Apple, a visão prospectiva do investidor foi uma quebra estrutural do retorno negativo e comprova-se que as alocações sofreram uma redução nos pesos das carteiras, analogamente, para o caso da Pfizer, a visão prospectiva do investidor 
foi uma quebra estrutural do retorno positivo e comprova-se que as alocações sofreram um incremento nos pesos das carteiras.

Para o caso da visão de mercado de tipo relativo, a visão prospectiva do investidor foi uma quebra estrutural do retorno correlacionando o retorno da criptomoeda Ethereum e Ripple, a qual é comprovada na alocação de pesos semelhantes, conforme a Tabela 15.

\begin{tabular}{ccrccccr} 
Markowitz & $\mu_{p}$ & \multicolumn{1}{c}{$\sigma_{p}$} & CVaR & Ômega & $\mu_{p}$ & \multicolumn{1}{c}{$\sigma_{p}$} & CVaR_H \\
\hline Carteira C5 & $1,18 \%$ & $6,07 \%$ & $11,34 \%$ & Carteira C5 & $1,32 \%$ & $4,59 \%$ & $8,14 \%$ \\
Carteira C6 & $4,02 \%$ & $11,27 \%$ & $19,22 \%$ & Carteira C6 & $2,97 \%$ & $7,13 \%$ & $11,74 \%$ \\
Carteira C7 & $4,51 \%$ & $12,13 \%$ & $20,50 \%$ & Carteira C7 & $3,17 \%$ & $7,35 \%$ & $11,99 \%$ \\
Carteira C8 & $4,51 \%$ & $12,13 \%$ & $20,50 \%$ & Carteira C8 & $3,18 \%$ & $7,45 \%$ & $12,18 \%$ \\
\hline
\end{tabular}

Tabela 16. Estatísticas de risco-retorno da carteira geral do investidor. Fonte: Elaboração Própria.

A Tabela 16, mostra as estatísticas da carteira geral do investidor e a Figura 15 , mostra graficamente a comparação do CVaR (5\%), calculada por ambas as configurações.

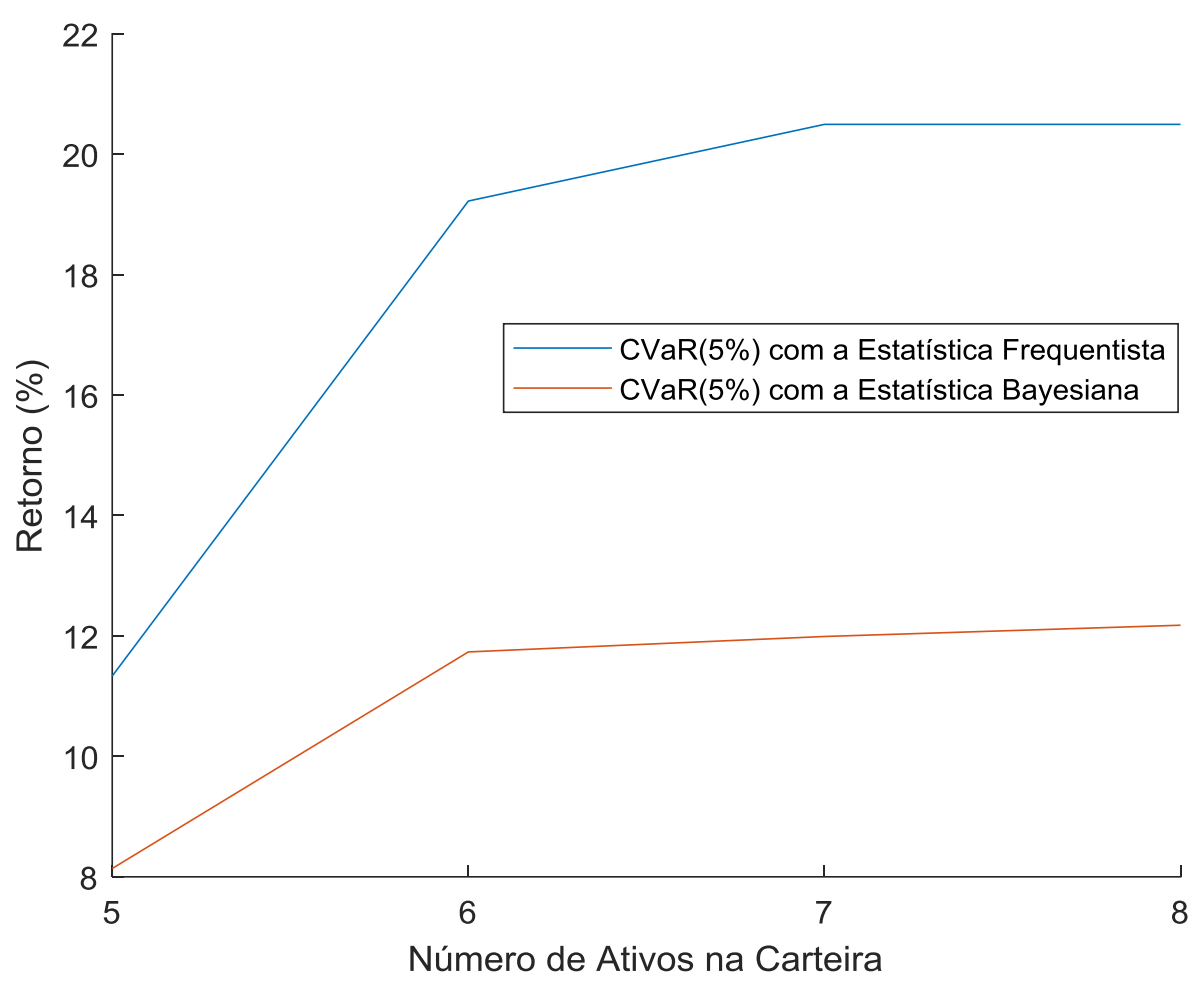

Figura 15. Comparação do risco das carteiras com o CVaR. Fonte: Elaboração Própria. 
Na Figura 15, mostra-se o comportamento do CVaR (5\%) para a carteira geral do investidor, entretanto, a diferença entre o CVaR Frequentista e Bayesiano é que o CVaR Bayesiano considera as visões de mercado sob a ótica do investidor. O impacto das visões do mercado provocou uma diminuição do risco da carteira, porém, poderia ter acontecido o contrário com outros tipos de visões.

\subsection{2.}

\section{Aplicação da etapa da transformação de Mahalanobis}

O experimento numérico desta etapa consiste em corrigir a quebra estrutural a nível dos dados da série temporal dos retornos. Para o qual, foram comparadas as carteiras otimizadas, baseadas na correção parcial realizada a nível dos parâmetros dos retornos versus a correção realizada a nível dos dados da série temporal dos retornos. Para realizar esta comparação, precisa-se configurar a Figura 13 da seguinte maneira: (i) A metodologia de Markowitz seria a configuração que consiste em conectar a saída da Etapa 7, com a entrada da Etapa 9 e; (ii) A metodologia de Ômega seria a configuração completa da Figura 13, nota-se que a metodologia de Markowitz utiliza a distribuição analítica dos dados e a metodologia de Ômega utiliza a distribuição numérica dos dados, ou seja, a metodologia Ômega utiliza o formato real da distribuição dos dados. A seguir, na Tabelas 17 e 18, apresentam-se os resultados obtidos da alocação de ativos (pesos) por ambas as metodologias.

\begin{tabular}{lrrrrrrrr} 
& AAPL & PFE & \multicolumn{1}{c}{ JPM } & VZ & KO & BTC & ETH & XRP \\
\hline Carteira C5 & $12,19 \%$ & $51,44 \%$ & $17,59 \%$ & $18,40 \%$ & $0,39 \%$ & & & \\
Carteira C6 & $0,33 \%$ & $43,57 \%$ & $1,83 \%$ & $26,73 \%$ & $0,00 \%$ & $27,54 \%$ & & \\
Carteira C7 & $0,00 \%$ & $39,83 \%$ & $7,51 \%$ & $24,94 \%$ & $0,00 \%$ & $21,61 \%$ & $6,12 \%$ & \\
Carteira C8 & $0,00 \%$ & $39,06 \%$ & $7,39 \%$ & $25,17 \%$ & $0,00 \%$ & $22,40 \%$ & $3,61 \%$ & $2,38 \%$ \\
\hline
\end{tabular}

Tabela 17. Alocação de ativos realizada com a metodologia de Markowitz. Fonte: Elaboração Própria.

\begin{tabular}{lccrrrrrr} 
& AAPL & PFE & \multicolumn{1}{c}{ JPM } & \multicolumn{1}{c}{ VZ } & \multicolumn{1}{c}{ KO } & BTC & ETH & XRP \\
\hline Carteira C5 & $6,73 \%$ & $47,52 \%$ & $21,50 \%$ & $3,55 \%$ & $20,70 \%$ & & & \\
Carteira C6 & $7,44 \%$ & $36,00 \%$ & $1,00 \%$ & $32,06 \%$ & $0,59 \%$ & $22,90 \%$ & & \\
Carteira C7 & $8,10 \%$ & $30,07 \%$ & $11,98 \%$ & $21,02 \%$ & $8,84 \%$ & $16,28 \%$ & $3,70 \%$ & \\
Carteira C8 & $3,05 \%$ & $34,79 \%$ & $8,59 \%$ & $29,61 \%$ & $2,47 \%$ & $14,99 \%$ & $1,61 \%$ & $4,88 \%$ \\
\hline
\end{tabular}

Tabela 18. Alocação de ativos realizada com a metodologia Ômega. Fonte: Elaboração Própria. 
Nas Tabelas 17 e 18, observa-se que ambas as metodologias determinam distintas alocações de ativos, mesmo que estejam utilizando as mesmas visões do mercado, a diferença é que a metodologia de Markowitz utiliza a distribuição analítica dos dados e a metodologia Ômega utiliza a distribuição real dos dados.

A Tabela 19, mostra-se as estatísticas da carteira geral do investidor e na Figura 16, mostra-se graficamente a comparação do CVaR (5\%) calculada por ambas metodologias.

\begin{tabular}{cccrcccc} 
Markowitz & $\mu_{p}$ & $\sigma_{p}$ & \multicolumn{1}{c}{ CVaR } & Ômega & $\mu_{p}$ & $\sigma_{p}$ & CVaR_H \\
\hline Carteira C5 & $1,32 \%$ & $4,59 \%$ & $8,14 \%$ & Carteira C5 & $1,28 \%$ & $4,56 \%$ & $11,02 \%$ \\
Carteira C6 & $2,97 \%$ & $7,13 \%$ & $11,74 \%$ & Carteira C6 & $2,64 \%$ & $6,40 \%$ & $10,53 \%$ \\
Carteira C7 & $3,17 \%$ & $7,35 \%$ & $11,99 \%$ & Carteira C7 & $2,58 \%$ & $6,14 \%$ & $11,95 \%$ \\
Carteira C8 & $3,18 \%$ & $7,45 \%$ & $12,18 \%$ & Carteira C8 & $2,76 \%$ & $6,62 \%$ & $11,00 \%$ \\
\hline
\end{tabular}

Tabela 19. Estatísticas de risco-retorno da carteira geral do investidor. Fonte: Elaboração Própria.

A Figura 16, mostra o comportamento do CVaR (5\%) para a carteira geral do investidor.

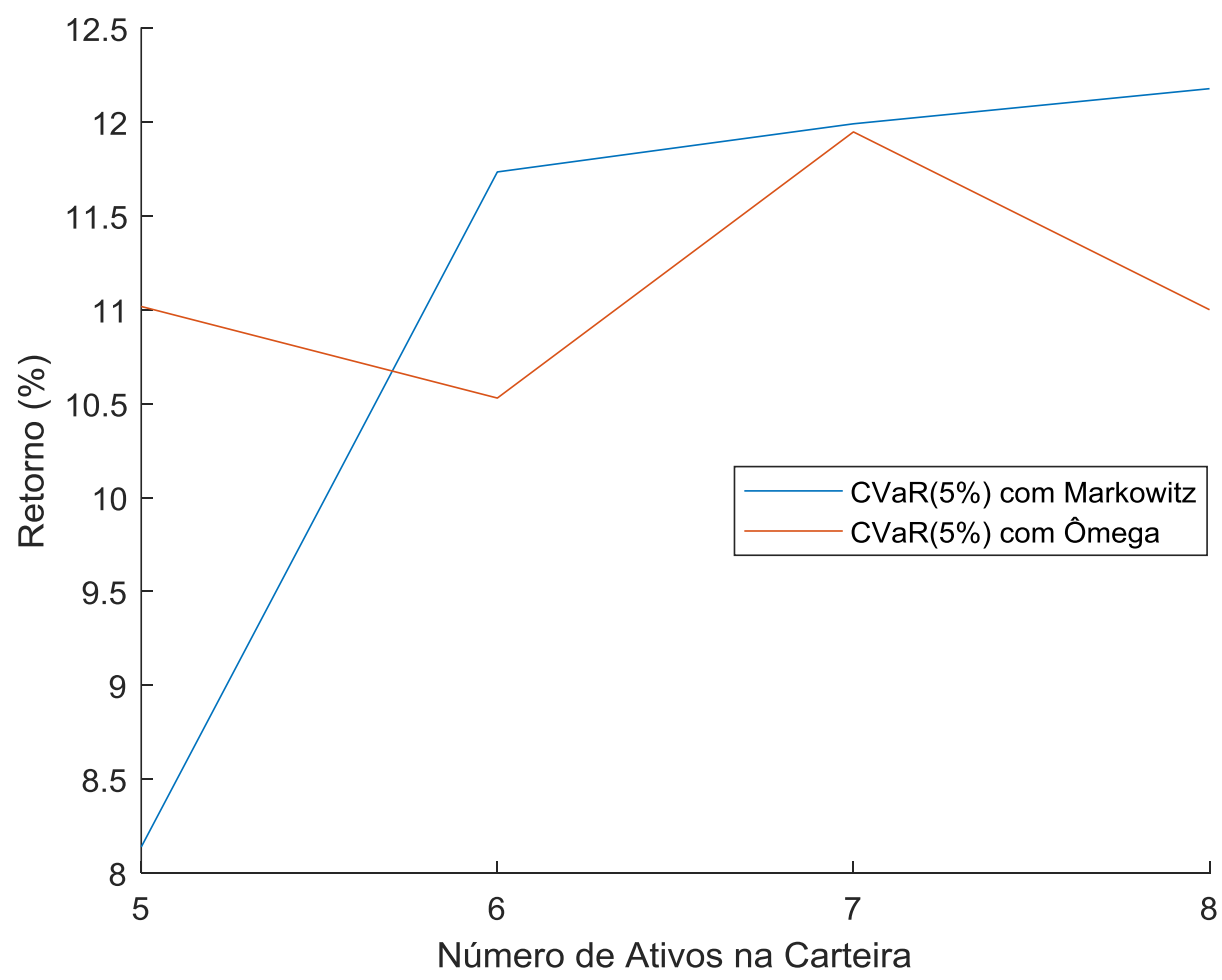

Figura 16. Comparação do risco das carteiras com o CVaR. Fonte: Elaboração Própria.

Nota-se que o CVaR_H com a metodologia Ômega tem um comportamento irregular devido ao fato de que a manipulação realizada pelas visões do investidor 
altera a estrutura de risco-retorno entre os ativos da carteira, e a medida Ômega captura corretamente o risco da carteira, entretanto, o CVaR com a metodologia de Markowitz parece menos sensível às mudanças das visões do mercado. 


\section{5 \\ Conclusões e trabalhos futuros}

A principal contribuição desta pesquisa foi adaptar a metodologia clássica de alocação de ativos para analisar carteiras com retornos não Gaussianos provocados, tanto por mudanças de regime quanto por quebras estruturais.

As mudanças de regime (ou estados) mudam os parâmetros da distribuição dos retornos, entre um número finito de estados, de forma recorrente ao longo do tempo. Estas mudanças de regime são causadas, por exemplo: por crises financeiras, recessões econômicas, hiperinflação, mudanças nas políticas fiscais, etc.

As quebras estruturais mudam os parâmetros de forma permanente, entre um número infinito de estados, não recorrentes ao longo do tempo. Estas quebras estruturais são causadas por eventos de longa duração, por exemplo: mudanças climáticas, descoberta de novas tecnologias, disputas geopolíticas, novas tendências sociais, etc.

Para contornar o problema das mudanças de regime, propõe-se a substituição do mecanismo de otimização baseada no índice de Sharpe pela otimização baseado na medida Ômega. Isto porque a medida Ômega tem a vantagem de quantificar o risco-retorno de qualquer distribuição de probabilidade e não somente distribuições Gaussianas como acontece com o índice de Sharpe, ou seja, os retornos não Gaussianos provocadas pelas mudanças de regime são tratados naturalmente pela medida Ômega.

Para contornar o problema das quebras estruturais, propõe-se a substituição do procedimento de estimação dos parâmetros da distribuição dos retornos, baseada em técnicas da estatística Frequentista por técnicas da estatística Bayesiana. Isto porque a estatística Bayesiana, tem a vantagem de combinar as informações públicas do mercado (dados históricos dos retornos) com informações privadas do investidor (visões prospectivas do mercado), permitindo corrigir a quebra estrutural, e na sequência, tratar o retorno não Gaussiano utilizando o mecanismo de otimização baseada na medida Ômega.

Os experimentos realizados, tanto com dados sintéticos (gerados artificialmente), quanto com dados reais do mercado, comprovam e validam as adequações empregadas nesta pesquisa. 
Como trabalho futuro sugere-se desenvolver critérios ou modelos para formular apropriadamente as visões do mercado, além disso, poderiam ser realizados testes do tipo Backtesting para avaliar as qualidades preditivas desses modelos. Para finalizar, sugere-se também aplicar a metodologia proposta para portfólios de renda fixa. 


\section{6}

\section{Referências Bibliográficas}

AHMED, W. M. A.; AL MAFRACHI, M. Do higher-order realized moments matter for cryptocurrency returns? International Review of Economics and Finance, v. 72, n. C, p. 483-499, 2021.

BAUDER, D. et al. Bayesian mean-variance analysis: optimal portfolio selection under parameter uncertainty. Quantitative Finance, v. 21, n. 2, p. 221-242, 2021.

BERTSEKAS, D. P. Constrained Optimization and Lagrange Multiplier MethodsAthena Scientific, MIT, 1996. Disponível em: $<$ http://adsabs.harvard.edu/abs/1982colm.book.....b > .

BLACK, F.; LITTERMAN, R. Global Portfolio Optimization. Financial Analysts Journal, v. 48, n. 5, p. 28-43, 1992.

BODIE, Z.; KANE, A.; MARCUS, A. J. Investments. 9th. ed. New York: Mc Graw-Hill, 2009.

BODNAR, T.; MAZUR, S.; OKHRIN, Y. Bayesian estimation of the global minimum variance portfolio. European Journal of Operational Research, v. 256, n. 1, p. 292-307, 2017.

CARHART, M. M. . On Persistence in Mutual Fund Performance. The Journal of Finance, v. 52, n. 1, p. 57-82, 1997.

CASTRO, J. G. et al. Crypto-assets portfolio optimization under the omega measure. The Engineering Economist, v. 65, n. 2, p. 114-134, 2020.

CHU, C. S. J.; SANTONI, G. J.; LIU, T. Stock market volatility and regime shifts in returns. Information Sciences, v. 94, n. 1-4, p. 179-190, 1996.

Coinmarketcap. Disponível em: <https://coinmarketcap.com/>. Acesso em: 30 abr. 2021.

CRUZ, E. A. T.; MEDINA, P. D. V.; SALAZAR, H. D. A. Optimización de portafolios de acciones utilizando los multiplicadores de Lagrange. Scientia et Technica, v. 18, n. 1, p. 114-119, 2013. 
D'AVOLIO, G. The market for borrowing stock. Journal of Financial Economics, v. 66, p. 271-306, 2002.

DOUCET, A.; DE FREITAS, N.; GORDON, N. Statistics for Engineering and Information Science (Sequential Monte Carlo Methods in Practice). 1. ed. [s.I.] SPRINGER VERLAG GMBH, 2001.

FAMA, E. F. . The Behavior of Stock-Market Prices Author ( $\mathrm{s}$ ): Eugene F . Fama Published by: The University of Chicago Press Stable. The Journal of Business, v. 38, n. 1, p. 34-105, 1965.

FAMA, E. F. .; FRENCH, K. R. . Common risk factors in the returns on stocks and bonds. Journal of Financial, v. 33, n. 1, p. 3-56, 1993.

GREYSERMAN, A.; JONES, D. H.; STRAWDERMAN, W. E. Portfolio selection using hierarchical Bayesian analysis and MCMC methods. Journal of Banking and Finance, v. 30, n. 2, p. 669-678, 2006.

HÄRDLE, W. K.; SIMAR, L. The Multinormal Distribution. In: SPRINGER (Ed.). . Applied Multivariate Statistical Analysis. Fisth Edit ed. New York: [s.n.]. p. 550.

HARVEY, C. R. et al. Portfolio selection with higher moments. Quantitative Finance, v. 10, n. 5, p. 469-485, 2010.

IDZOREK, T. M. . A step-by-step guide to the Black-Litterman model: Incorporating user-specified confidence levels. Forecasting Expected Returns in the Financial Markets, p. 17-38, 2007.

JARQUE, C. M.; BERA, A. K. Efficient tests for normality, homoscedasticity and serial independence of regression residuals. Economics Letters, v. 6, n. 3, p. 255-259, 1980.

JOBSON, J. D.; KORKIE, B. Putting Markowitz theory to work. Journal of Portfolio Management, v. 7, n. 4, p. 70-74, 1981.

JOHNSON, R. A.; WICHERN, D. W. Sample Mean, Covariance and Correlation as Matrix Operations. In: Applied Multivariate Statistical Analysis. 6th. ed. New Jersey: Pearson, 2007. p. 1-773.

KAZEMI, H.; SCHNEEWEIS, T.; GUPTA, R. Omega as a Performance Measure. Journal of Performance Measurement, v. 8, p. 16--25, 2004. 
KEATING, C.; SHADWICK, W. F. A Universal Performance Measure. Journal of Perfomance Measurement, v. 6, n. 3, p. 59-84, 2002.

LEWIN, M.; CAMPANI, C. H. Gestão de Carteiras sob Múltiplos Regimes: Estratégias que Performam Acima do Mercado. Journal of Contemporary Administration, v. 24, n. 4, p. 300-316, 2020.

LINNERTOVÁ, D. Short Introduction of Short Selling. Financial Assets and Investing, v. 66, n. 2, p. 28-33, 2011.

MARKOWITZ, H. Portfolio Selection. The Journal of Financeinance, v. 7, n. 1, p. 77-91, 1952.

MERTON, R. C. An Analytic Derivation of the Efficient Portfolio Frontier. The Journal of Financial and Quantitative Analysis, v. 7, n. 4, p. 18511872, 1972.

MHIRI, M.; PRIGENT, J.-L. International Portfolio Optimization with Higher Moments. International Journal of Economics and Finance, v. 2, n. 5, p. 157-169, 2010.

MICHAUD, R. O. The Markowitz Optimization Enigma: Is "Optimized" Optimal? Financial Analysts Journal, v. 45, n. 1, p. 31-42, 1989.

NAQVI, B. et al. Portfolio optimisation with higher moments of risk at the Pakistan stock exchange. Economic Research-Ekonomska Istrazivanja, v. 30, n. 1, p. 1594-1610, 2017.

ÑÍGUEZ, T. et al. Higher-order Moments in the Theory of Diversification and Portfolio Composition. Lancaster: [s.n.].

OLIVEIRA, A. B. Ensaios em alocação de portfólio com mudança de regime. [s.l.] Fundación Getulio Vargas, 2014.

ROBERT, C. P.; CASELLA, G. Monte Carlo Statistical Methods. 2. ed. [s.I.] Springer, New York, NY, 2004.

SARANYA, K.; PRASANNA, P. K. Portfolio Selection and Optimization with Higher Moments: Evidence from the Indian Stock Market. Asia-Pacific Financial Markets, v. 21, n. 2, p. 133-149, 2014.

SHARPE, W. F. Mutual Fund Performance. The Journal of Business, v. 39, n. 1, p. 119-138, 1966. 
SONG, Y. Modelling Regime Switching and Structural Breaks with an Infinite Hidden Markow. Journal of Applied Econometrics, v. 29, n. 5, p. 825-842, 2014.

SOURY, H.; ALOUINI, M. S. New results on the sum of two generalized Gaussian random variables. Global Conference on Signal and Information Processing, p. 1017-1021, 2015.

SUÁREZ, F. Método de los multiplicadores de Lagrange. Interpretación general y económica de éstos. Facultad de Ciencias Económicas, v. 7, n. 2, p. 30-33, 1999.

TITO, E. A. H. et al. Um método universal para seleção de carteiras de ações e criptomoedas. ANAIS DO LII SIMPóSIO BRASILEIRO DE PESQUISA OPERACIONAL. Anais...Campinas, Galoá, 2020Disponível em: <https://proceedings.science/sbpo-2020/papers/um-metodo-universalpara-selecao-de-carteiras-de-acoes-e-criptomoedas $>$.

USTA, I.; KANTAR, Y. M. Mean-variance-skewness-entropy measures: A multi-objective approach for portfolio selection. Journal Entropy, v. 13, n. 1, p. 117-133, 2011.

YAHOO FINANCE. Disponível em: <https://finance.yahoo.com/>. Acesso em: 30 jan. 2021.

ZHAO, D. et al. Portfolio Selection Based on Bayesian Theory. Mathematical Problems in Engineering, v. 1, n. 11, p. 1-11, 2019. 


\section{Anexo 1}

Este anexo apresenta o desenvolvimento das equações (3.42), (3.43), (3.44) a partir da Equação (3.41).

Calculando o termo $\boldsymbol{g}^{T} \boldsymbol{\Sigma} \boldsymbol{g}$

$$
\begin{aligned}
& \boldsymbol{g}^{T} \boldsymbol{\Sigma} \boldsymbol{g}=\frac{1}{d^{2}}\left(b \boldsymbol{\Sigma}^{-1} \mathbf{1}-a \boldsymbol{\Sigma}^{-1} \boldsymbol{\mu}\right)^{T} \boldsymbol{\Sigma}\left(b \boldsymbol{\Sigma}^{-1} \mathbf{1}-a \boldsymbol{\Sigma}^{-1} \boldsymbol{\mu}\right) \\
& \boldsymbol{g}^{T} \boldsymbol{\Sigma} \boldsymbol{g}=\frac{1}{d^{2}}\left(b \mathbf{1}^{T} \boldsymbol{\Sigma}^{-1}-a \boldsymbol{\mu}^{T} \boldsymbol{\Sigma}^{-1}\right)\left(b \boldsymbol{\Sigma} \boldsymbol{\Sigma}^{-1} \mathbf{1}-a \boldsymbol{\Sigma} \boldsymbol{\Sigma}^{-1} \boldsymbol{\mu}\right) \\
& \boldsymbol{g}^{T} \boldsymbol{\Sigma} \boldsymbol{g}=\frac{1}{d^{2}}\left(b \mathbf{1}^{T} \boldsymbol{\Sigma}^{-1}-a \boldsymbol{\mu}^{T} \boldsymbol{\Sigma}^{-1}\right)(b \mathbf{1}-a \boldsymbol{\mu}) \\
& \boldsymbol{g}^{T} \boldsymbol{\Sigma} \boldsymbol{g}=\frac{1}{d^{2}}\left(b \mathbf{1}^{T} \boldsymbol{\Sigma}^{-1}-a \boldsymbol{\mu}^{T} \boldsymbol{\Sigma}^{-1}\right)(b \mathbf{1}-a \boldsymbol{\mu}) \\
& \boldsymbol{g}^{T} \boldsymbol{\Sigma} \boldsymbol{g}=\frac{1}{d^{2}}\left(b^{2} \mathbf{1}^{T} \boldsymbol{\Sigma}^{-1} \mathbf{1}-a b \mathbf{1}^{T} \boldsymbol{\Sigma}^{-1} \boldsymbol{\mu}-a b \boldsymbol{\mu}^{T} \boldsymbol{\Sigma}^{-1} 1+a^{2} \boldsymbol{\mu}^{T} \boldsymbol{\Sigma}^{-1} \boldsymbol{\mu}\right) \\
& \boldsymbol{g}^{T} \boldsymbol{\Sigma} \boldsymbol{g}=\frac{1}{d^{2}}\left(b^{2} c-2 a^{2} b+a^{2} b\right) \\
& \boldsymbol{g}^{T} \boldsymbol{\Sigma} \boldsymbol{g}=\frac{1}{d^{2}}\left(b^{2} c-a^{2} b\right) \\
& \boldsymbol{g}^{T} \boldsymbol{\Sigma} \boldsymbol{g}=\frac{b}{d^{2}}\left(b c-a^{2}\right) \\
& \boldsymbol{g}^{T} \boldsymbol{\Sigma} \boldsymbol{g}=\frac{b}{d^{2}}(d) \\
& \boldsymbol{g}^{T} \boldsymbol{\Sigma} \boldsymbol{g}=\frac{b}{d} \\
&
\end{aligned}
$$

Procedendo analogamente

$$
\begin{aligned}
& \boldsymbol{g}^{T} \boldsymbol{\Sigma} \boldsymbol{g}=-\frac{a}{d} \\
& \boldsymbol{h}^{T} \boldsymbol{\Sigma} \boldsymbol{h}=\frac{c}{d}
\end{aligned}
$$


Substituindo (3.42), (3.43), (3.44) em (3.41)

$$
\begin{gathered}
\sigma_{p}^{2}=\boldsymbol{h}^{T} \boldsymbol{\Sigma} \boldsymbol{h} \mu_{p}^{2}+2 \boldsymbol{g}^{T} \boldsymbol{\Sigma} \boldsymbol{h} \mu_{p}+\boldsymbol{g}^{T} \boldsymbol{\Sigma} \boldsymbol{g} \\
\sigma_{p}^{2}=\frac{c}{d} \mu_{p}^{2}+-\frac{2 a}{d} \mu_{p}+\frac{b}{d}
\end{gathered}
$$

